Aus dem Institut für Tierphysiologie und Tierernährung der Georg-August-Universität Göttingen

\title{
Untersuchungen zum ruminalen Biotinumsatz beim Rind
}

\author{
Dissertation \\ zur Erlangung des Doktorgrades \\ der Fakultät für Agrarwissenschaften \\ der Georg-August-Universität zu Göttingen
}

vorgelegt von

Benjamin Schröder

geboren in Höxter

Göttingen, Juli 2004 
D7

Referent:

Prof. Dr. sc. agr. Hj. Abel

Korreferent:

Prof. Dr. agr. habil. G. Flachowsky

Tag der mündlichen Prüfung:

15.Juli 2004 
für Laurenz, Jasper und Constantin 


\section{Inhaltsverzeichnis}

1 Einleitung

2 Literaturübersicht 3

2.1 Chemisch-physikalische Charkterisierung von Biotin 3

2.2 Funktionen von Biotin im Stoffwechsel

2.2.1 Biotin als Bestandteil von Carboxylasen

2.2.2 Die Bedeutung von Biotin in Epidermiszellen und bei der Behandlung von Lahmheiten _ 8

2.2.3 Einfluss von Biotinzulagen auf Leistungsparameter bei der Milchkuh _ 10

2.2.4 Sonstige Funktionen__ 11

2.3 Aufnahme und Metabolismus von Biotin _ 12

2.4 Besonderheiten im Biotinmetabolismus beim Wiederkäuer _ 13

2.4.1 Mikrobielle Synthese von Biotin __ 13

2.4.2 Mikrobieller Biotinabbau ___ 15

2.4.3 Biotin in der Wiederkäuerfütterung___ 16

2.4.4 Bedeutung der Protozoen__ 21

2.5 Schlussfolgerungen für die eigenen Untersuchungen 22

3 Material und Methoden 23

3.1 In vitro-Untersuchungen 23

3.1.1 Versuchsplan für RUSITEC-Untersuchungen 23

3.1.2 Pansensimulationstechnik (RUSITEC)___ 24

3.1.3 Spendertiere und deren Fütterung __ 28

3.1.4 Entnahme von Pansensaft und festem Panseninhalt___ 28

3.1.5 Defaunierung des Pansensaftes __ 29

3.1.6 Arbeitsabläufe beim Betrieb des RUSITEC-Systems__ 29

3.1.7 Analytische Methoden _ 31

3.1.7.1 Bestimmung des $\mathrm{pH}$-Wertes__ 31

3.1.7.2 Messung des Redoxpotenzials __ 31

3.1.7.3 Messung des $\mathrm{NH}_{3}$-Gehaltes __ 31

3.1.7.4 Messung der Fermentationsgase __ 32

3.1.7.5 Bestimmung der Protozoenzahl _ـ 33

3.1.7.6 Messung der flüchtigen Fettsäuren _ 34

3.1.7.7 Bestimmung der mikrobiellen Proteinsynthese ___ 36

3.2 In vivo-Untersuchungen 37

3.2.1 Versuchsaufbau _ 37

3.2.2 Versuchstiere und deren Haltung___ 40

3.2.3 Gewinnung von Duodenalchymusproben__ 41

3.2.4 Analytische Methoden __ 41 
3.2.4.1 Bestimmung der duodenalen Flussmenge ___ 41

3.2.4.1.1 Herstellung und Verabreichung des Chrommarkers ___ 41

3.2.4.1.2 Bestimmung der Chromkonzentration__ 42

3.2.4.1.3 Berechnung der Trockensubstanzflüsse ___ 42

3.2.4.2 Bestimmung der mikrobiellen Proteinsyntheseleistung___ 42

3.2.4.2.1 Rechnerische Bestimmung der Mengen an nicht abgebautem

Futterprotein (UDP) sowie fermentierter organischer Substanz (FOS) ___ 43

3.3 Bestimmung des Biotingehaltes

3.4 Mathematisch-stattstische Auswertung der Versuchsergebnisse __ 45

4 Untersuchungsergebnisse _ 47

4.1 In vitro-Untersuchungen

$\begin{array}{lll}4.1 .1 & \text { Fermentationsparameter } & 47\end{array}$

4.1.2 Biotinumsatz in den in vitro-Untersuchungen ___ 51

4.2 In vivo-Untersuchungen

5 Diskussion $\quad 56$

5.1 In vitro-Untersuchungen

5.1.1 Fermentationsparameter — 57

5.1.1.1 Einfluss der Ration __ 58

5.1.1.2 Einfluss der Defaunierung__ 60

5.1.2 Biotinumsatz_ 62

5.1.2.1 Einfluss der Ration __ 62

5.1.2.2 Einfluss der Defaunierung___ 62

5.2 In vivo-Untersuchungen

6 Schlußfolgerungen

7 Zusammenfassung $\quad 67$

8 Summary 68

9 Literaturverzeichnis $\quad 69$ 


\section{Abkürzungen}

\begin{tabular}{|c|c|}
\hline * & signifikant bei $p<0,05$ \\
\hline ** & signifikant bei $p<0,01$ \\
\hline *** & signifikant bei $p<0,001$ \\
\hline$\Sigma$ & Summe \\
\hline Abb. & Abbildung \\
\hline ad & $\mathrm{zu}$ \\
\hline ADF & saure Detergenzienfaser \\
\hline AMP & Adenosin-Monophosphat \\
\hline AOAC & Association Of Analytical Communities \\
\hline ATP & Adenosin-Triphosphat \\
\hline $\mathrm{Al}_{2}\left(\mathrm{SO}_{4}\right)_{3} \times \mathrm{H}_{2} \mathrm{O}$ & Aluminiumsulfat-Hydrat \\
\hline ATCC & American Type Culture Collection \\
\hline Aufn. & Aufnahme \\
\hline bes. & besonders \\
\hline C & Kohlenstoff \\
\hline $\mathrm{C} 2$ & Essigsäure \\
\hline C3 & Propionsäure \\
\hline${ }^{\circ} \mathrm{C}$ & Grad Celsius \\
\hline $\mathrm{CaCl}$ & Calciumchlorid \\
\hline CDP & Cytosin-Diphosphat \\
\hline $\mathrm{CH}$ & Schweiz \\
\hline $\mathrm{CH}_{4}$ & Methan \\
\hline$\left(\mathrm{CH}_{3} \mathrm{COO}\right)_{2} \mathrm{Co} \times 4 \mathrm{H}_{2} \mathrm{O}$ & Cobaltacetat \\
\hline $\mathrm{cm}$ & Centimeter \\
\hline $\mathrm{CO}_{2}$ & Kohlendioxid \\
\hline CoA & Coenzym A \\
\hline $\mathrm{Cr}_{2} \mathrm{O}_{3}$ & Chrom-(III)-Oxid \\
\hline CTP & Cytosin-Triphosphat \\
\hline$D$ & Deutschland \\
\hline d & Tag \\
\hline DK & Dänemark \\
\hline Duod. & Duodenum \\
\hline E.C. & Enzyme Commission \\
\hline Ed. & Editor (Plural: Eds.) \\
\hline
\end{tabular}




\section{Abkürzungen}

$\mathrm{F}$

Fa.

FAD

FID

FOS

FS

$g$

GE

Grassil.

$\mathrm{H}$

$\mathrm{HCO}_{3}{ }^{-}$

$\mathrm{HgCl}_{2}$

$\mathrm{H}_{2} \mathrm{O}$

$\mathrm{H}_{2} \mathrm{O}_{\text {dest. }}$.

$\mathrm{H}_{3} \mathrm{PO}_{4}$

$\mathrm{H}_{2} \mathrm{SO}_{4}$

IC4

IC5

ISTD

$\mathrm{K}_{\mathrm{m}}$

$\mathrm{KCl}$

$\mathrm{kg}$

kJ

Konz.

$\mathrm{kPa}$

I

LB

$M$

$\mathrm{m}$

$1 \mathrm{M}$

mA

Markersubst.

mg

$\min$.
Fermenter

Firma

Food and Drug Administration

Flammenionisationsdetektor

fermentierte organische Substanz

Frischsubstanz

Gramm; Erdbeschleunigung

Bruttoenergie

Grassilage

Heu

Hydrogencarbonat

Quecksilberchlorid

Wasser

destilliertes Wasser

Phosphorsäure

Schwefelsäure

iso-Buttersäure

iso-Valeriansäure

interner Standard

Michaelis-Menten-Konstante

Kaliumchlorid

Kilogramm

Kilojoule

Konzentrat

Kilopascal

Liter

Lactobacillus

Mais

Meter

1 molare Lösung

Milliampere

Markersubstanz

Milligramm

Minute 


\section{Abkürzungen}

\begin{tabular}{|c|c|}
\hline MLF & Milchleistungsfutter \\
\hline $\mathrm{mm}$ & Millimeter \\
\hline $\mathrm{mm}^{3}$ & Kubikmillimeter \\
\hline $\mathrm{mmol}$ & Millimol \\
\hline $\mathrm{ml}$ & Milliliter \\
\hline $\mathrm{MJ}$ & Megajoule \\
\hline$\mu \mathrm{m}$ & Mikrometer \\
\hline$\mu \mathrm{mol}$ & Mikromol \\
\hline$\mu g$ & Mikrogramm \\
\hline$\mu l$ & Mikroliter \\
\hline $\mathrm{MgCl} \times 6 \mathrm{H}_{2} \mathrm{O}$ & Magnesiumchlorid-Hexahydrat \\
\hline mind. & mindestens \\
\hline MinF. & Mineralfutter \\
\hline $\mathrm{n}$ & Stichprobenumfang \\
\hline $\mathrm{N}_{2}$ & Stickstoff \\
\hline${ }^{14} \mathrm{~N}$ & Stickstoff der Atommasse $14 \mathrm{u}$ \\
\hline${ }^{15} \mathrm{~N}$ & Stickstoff der Atommasse $15 \mathrm{u}$ \\
\hline $\mathrm{NaCl}$ & Natriumchlorid \\
\hline $\mathrm{NAD}^{+}$ & Nicotinamid-Adenin-Dinucleotid \\
\hline $\mathrm{NADH}$ & Reduktionsform von $\mathrm{NAD}^{+}$ \\
\hline $\mathrm{NaHCO}_{3}$ & Natrium-Hydrogen-Carbonat \\
\hline $\mathrm{Na}_{2} \mathrm{HPO}_{4} \times 12 \mathrm{H}_{2} \mathrm{O}$ & Di-Natrium-Hydrogen-Phosphat-Dodecahydrat \\
\hline NAN & Nicht-Ammoniak-Stickstoff \\
\hline NC4 & n-Buttersäure \\
\hline NC5 & n-Valeriansäure \\
\hline NDF & neutrale Detergenzienfaser \\
\hline NEL & Netto-Energie Laktation \\
\hline $\mathrm{ng}$ & Nanogramm \\
\hline $\mathrm{NH}_{3}$ & Ammoniak \\
\hline $\mathrm{NH}_{4}^{+}$ & Ammonium \\
\hline $\mathrm{NH}_{4}-\mathrm{N}$ & Stickstoff in Form von Ammonium \\
\hline n. I. & nach Inkubation \\
\hline NIRS & Nah-Infrarot-Spektrometrie \\
\hline $\mathrm{nm}$ & Nanometer \\
\hline
\end{tabular}




\begin{tabular}{ll} 
Abkürzungen & \\
NPN & Nicht-Protein-Stickstoff \\
OS & organische Substanz \\
p & Wahrscheinlichkeit \\
$P_{\mathrm{i}}$ & Phosphat \\
RUSITEC & Rumen Simulation Technique \\
S & Schwefel \\
sbk. & subkutan \\
SCFA & short chain fatty acids \\
Tab. & Tabelle \\
T & Trockensubstanz \\
UDP & undegradable protein (unabgebautes Futterprotein) \\
USA & Vereinigte Staaten von Amerika \\
v/v & Mischungsverhältnis pro Volumeneinheit \\
W & Weizen \\
XA & Rohasche \\
XF & Rohfaser \\
XL & Rohfett \\
XP & Rohprotein \\
XX & N-freie Extraktstoffe \\
Z.B. & zum Beispiel \\
X & grö als \\
& \\
\hline &
\end{tabular}




\section{Verzeichnis der Tabellen und Abbildungen sowie des Anhangs}

\section{Tabellen}

Nr.

Titel

Seite

1 Literaturübersicht zu Auswirkungen von Biotinsupplementierungen auf die Klauengesundheit von Milchkühen nach KOFLER (2001)

2 Literaturübersicht zu Biotingehalten in ausgewählten Futtermitteln für Wiederkäuer

3 Bioverfügbarkeit von Biotin in ausgewählten Futtermitteln (ROCHE 2002)

4 Schema des Versuchsaufbaus der in vitro-Untersuchungen

5 Zusammensetzung des eingesetzten Puffers

6 Substrateinwaage, Pufferzulauf und Dosierung des Defaunierungs-Detergenzes für alle 10 Fermenter

7 Gehalte an Trockensubstanz (\%), Weender Rohnährstoffen (\% in T) sowie den Zellwandfraktionen ADF und NDF (\% in T) der verwendeten in vitro-Substrate

8 Gehalte an Trockensubstanz (\%) und Weender Rohnährstoffen (\% in T) der bei der Fütterung der Spendertiere zum Einsatz gekommenen Futtermittel

9 Chromatographiebedingungen zur Bestimmung der Zusammensetzung des Fermentationsgases

10 Chromatographiebedingungen zur Bestimmung der SCFA

11 Berechnungsgrundlage zur Herstellung eines SCFA-Standardgemischs

12 Charakteristik der Futterrationen in den in vivo-Versuchen

13 Versuchstiere und Futterrationen in den in vivo-Untersuchungen (angeben in Trockensubstanz pro Tier und Tag)

14 Zusammensetzung der Kraftfuttermischungen in den in vivo-Untersuchungen (Mischungsanteile in \%) 
15 Versuchsschema zur Überprüfung des Einflusses von mais- und weizenbetonten Kraftfutterrationen

16 Gehalte an Trockensubstanz (\%), Weender Rohnährstoffen (\% in T) sowie den 40 Zellwandfraktionen ADF und NDF (\% in T) der in den in vivo-Versuchen eingesetzten Futtermittel

17 Biotingehalte der in den in vitro- und in vivo- Untersuchungen eingesetzten 45 Futtermittel

18 Einfluss der Ration und des Faunierungsstatus' auf Fermentationsparameter in 48 der Pansensimulation RUSITEC

19 Biotinumsatz in den in vitro-Untersuchungen $(\mu \mathrm{g} / \mathrm{d})$

20 Einfluss der Rationen auf duodenale Flussmengen an Trockensubstanz, Mikro53 ben-N, fermentierter organischer Substanz, unabgebautem Futterprotein und Biotin in den in vivo-Versuchen

\section{Abbildungen}

$\mathrm{Nr}$.

Titel

Seite

1 Strukturformel von D-(+)-Biotin

2 Beteiligungen der biotinabhängigen Enzyme an Gluconeo- und Lipogenese nach WEISS UND ZIMMERLY (2000)

3 Mikrobielle Synthese von Biotin (DAKSHINAMURTI UND CHAUHAN 1989) 14

4 Mikrobieller Abbau von D-(+)-Biotin nach McCoRmıck (1975) 16

5 Schematischer Aufbau eines RUSITEC-Fermenters (CZERKAWSKI und 25 BRECKENRIDGE 1977)

6 RUSITEC-System 


\section{Anhang}

Nr.

Titel

Seite

A 1 Mittlere Substrateinwaage der in vitro-Untersuchungen [g T / d]

88

A 2 Mittlere Mengen an festen Inkubationsrückständen der in vitro- Untersuchun- 88 gen $[g \mathrm{~T} / \mathrm{d}]$

A 3 Zusammensetzung der eingesetzten Mineralstoffmischungen

A 4 Analysenvorschrift zur Bestimmung der Biotinkonzentration in Milch (gilt 90 auch für Pansensaft und Fermenterflüssigkeit aus der Pansenssimulation) und Futtermitteln (gilt auch für feste Fermetationsrückstände aus der Pansenfermentation und getrockneten Duodenalchymus )

A 5 Erfasste Einzeldaten der in vitro-Untersuchungen (nicht volumenkorrigiert)

A 6 Erfasste Einzeldaten der in vitro-Untersuchungen (volumenkorrigiert)

A 7 Biotinkonzentrationen in den Inkubationsrückständen aus den in vitro-Unter- 105 suchungen (in $\mu \mathrm{g}$ Biotin / kg festem Rückstand bzw. in $\mu \mathrm{g}$ Biotin / Liter Überlaufflüssigkeit)

A 8 Erfasste Einzelwerte der bei den in vivo-Untersuchungen untersuchten Para- 106 meter 


\section{Einleitung}

Biotin wird wie alle Vitamine des B-Komplexes von den Mikroorganismen im Pansen von Wiederkäuern gebildet. Diese ruminale mikrobielle Synthese wird allgemein zusammen mit der mit dem Futter aufgenommenen Menge Biotin als versorgungssichernd angesehen.

Bei hochleistenden Milchkühen bestehen diesbezüglich jedoch Zweifel, da Biotinsupplementierungen des Futters in zahlreichen Untersuchungen positive Effekte zeigten, die sich besonders auf die Klauengesundheit und teilweise auch auf die Milchleistung bezogen.

Der erstgenannte Effekt hat dabei die größere wirtschaftliche Bedeutung. So ist z. B. in deutschen Milchviehbeständen in den letzten 25 Jahren keine Abgangsursache so überproportional angewachsen wie Klauen- und Gliedmaßenschäden (DISTL UND SCHMID 1994). Nach LOTTHAMmeR (2000) liegen die Abgänge aus diesen Gründen mit $16 \%$ aller Abgänge an zweiter Stelle hinter Fruchtbarkeitsproblemen. Die Kosten für Behandlungen von Lahmheiten sowie die Verluste aus Abgängen, Leistungseinbußen und behandlungsbedingter Milchsperre können in Abhängigkeit von der Schwere der Lahmheit bis zu ca. 177 Euro pro Tier und Jahr betragen (KÜMPER 1998).

Wie bereits erwähnt, besteht Ungewissheit, ob die Biotinversorgung, die über das Futter und die enterale mikrobielle Synthese stattfindet, immer ausreicht, um z. B. bei der Milchkuh die besonders zu Beginn der Laktation ablaufenden biotinabhängigen lipo- und besonders auch gluconeogenetischen Prozesse ausreichend abzudecken (WHITEHEAD 1991).

Aufgrund mangelnder Kenntnisse können gegenwärtig noch keine exakten Empfehlungen zur Versorgung bzw. zum Bedarf an B-Vitaminen für Wiederkäuer angegeben werden (FLACHOWSKY 1999).

Daher sind spezielle Untersuchungen erforderlich, mit deren Hilfe überprüft werden kann, ob die ruminale Eigensynthese zur Bedarfsdeckung ausreicht.

Als wesentlicher Einflussfaktor auf die Biotinumsetzungen im Pansen gilt das Verhältnis von Raufutter zu Konzentrat der gefütterten Ration (MILLER ET AL. 1986; ABEL ET AL. 2001), aber vermutlich auch die abbaukinetischen Eigenschaften, also die Geschwindigkeit des fermentativen Abbaus der eingesetzten Futterkohlenhydrate im Pansen sowie die Größe und Zusammensetzung der Protozoenpopulation.

In der vorliegenden Arbeit stehen die Einflüsse dieser drei Faktoren auf die Zusammenhänge zwischen den mikrobiellen Stoffwechselvorgängen im Pansen und dem Biotinstatus bzw. dem Biotinfluss in das Duodenum im Mittelpunkt des Interesses, die durch systematische Untersuchungen mit Hilfe der Pansensimulationstechnik RUSITEC und an duodenalkanülierten Milchkühen erfasst wurden. Dazu wurden Fermentations- und Syntheseleistungen ge- 
messen, Biotinbilanzen errechnet und Biotinflussmessungen am Dünndarm der Kühe durchgeführt.

Die Untersuchungen sollen so einen Beitrag zur Erweiterung der Kenntnisse über den Bitinhaushalt des mikrobiellen Pansenstoffwechsels und zur Biotinversorgung von Milchkühen liefern. 


\section{Literaturübersicht}

\subsection{Chemisch-physikalische Charakterisierung von Biotin}

Biotin gehört zu den Vitaminen des wasserlöslichen B-Komplexes und wurde in der Literatur auch Vitamin H, Hautvitamin, Coenzym R und antiseborrhoisches Vitamin genannt (BITSCH UND BARTEL 1994).

Chemisch gesehen handelt es sich um eine Kombination aus Harnstoff, Thiophen und Valeriansäure. DU VIGNEAUD ET AL. (1942) erkannten die chemische Struktur des Biotinmoleküls als cis-Hexahydro-2-Keto-1H-Thienol[3,4]imidazol-4-Valeriansäure mit der Summenformel $\mathrm{C}_{10} \mathrm{H}_{16} \mathrm{~N}_{2} \mathrm{O}_{3} \mathrm{~S}$, charakterisiert durch einen Imidazol- und einen Thiophenring, die miteinander kondensiert sind.

Das Biotinmolekül mit seinen drei asymmetrisch angeordneten Kohlenstoffatomen kommt in vier diastereoisomeren Formen vor, nämlich als Biotin, Allobiotin, Epibiotin und Epiallobiotin, jedes davon sowohl als D- und L-Enantiomer. Es ergeben sich so insgesamt 8 optisch aktive Formen für die Struktur, von denen lediglich das D-(+)-Biotin biologisch aktiv ist (GYÖRGY UND ZILLIKEN, 1974).

Abbildung 1 stellt die Strukturformel des D-(+)-Biotins dar.

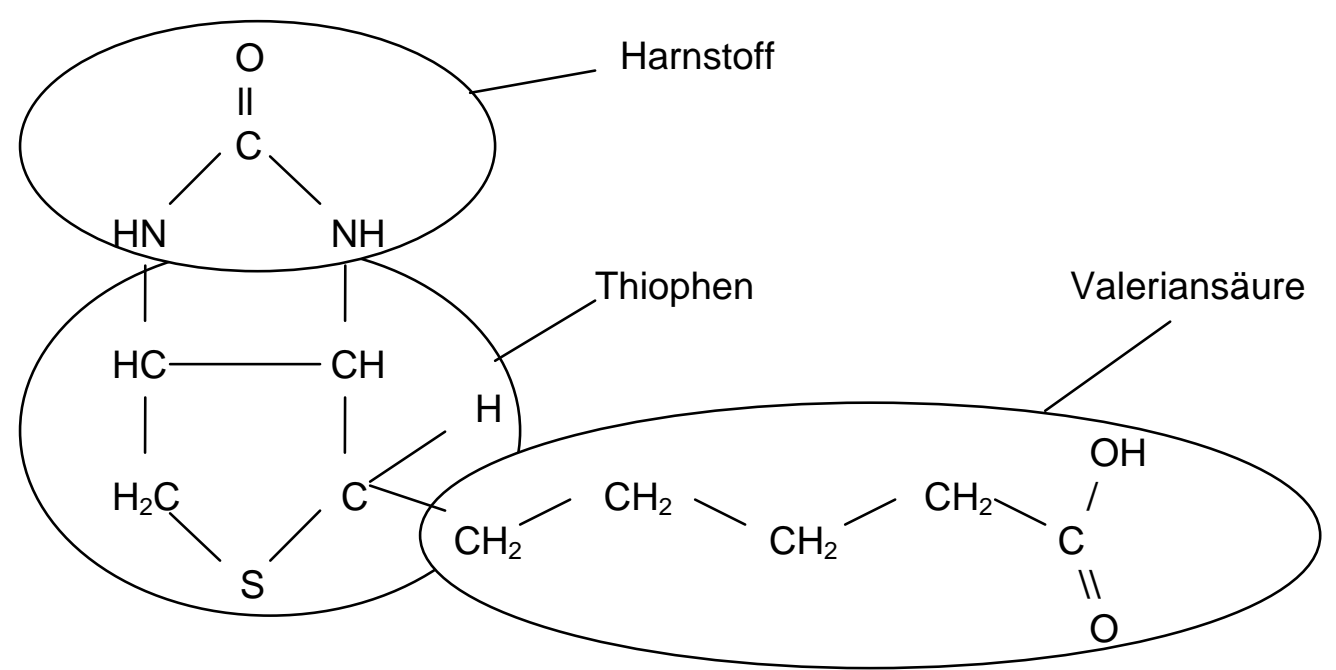

Abb. 1 Strukturformel von D-(+)-Biotin

Biotin kristallisiert in langen, weißlichen Nadeln aus wässrigen Lösungen. Der Schmelzpunkt liegt bei 232 bis $233^{\circ} \mathrm{C}$. Es ist in kaltem Wasser schwerer löslich als in warmem (ca. $220 \mathrm{mg}$ bzw. $0,9 \mathrm{mmol}$ pro $1 \mathrm{H}_{2} \mathrm{O}$ bei $25^{\circ} \mathrm{C}$ ), ferner ist es löslich in verdünntem Alkohol und $95 \%$ igem 
Ethanol (ca. $800 \mathrm{mg}$ bzw. 3,27 mmol pro 1 I 95\%-igem Ethanol), wohingegen es in anderen organischen Lösungsmitteln und Fetten unlöslich ist.

Biotin ist hitzebeständig und in neutralen und mäßig sauren Lösungen für mehrere Monate stabil, ebenso in leicht basischen Lösungen bis zu einem pH-Wert von ca. 9.

Starke Säuren und Basen, Formaldehyd und ultraviolettes Licht zerstören, ranzige Fette und Cholin inaktivieren es (ScOTT ET AL. 1982).

\subsection{Funktionen von Biotin im Stoffwechsel}

\subsubsection{Biotin als Bestandteil von Carboxylasen}

Biotin erfüllt seine wichtigste Funktion im Stoffwechsel als prosthetische Gruppe von Carboxylasen. Das Vitamin kann $\mathrm{CO}_{2}$ während des Carboxylierungsvorgangs bis zur Abgabe an das Substrat vorübergehend im Enzym fixieren und halten (WHITEHEAD 1991).

Durch kovalente Amidbindung zwischen der Carboxylgruppe des Biotin und der $\varepsilon$-Aminogruppe eines spezifischen Lysinrestes des Enzymproteins (LYNEN 1967), welche durch die Holocarboxylase-Synthetase (Klassifikationszahl E.C. 6.3.4.10) katalysiert wird, entsteht in zwei Reaktionsschritten das sog. Biotinyllysin oder Biocytin. Gebundenes Biotin wirkt bei bestimmten carboxylierenden Enzymen als Carrier für $\mathrm{CO}_{2}$. Dabei liegt es in Form des sehr labilen Carboxybiotin-Derivates vor.

Der Gesamtverlauf von Carboxylierungsreaktionen, an denen Biotin beteiligt ist, wird durch die folgende Gleichung veranschaulicht (LEHNINGER1987):

$$
\begin{aligned}
\text { ATP }+\mathrm{HCO}_{3}^{-}+\text {Biotinyl-Enzym } & \longleftrightarrow \text { ADP }+\mathrm{P}_{\mathrm{i}}+\text { Carboxybiotinyl-Enzym } \\
\text { Carboxybiotinyl-Enzym }+ \text { Substrat } & \longleftrightarrow \text { Biotinyl-Enzym }+ \text { carboxyliertes Substrat } \\
\text { ATP }+\mathrm{HCO}_{3}{ }^{-}+\text {Substrat } & \longleftrightarrow \text { ADP }+\mathrm{P}_{\mathrm{i}}+\text { carboxyliertes Substrat }
\end{aligned}
$$

Fehlt die Holocarboxylase-Synthetase, wird keine der biotinabhängigen Carboxylasen gebildet, was für junges Leben letal wirkt (NYHAN 1987).

Carboxylasen von Mikroorganismen und höheren Tieren weisen in der Nähe der BiotinLysin-Bindung homologe Aminosäuresequenzen auf, die evolutionsgeschichtlich auf einen gemeinsamen Vorfahren verschiedener Carboxylasen hindeuten (DAKSHINAMURTI UND CHAUHAN 1989).

Bei Säugetieren kommen vier biotinabhängige Enzyme vor, nämlich Pyruvat-, Acetyl-CoA-, Propionyl-CoA- und $\beta$-Methylcrotonyl-CoA-Carboxylase. Sie alle katalysieren die Aufnahme von Bicarbonat in organische Verbindungen. 
Pyruvatcarboxylase (E.C. 6.4.1.1) spielt eine wichtige Rolle im Verlauf der Gluconeogenese (JUNGERMANN UND MöLLER 1984). Sie katalysiert innerhalb der Mitochondrien die Umwandlung von Pyruvat zu Oxalacetat und Acetyl-CoA. Oxalacetat ist ein Zwischenprodukt in der Biosynthese von Phosphoenolpyruvat und der Gluconeogenese, die hauptsächlich im Zellplasma der Leberzellen (85 - 90\%) und in geringerem Maße auch in den Nierenzellen des proximalen Tubulussystems (10 - 15\%) stattfindet (KOLB 1989).

Neben der Bedeutung des Enzyms für die Gluconeogenese hat es eine wichtige Funktion innerhalb der Lipogenese: Das bei der Decarboxylierung von Pyruvat anfallende Acetyl-CoA ist Ausgangsmolekül der Fettsäurensynthese. Es wird in den Mitochondrien gebildet, ist jedoch nicht in der Lage, durch die Membran der Zellorganellen in das Zellplasma, den Ort der Fettsäurensynthese, zu gelangen, sondern muss erst mit Oxalacetat zu Citrat kondensieren. Dieses kann die Membran passieren und ins Zellplasma gelangen, wo es wieder in die Ausgangssubstrate gespalten wird und das Acetyl-CoA in den Stoffwechselpfad der Lipogenese eintreten kann.

Pyruvat ist ferner ein Zwischenprodukt bei der Umwandlung von Lactat und den Aminosäuren Alanin, Cystein, Glycin und Serin in Glucose, so dass eine Glucosesynthese aus diesen Substraten ohne Pyruvatcarboxylase nicht stattfinden kann.

Pyruvatcarboxylase wird streng reguliert über die Konzentration an Acetyl-CoA. Aufgrund seiner wichtigen Bedeutung für den Energiemetabolismus hat dieses Enzym eine hohe Priorität für Biotin, was sich darin zeigt, dass ein geringer Mangel dieses Vitamins die Enzymaktivität nicht beeinflusst (ZEMPLENI UND MOCK 1999).

Ein Aktivitätsverlust der Pyruvatcarboxylase führt zu einer Drosselung der Gluconeogenese und folglich zu einer Anhäufung von Pyruvat und Lactat unter Verbrauch des Reduktionsäquivalents $\mathrm{NADH}+\mathrm{H}^{+}$, was in der Leber einen Anstieg der $\mathrm{NAD}^{+} / \mathrm{NADH}+\mathrm{H}^{+}-$Relation zur Folge hat (DEODHAR UND MISTRY 1969).

Acetyl-CoA-Carboxylase (E.C. 6.4.1.2), bei welcher als erstem Enzym Biotin als prosthetische Gruppe nachgewiesen wurde (WAKIL UND GIBSON 1960), dient als Katalysator bei der Umwandlung von Acetyl-CoA zu Malonyl-CoA. Durch wiederholte Kondensationen, Reduktionen und Dehydrationen mehrerer Malonyl-CoA-Moleküle werden im Zellplasma dann Fettsäuren synthetisiert. Somit ist die Acetyl-CoA-Carboxylase das Schlüsselenzym für den zentralen Stoffwechselpfad der Fettsäurenbiosynthese und unterliegt strengen Regulationsmechanismen. Aufgrund dieser wichtigen Bedeutung hat die Acetyl-CoA-Carboxylase eine hohe Priorität für Biotin und bleibt von Schwankungen in der Biotinversorgung bis hin zu einem schwerwiegenden Defizit unbeeinflusst (ZEMPLENI UND MOCK 1999).

Die durch Acetyl-CoA-Carboxylase katalysierte Reaktion ist der geschwindigkeitsbestimmende Schritt bei der Biosynthese der Fettsäuren (LEHNIGER 1987), ein Aktivitätsverlust des 
Enzyms führt aber nicht nur zur Verlangsamung, sondern auch zu Störungen im Ablauf der Fettsäurensynthese. Es kann in Folge eine Erhöhung des Anteils an Palmitoleinsäure, hauptsächlich auf Kosten von Stearinsäure, im Fettgewebe der Leber und anderer Organe festgestellt werden.

Propionyl-CoA-Carboxylase (E.C. 6.4.1.3) ist am Propionatstoffwechsel beteiligt. Das aus verschiedenen Stoffwechselprozessen stammende Propionat wird in Propionyl-CoA umgewandelt, welches dann intramitochondrial durch die katalytische Wirkung der Propionyl-CoACarboxylase zu Methylmalonyl-CoA carboxyliert wird. Dieses wird über Succinyl-CoA weiter in Oxalacetat umgewandelt und in den Zitronensäurezyklus aufgenommen (WOOD UND BARDEN 1977). Propionat und Propionyl-CoA spielen bei Nicht-Wiederkäuern nur eine geringe Rolle, sie fallen dort intermediär nur bei der $\beta$-Oxidation von ungeradzahligen Fettsäuren sowie beim Abbau der Aminosäuren Threonin, Valin, Methionin und Isoleucin an. Daher hat bei biotinmangelversorgten Monogastriden die Aufrechterhaltung der Propionyl-CoACarboxylase eine niedrigere Priorität als die von Pyruvat- und Acetyl-CoA-Carboxylase (Mock 1999).

Bei Wiederkäuern entsteht Propionat im mikrobiellen Stoffwechsel des Pansens und gilt als wichtigster glucogener Vorläufer. Wiederkäuer sind bezüglich der Energieversorgung aufgrund des ruminalen Abbaus von Glucose weitgehend von diesem Vorgang abhängig (WHITEHEAD 1991). Die Propionyl-CoA-Carboxylase hat somit bei Wiederkäuern eine hohe Priorität für Biotin, da sonst bereits marginale Biotindefizite die Milchproduktion durch eine reduzierte Gluconeogenese einschränken würden (WEISS UND ZIMMERLY 2000).

Die Propionatbildung selbst ist beim Wiederkäuer von der Fütterung abhängig: Während beim Einsatz raufutterreicher Rationen die Bildung über den randomizing pathway, also über Succinat verläuft (BALDWIN 1965), gewinnt bei konzentrat- und stärkereicher Fütterung der biotinunabhängige Acrylatweg an Bedeutung (SCHEIFINGER UND WOLIN 1973; RUSSEL UND WALLACE 1988). Das Ausmaß der Propionatbildung hängt dabei entscheidend von der Anwesenheit methanogener Bakterien im Pansen ab, die den aus der Glycolyse anfallenden Wasserstoff von den Reduktionsschritten der Succinat- und Propionatbildung auf Methan umlenken (SCHEIFINGER ET AL. 1975; CHEN UND WOLIN 1977).

Die $\beta$-Methylcrotonyl-CoA-Carboxylase (E.C. 6.4.1.4) ist am Abbau der Aminosäure Leucin beteiligt. Sie katalysiert unter ATP-Verbrauch die Umwandlung von $\beta$-Methylcrotonyl-CoA zu $\beta$-Methylglutaconyl-CoA. Endprodukte des Leucin-Abbaus sind Acetyl-CoA und Acetacetat (BONJOUR 1991). Bei Biotinmangel wird ein anderer Stoffwechselpfad mit den Endprodukten Methylcrotonyl-Glycin und 3-Hydroxy-Isovaleriat eingeschlagen. Da diese Säuren schon nach einer kurzen Zeit des Biotinmangels in steigenden Mengen im Harn nachzuweisen sind, wird die Priorität für Biotin als nur gering eingestuft (MOcK 1999). 
Erstes Anzeichen für einen Biotinmangel ist generell eine verminderte Aktivität der biotinabhängigen Enzyme in der Leber, nachgewiesen von ARINZE UND MISTRY (1971) bei Hühnern und Ratten. Dies hat zur Folge, dass die betroffenen Stoffwechselwege verlangsamt ablaufen. Durch Zufuhr von Biotin wird die Aktivität jedoch wieder in Gang gebracht, da die Apoenzyme auch im Mangelzustand nicht abgebaut, sondern nur katalytisch inaktiv werden.

MILLIGAN ET AL. (1967) beobachteten bei ruminalen Mikroorganismen in vitro einen Rückgang des Celluloseabbaus und der Produktion von Propion- und Essigsäure, wenn im eingesetzten Medium das Biotin vollständig entzogen oder durch Avidin gebunden wurde. Dieser starke Rückgang der Propionatsynthese unter Biotin-Mangelbedingungen steht in Einklang mit der schon erwähnten Beobachtung, dass die Hemmung von einem oder mehreren biotinabhängigen Enzymen auch die Propionatbildung beeinflusst. Das Untersuchungsergebnis von SCHEIFINGER (1975) belegte ebenfalls, dass Bakterien des saccharolytischen Stammes Selenomonas ruminantium Biotin für die Decarboxylierung von Succinat zu Pyruvat benötigen, die als eine der wichtigsten Reaktionen im Verlauf der Pansenfermentation angesehen werden kann.

Abbildung 2 stellt noch einmal die biotinabhängigen Stoffwechselwege dar.

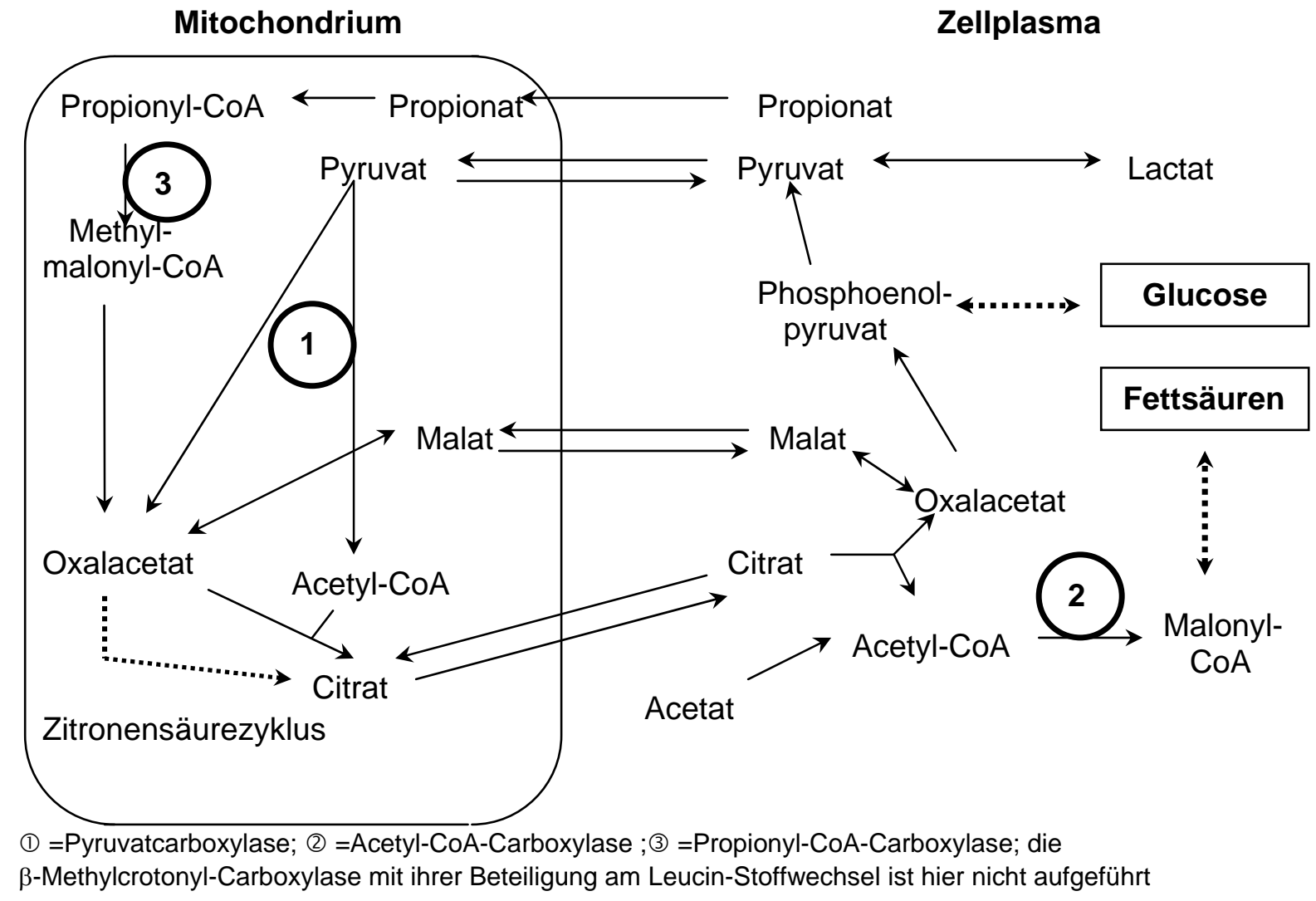

Abb. 2: Beteiligungen der biotinabhängigen Enzyme an Gluconeo- und Lipogenese nach WEISS UND ZIMMERLY (2000) 


\subsubsection{Die Bedeutung von Biotin in Epidermiszellen und bei der Behandlung von Lahmheiten}

Biotin spielt eine wesentliche Rolle bei der Differenzierung von Epidermiszellen in der Haut (FRITSCHE ET AL. 1991) sowie bei der Synthese von Keratin in den Epidermiszellen (MüLLING ET AL. 1999a). Die im Hinblick auf die großen landwirtschaftlichen Nutztiere in diesem Zusammenhang wichtigste Funktion von Biotin liegt in der Steigerung der Qualität des Zwischenzellkittes der Hornzellen, wodurch direkt deren Elastizität und Widerstandsfähigkeit bedingt wird (SMART UND CYMBALUK 1997). Für diesen Zellzusammenhang durch den Kitt werden Lipide, insbesondere Glycolipide, verantwortlich gemacht (WERTZ UND DOWNIG 1983). MÜLLING ET AL. (1999b) verglichen die Lipidmenge und Fettsäurezusammensetzung im Zwischenzellkitt der Klauen biotinmangel- und normalversorgter Kälber. Die beobachtete Verschlechterung der Struktur des Kittes wurde mit dem verzeichneten Rückgang der langkettigen Fettsäuren im Lipidanteil des Kittes der mangelversorgten Tiere erklärt, was noch einmal die Wichtigkeit der unter 2.2.1 beschriebenen Wirkung von Biotin als prosthetische Gruppe von Schlüsselenzymen der Lipogenese aufzeigt. MEYER ET AL. (2002) berichteten ebenfalls von veränderten Fettsäuremustern des Zwischenzellkittes zugunsten der langkettigen Fettsäuren mit 18 oder mehr C-Atomen und verbesserter Klauenhärte und -qualität bei biotinsupplementierten Kühen im Vergleich zu unsupplementierten.

Biotinmangel begünstigt folglich generell das Auftreten von Klauenerkrankungen infolge der verminderten Hornqualität und fördert dadurch die Entwicklung von Hornspalten, losen Wänden und Ballenfäule (CAMPELL ET AL. 2000).

Biotinergänzungen zum Futter zeigten bei Schweinen (BROOKS ET AL. 1977; WEBB ET AL. 1984; Geyer ET AL. 1984; Bryant et AL. 1985a,c) und Pferden (COMBEN ET AL. 1984; KEMPSON 1990; JOSSEK ET AL. 1995) positive Wirkungen auf die Klauengesundheit.

Auch bei Rindern können durch Biotinergänzungen Lahmheiten vermieden werden. DISTL UND SCHMID (1994) verabreichten Milchkühen über einen Zeitraum von 11 Monaten täglich 20 mg Biotin und verglichen die Klauengesundheit mit der von unbehandelten Kontrolltieren. Der Biotinzusatz reduzierte die Häufigkeit von Sohlengeschwüren (Laminitis = Pododermatitis aseptica diffusa) und verbesserte die Härte des Klauenhorns. In einer anderen Untersuchung erbrachte die gleiche Supplementierung eine erhöhte Zugfestigkeit des Sohlenhorns und des distalen Kronenhorns, aber keinen Effekt auf die Wachstumsrate des Klauenhorns (SCHMIDT UND GEIER 1994). Dagegen konnte unter Feldbedingungen bei 160 Kühen und Tagesgaben von 20 mg pro Tier kein Heilungsprozess bei Hornläsionen beobachtet werden, jedoch wurde die Hornneubildung beschleunigt (HUNKELER ET AL. 1996).

VOIGT ET AL. (2000) führten eine 18 Monate dauernde Langzeitstudie an Milchkühen durch, in der Tagesgaben von 10 mg pro Tier das Auftreten von Sohlengeschwüren und Ballenfäule 
gegenüber unsupplementierten Tieren verminderten. Da die Ergebnisse erst gegen Ende der Studie deutlicher hervortraten, hielten die Autoren die Höhe der Applikation für zu niedrig, um den positiven Effekt von Biotin vollständig auszuschöpfen.

Weitere Untersuchungen zum Einfluss von Biotingaben auf die Klauengesundheit sind in der folgenden Tabelle 1 zusammengestellt.

Tabelle 1: Literaturübersicht zu Auswirkungen von Biotinsupplementierungen auf die Klauengesundheit von Milchkühen nach KOFLER (2001)

\begin{tabular}{|l|c|l|}
\hline \hline \multicolumn{1}{|c|}{ Studie } & $\begin{array}{c}\text { Dosis } \\
\mathbf{( m g / d )}\end{array}$ & \multicolumn{1}{|c|}{ Ergebnisse } \\
\hline \hline HOCHSTETTER 1998 & 20 & $\begin{array}{l}\text { Reduktion der Inzidenz von Dermatitis digitalis und } \\
\text { Sohlenblutungen nach 6 Monaten }\end{array}$ \\
\hline MIDLA ET AL. 1998 & 20 & $\begin{array}{l}\text { Reduktion der Inzidenz von losen Wänden an der } \\
\text { weißen Linie nach 7 Monaten }\end{array}$ \\
\hline FITZGERALD ET AL. 2000 & 20 & $\begin{array}{l}\text { Reduktion des Lahmheitsscore und Reduktion der } \\
\text { Behandlung wegen Klauenleiden nach 12 Monaten }\end{array}$ \\
\hline HEDGES ET AL. 2001 & 20 & $\begin{array}{l}\text { Reduktion der Inzidenz von Erkrankungen der wei- } \\
\text { ßen Linie }\end{array}$ \\
\hline PÖTZSCH ET AL. 2003 & 20 & $\begin{array}{l}\text { Reduktion der Inzidenz von Erkrankungen der wei- } \\
\text { Ben Linie }\end{array}$ \\
\hline BERGSTEN ET AL. 2003 & 20 & $\begin{array}{l}\text { Reduktion der Inzidenz von Sohlenblutungen, kein } \\
\text { Einfluss auf Hufrisse und -erosionen }\end{array}$ \\
\hline \hline
\end{tabular}

Zu beachten bleibt dabei, dass die Biotinsupplementation über einen langen Zeitraum erfolgen muss, da eine Verbesserung der Hornqualität nur in neu gebildetem und nachwachsendem Horn eintritt, das Sohlen- und Ballenhorn jedoch ca. 3 bis 4 Monate und das Wandhorn sogar 18 bis 20 Monate benötigt, um vollständig erneuert zu werden (MüLLING 1998). Selbst nach Applikation hoher Dosierungen von $40 \mathrm{mg}$ pro Tier und Tag war nach 50 Tagen ein positiver Effekt in nachwachsendem Sohlenhorn nach der Behandlung leichter Sohlengeschwüre bei Milchkühen nur histologisch nachzuweisen, makroskopisch waren die Veränderungen nicht belegbar (LASCHER ET AL 2002).

HUGUCHI ET AL. (2002) beschrieben, dass die Biotinkonzentration im Blutserum von Kühen, die an Laminitis leiden, signifikant niedriger liegt als bei Tieren mit gesundem Klauenhorn. Wird mit dem Futter eine Zulage von 20 mg Biotin pro Tier und Tag verabreicht, so steigt der Biotingehalt im Blutplasma von ursprünglich 400 bis $800 \mathrm{ng} / \mathrm{l}$ auf das Zehnfache (FRIGG ET AL. 1993a, b). Auch KLÜNTER UND STEINBERG (1993) stellten eine direkt proportionale Beziehung der Biotinkonzentration im Blutplasma zur Biotinaufnahme im Dosierungsbereich zwischen 0 und $80 \mathrm{mg}$ Biotin pro Tier und Tag fest und zeigten, dass der Biotinspiegel über die gesamte Dauer der Supplementation auf dem hohen Niveau bleibt und erst nach Absetzen 
der Zufütterung wieder abfällt. Dieser Abfall der Biotinkonzentration am Ende der Supplementation zeigt, dass es im Organismus keinen Speicher für Biotin gibt.

Als Dosis für die Biotinsupplementierung zur Prophylaxe und Therapie von Klauenschädigungen werden für Kalbinnen ab einem Alter von 15 Monaten und für trockenstehende Kühe 10 - 20 mg pro Tag, für laktierende Kühe 20 mg pro Tag empfohlen (SEYMOUR 1998). Dabei bleibt jedoch zu beachten, dass die für Klauenschäden ursächlichen Mängel in den Haltungsbedingungen wie z.B. Versäumnisse bei der Klauenpflege oder unebene bzw. ständig feuchte Stallböden beseitigt werden müssen, wenn die Supplementierung Erfolg zeigen soll (KOLB ET AL. 1999).

\subsubsection{Einfluss von Biotin auf Leistungsparameter bei der Milchkuh}

GIRARD ET AL. (1998) sowie FITZGERALD ET AL. (2000) stellten in Versuchen an Milchkühen keinen direkten Einfluss von Biotinzulagen auf die Leistung der Tiere fest. Im Gegensatz dazu stehen allerdings Ergebnisse von MIDLA ET AL. (1998), BERGSTEN ET AL. (1999; 2003) SOwie MARGERISON ET AL. (2002), die bei Kühen mit 20 mg Biotinsupplementierung pro Tag und gleichbleibender Futter-TS-Aufnahme eine erhöhte Milchleistung bei gleichbleibenden Inhaltsstoffen gegenüber unsupplementierten Kontrolltieren belegten, ohne dass eine mögliche Ursache genannt wird. Zwei Thesen zum Wirkprinzip einer Biotinsupplementation wurden von ZIMMERLY UND WEISS (2001) aufgestellt, deren Überprüfung noch aussteht:

- Die Steigerung der Milchmenge bei biotinsupplementierten Kühen wird durch eine verbesserte Faserverdaulichkeit hervorgerufen, welche in Folge den Nettoenergiegehalt der gesamten Ration anhebt. Dadurch wird die Milchproduktion gesteigert.

- Die Aktivität der Propionyl-CoA-Carboxylase (s. 2.2.1) wird gesteigert. Folglich wird auch mehr Glucose über die Gluconeogenese bereitgestellt, die wiederum die Synthese von Lactose und damit die Milchmenge steigert.

MAJEE ET AL. (2003) beobachteten bei Kühen nach einer Biotinzulage von 20 mg/Tag einen Anstieg der Trockenmasse-Aufnahme um 0,7 kg gegenüber einer Kontrollgruppe, die Milchleistung lag bei den supplementierten Tieren ebenfalls über der der unsupplementierten. Die Autoren kamen zu dem Schluss, dass Biotin die Milchleistung eher direkt über Effekte auf die Futteraufnahme und/oder Nährstoffverdaulichkeit steigert als indirekt über eine verbesserte Klauengesundheit. Auch in Versuchen von BONOMI ET AL. (1996) wurde die Milchmenge durch Biotinsupplementation gesteigert, parallel aber die Menge an Milchinhaltsstoffen gesenkt. Außerdem stieg die Plasmakonzentration an Glucose, während die von Acetat sank. Letzteres lässt sich mit der schon beschriebenen Funktion von Biotin als Co-Faktor bei der Gluconeo- und Lipogenese erklären. 
Ferner konnte in Versuchen mit Biotinzulage die Zeit zwischen Kalbung und erfolgreicher neuer Belegung gegenüber einer Kontrollguppe um 15 Tage (BONOMI ET AL. 1996) gesenkt werden. Auch BERGSTEN ET AL. (2003) beobachteten im Vergleich zu einer unbehandelten Kontrollgruppe bei Kühen in der ersten Laktation, die $20 \mathrm{mg}$ Biotin pro Tag zugefüttert bekamen, eine signifikante Verkürzung der Zeit zwischen Kalbung und erneuter Konzeption sowie weniger Besamungen pro Trächtigkeit.

\subsubsection{Sonstige Funktionen}

Ein Biotinmangel wirkt sich auch auf weitere Stoffwechselvorgänge aus. Ursache hierfür sind vermutlich fehlende Substrate wie Dicarbonsäuren und Energieäquivalente, die die Proteinbiosynthese und damit die Synthese von Ribonukleinsäuren beeinträchtigen (DAKSHINAMURTI UND LITVAK 1970). FRIGG UND ROHR (1978) beobachteten sterische Veränderungen in der Leber, die zu einer Verringerung des endoplasmatischen Retikulums um 30\% führten und als morphologischer Ausdruck einer reduzierten Proteinbiosynthese angesehen wurden.

Andererseits wiesen BOECKX UND DAKSHINAMURTI (1974) bei biotinmangelversorgten Ratten nach Biotinzulagen einen verstärkten Einbau von Aminosäuren in Proteine nach.

Auch bei der Infektionsabwehr ist Biotin von Bedeutung: Ein Mangel des Vitamins hemmte bei wachsenden Ratten die Entwicklung des lymphatischen Gewebes (Thymus, Milz, Lymphknoten) und führte nach Belastung mit Antigenen zur verminderten Entwicklung von antikörperbildenden Zellen in der Milz (AXELROD UND PRUZANSKY 1955). Wie sich später herausstellte, spielt Biotin eine wichtige Rolle bei der Reifung der Lymphozyten und deren Fähigkeit, auf Stimulation zu reagieren (BAezSAldANA et AL. 1998). PetRelLI ET AL. (1981) beschrieben eine signifikante Reduktion des Gehaltes von T- und B-Lymphozyten bei Meerschweinchen nach biotinfreier Ernährung über 8 Wochen, während bei Kontrolltieren mit einer wöchentlichen subkutanen Injektion von 0,5 mg Biotin der Gehalt an neutrophilen Granlozyten im Blut zunahm.

Biotin hat ferner Effekte auf die Genexpression, denn es kann mit Histonen reagieren und kovalent an sie binden. Biotinidase scheint dabei eine wichtige Rolle zu spielen, sowohl als ein intrazelluläres Biotinbindungsprotein als auch als Katalysator für die kovalente Bindung an Histone (Hymes UND WOLF 1996). Nach WATANABE UND ENDO (1984) gibt es Hinweise, dass die Biotinylation von Histonen während der embryonalen Entwicklung bei Mäusen antiteratogen wirkt. Auch beim Menschen kann ein marginaler Biotinmangel die praenatale Entwicklung stören und zu Fruchtschädigungen führen (ZEMPLENI UND MOcK 2000), und zwar besonders dann, wenn dieser Mangel im ersten Trimester der Schwangerschaft auftritt (MOCK ET AL. 2002). Bei Sauen verschlechtert sich durch Biotinmangel die Fruchtbarkeit ins- 
gesamt. Die Anzahl geborener Ferkel ist geringer und das Absetzgewicht niedriger. Zusätzlich ist die Zwischenwurfzeit verlängert (TRIBBLE ET AL. 1983; BRYANT ET AL. 1985 a,b,c).

Weiterhin scheint Biotin die testikuläre Proteinsynthese zu stimulieren. Ein Mangel an Biotin führte bei Ratten im Vergleich zu einer optimal versorgten Kontrollgruppe zu einem erniedrigten Spiegel von Testosteron und luteinisierendem Hormon im Serum (PAULOSE ET AL. 1989). Bei männlichen Ratten wurden nach einem Biotinmangel morphologische Veränderungen in den Hoden beobachtet, die mit dem niedrigeren Hormonspiegel die Spermatogenese zusätzlich beeinträchtigten (DELOST UND TERROINE 1956).

\subsection{Aufnahme und Metabolismus von Biotin}

LAMPEN ET AL. (1942) wiesen in Versuchen nach, dass Biotin des Futters sowohl in freier als auch in proteingebundener Form vorliegen kann.

Die proteingebundene Form wird durch Proteasen und Peptidasen des Gastrointestinaltraktes in Biocytin und biotinhaltige kurzkettige Peptide gespalten und unter katalytischer Wirkung der Biotinidase in freies Biotin überführt (WOLF ET AL. 1984).

Nach SAID UND REDHA (1987) erfolgt die Aufnahme des Biotins aus dem Dünndarm sowohl durch passive Diffusion als auch über einen aktiven Transportmechanismus. Der Carrier für den aktiven Transport wird dabei durch einen elektronenneutralen $\mathrm{Na}^{+}$-Gradienten gesteuert und ist energie-, $\mathrm{pH}$ - und temperaturabhängig. Die Michaelis-Menten-Konstante $\mathrm{K}_{\mathrm{m}}$, also die Substratkonzentration, bei der die Reaktionsgeschwindigkeit, hier die Aufnahmegeschwindigkeit, halbmaximal ist, berechneten SPENCER UND BRODY (1964) auf einen Wert von ca. 60 $\mu \mathrm{mol}$ und zogen daraus den Schluss, dass bei niedrigen Biotinkonzentrationen der aktive Transport überwiegt, während bei hohen Konzentrationen der Transport überwiegend passiv abläuft.

Untersuchungen mit präparierten Epithelzellen aus dem Rattendünndarm haben gezeigt, dass es entwicklungsphysiologische und anatomisch-topographische Unterschiede in der Fähigkeit der Zellen gibt, Biotin aktiv zu absorbieren: Mit zunehmendem Alter steigt die Absorption an. Außerdem ist die Fähigkeit zur Biotinabsorption der proximalen Dünndarmabschnitte größer als die der distalen (Duodenum > Jejunum > Ileum; SAID UND REDHA 1987) Diese Ergebnisse decken sich mit denen früherer Untersuchungen, in denen das erste Drittel des Dünndarms als der Ort der maximalen Biotinabsorption erkannt wurde (MAYNARD 1979). Im Dickdarm wird Biotin nach dem gleichen Prinzip in die Zellen aufgenommen wie im Dünndarm, die Aufnahmerate ist aber deutlich geringer. Dadurch ist der Anteil des auch bei Monogastriern durch die Mikroflora im Dickdarm (bes. Laktobazillen, Streptokokken) gebildeten und absorbierten Biotins an der absorbierten Gesamtmenge verhältnismäßig klein (KOPINSKI 
ET AL. 1989). Nach Applikation einer Lösung von radioaktiv markiertem Biotin direkt in den Dickdarm quantifizierte DROCHNER (1984) die Resorption von Biotin auf weniger als 8\%.

Das monogastrische Tier hat demnach nur einen geringen Nutzen von der im Dickdarm stattfindenden mikrobiellen Synthese von Biotin, wenn die Koprophagie verhindert wird.

\subsection{Besonderheiten im Biotinmetabolismus beim Wiederkäuer}

In den 40-er Jahren des letzten Jahrhunderts ergaben sich aus Untersuchungen der Biotinkonzentrationen in Futter und Panseninhalt erste Hinweise auf eine mikrobielle Biotinsynthese im Pansen (MCELROY UND JUKES 1940; WEGNER ET AL. 1941).

LARDINOIS ET AL. (1944) beobachteten, dass Zulagen von Harnstoff zu melasse- und stärkeergänzten Heurationen gegenüber Rationen ohne Harnstoffzulage zu erhöhten Biotingehalten des Panseninhaltes führten und beschrieben ferner, dass in Rationen ohne schnell fermentierbare Kohlenhydrate oder bei einer nur geringen Mikrobendichte im Pansensaft die Synthese der Vitamine des B-Komplexes nicht maximal ausfiel.

Erstmals beschrieben AGRAWALA ET AL. (1953), dass die Versorgung mit Vitaminen des BKomplexes bei Rindern und Schafen mit voll entwickeltem Vormagensystem durch die mikrobielle Synthese im Pansen erfolgt.

Ungewissheit besteht, ob diese Eigensynthese, auf deren Größenordnung hier noch eingegangen wird, immer ausreicht, um z.B. bei der Milchkuh die besonders zu Beginn der Laktation ablaufenden biotinabhängigen Prozesse ausreichend abzudecken (WHITEHEAD 1991).

Höhere tierische Leistungen mit daraus resultierendem höheren Nährstoff- und Energieumsatz, damit auch veränderten Fütterungsbedingungen und zunehmender Vitaminausscheidung über die Milch haben die Frage nach einer leistungsgerechten Versorgung von Hochleistungstieren mit B-Vitaminen verschärft. Aufgrund des noch lückenhaften Wissens können gegenwärtig noch keine exakten Empfehlungen zur Versorgung bzw. zum Bedarf an BVitaminen für Wiederkäuer angegeben werden (FLACHOWSKY 1999).

\subsubsection{Mikrobielle Synthese von Biotin}

Die mikrobielle Synthese von Biotin verläuft ausgehend von Pimelinsäure und L-Alanin unter Mitwirkung von 7-Keto-8-Aminopelargonsäure-Synthetase, 7,8-Diaminopelargonsäure-Aminotransferase und Dethiobiotin-Synthetase über Dethiobiotin zum D-Biotin.

Die genauen Abläufe sind aus Abbildung 3 auf der folgenden Seite ersichtlich.

Über die mikrobiell gebildete Menge von Biotin finden sich in der Literatur nur wenige Angaben, die in ihren Größenordnungen deutliche Unterschiede aufweisen: 
FRIGG ET AL. (1993b) ermittelten auf der Basis von duodenalen Flussraten bei 190 kg schweren Bullenkälbern, die mit verschiedenen Rationen auf Basis von Luzerneheu, Sudangras und extrudiertem Mais gefüttert wurden, Biotinsynthesemengen von 0 bis $10 \mathrm{mg} / \mathrm{d}$ in Abhängigkeit der gefütterten Ration.

ZINN ET AL. (1987) schätzten die mikrobielle ruminale Biotinsynthese auf 0,8 mg pro kg verdauter organischer Substanz. Unter Zugrundelegung dieses Verhältnisses läge die Syntheseleistung bei einer Milchkuh, welche täglich $20 \mathrm{~kg}$ Trockenmasse mit einer Verdaulichkeit der organischen Substanz von 65\% aufnimmt, bei 10mg Biotin pro Tag. In Untersuchungen an Mastrindern beobachteten MILLER ET AL. (1986), dass die Biotinsynthese in den Vormägen, besonders im Pansen, gemessen als Differenz des mit dem Chymus am Dünndarm anflutenden und des mit dem Futter aufgenommenen Biotins, mit 0,12 bis 1,33 mg pro Tag relativ gering ausfiel.

Bemerkenswert hingegen war die Zunahme des Gehalts an Biotin im Dünndarm um 1,3 bis 4,2 mg pro Tag, die auf die bereits erwähnte Aktivität der Darmflora zurückgeführt wurde (KOPINSKI ET AL. 1989, s. 2.3). Dieses enteral gebildete Biotin, das in den Zellen der Bakterien enthalten und daher möglicherweise nicht resorbierbar war, und die geringe Absorptionsfähigkeit des Dickdarmepithles für dieses Vitamin führte dazu, dass es zu einem großen Teil mit den Fäzes abgegeben wurde. So traten im Kot bis zu $6 \mathrm{mg}$ mehr Biotin auf, als mit dem Futter aufgenommen wurde. STEINBERG ET AL. (1994) bestätigten diese Beobachtung: Sie fanden im Kot von Milchkühen bis zu 10 mg mehr Biotin als im verabreichten Futter.

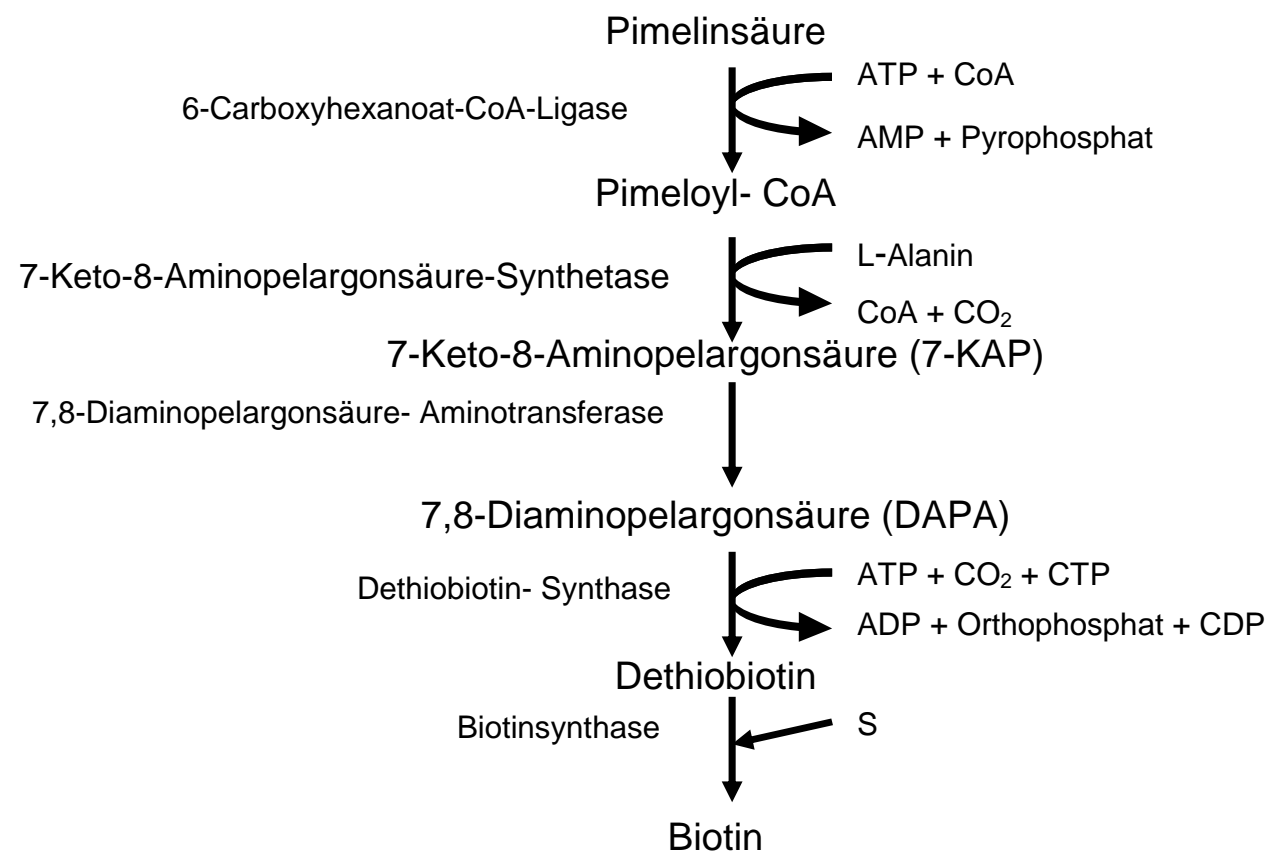

Abb. 3: $\quad$ Mikrobielle Synthese von Biotin (DAKSHINAMURTI UND CHAUHAN 1989) 
Durch eine höhere Biotinzufuhr mit dem Futter wird die Vermehrung biotinbildender Bakterien gefördert. Diesen Schluss ziehen MILLER ET AL. (1986) aus Untersuchungen, bei denen nach Verfütterung einer biotinreichen Ration mehr Biotin beim Übergang in den Dünndarm nachzuweisen war als bei einer vitaminärmeren Ration.

\subsubsection{Mikrobieller Biotinabbau}

Der mikrobielle Abbau von Biotin liefert als Endprodukte Harnstoff, $\mathrm{NH}_{4}^{+}, \mathrm{HCO}_{3}^{-}$und LCystein (CHRISTNER ET AL. 1964; BRADY ET AL. 1966).

Der Kohlenstoff, den die Mikroorganismen zum Wachstum benötigen, stammt aus dem Acetat. Dieses entsteht durch schrittweise $\beta$-oxidative Spaltung der Valeriansäure-Seitenkette. Es verbleibt dann Bisnorbiotin (bei Verkürzung um 2 Kohlenstoffatome) oder Tetranorbiotin (bei Verkürzung um 4 C-Atome) als Molekül.

IWAHARA ET AL. (1969) waren der Ansicht, dass diese $\beta$-Oxidation der Seitenkette des Biotins mit der Abspaltung beider Acetat-Einheiten Voraussetzung für die anschließende Spaltung des Harnstoff-Ringes ist, welche in zwei Schritten abläuft: Zuerst wird der Harnstoff abgespalten, der dann weiter $\mathrm{zu} \mathrm{NH}_{4}^{+}$und $\mathrm{CO}_{2}$ hydrolysiert wird.

Der Abbau des verbleibenden Thiophen-Ring-Fragmentes liefert organischen Schwefel sowie Schwefel auf verschiedenen Oxidations-/Reduktions-Niveaus (McCORMICK 1975).

Da nach Verfütterung biotinsupplementierten Futters und oraler Applikation des Vitamins beobachtet wurde, dass die Biotinflussraten am Duodenum und die Blutplasmaspiegel für Biotin anstiegen, wird der Abbau des Vitamins durch die ruminalen Mikroorganismen als nur gering eingeschätzt (ZINN ET AL. 1987; FRIGG ET AL. 1993b ).

Die Schritte des mikrobiellen Abbaus von Biotin sind in Abbildung 4 noch einmal schematisch dargestellt. 


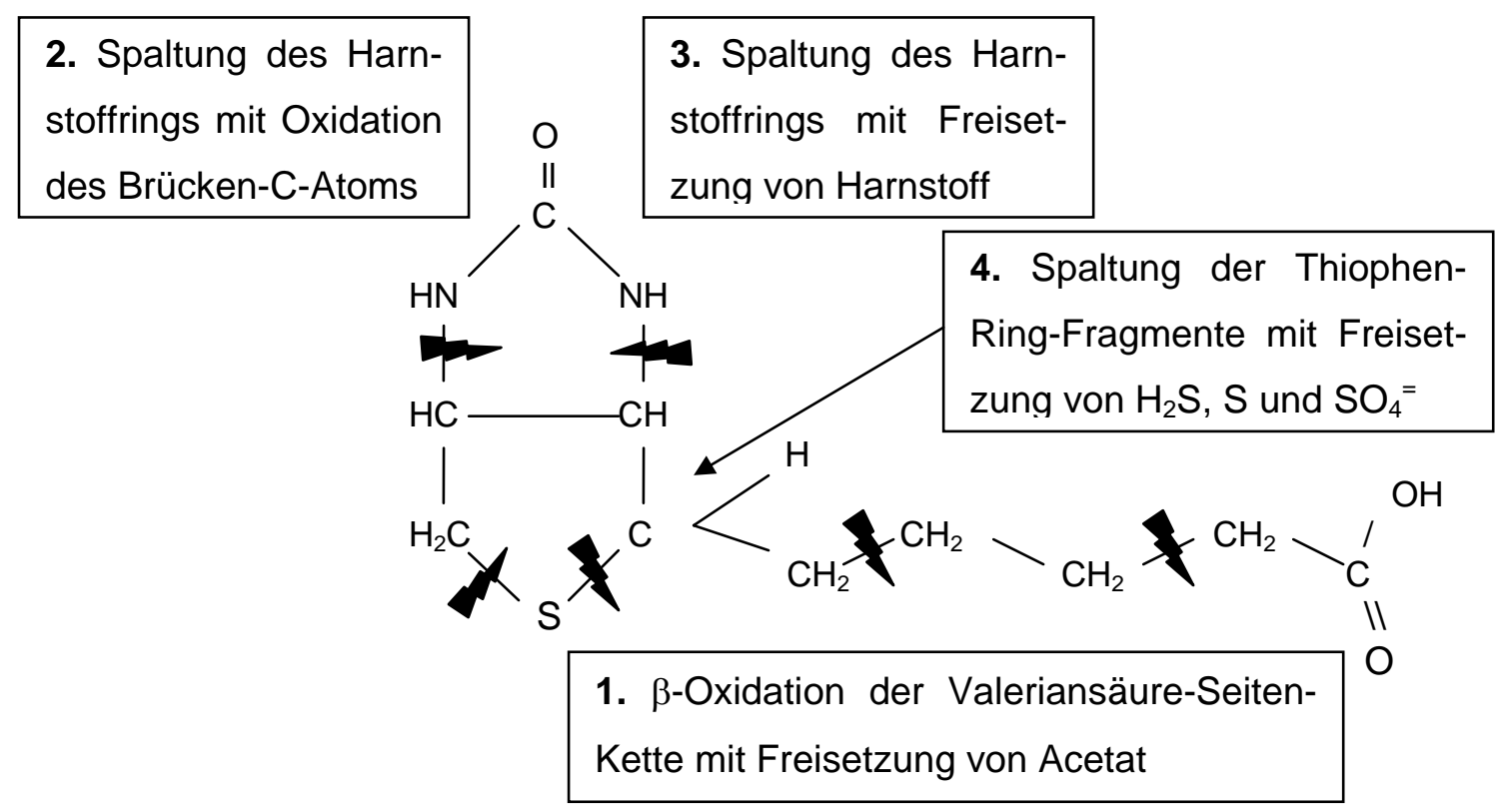

Die schwarzen Markierungen symbolisieren die Orte der Spaltungen, die Ordnungszahlen in den Beschreibungen die Reihenfolge der ablaufenden Reaktionen

Abb. 4:

Mikrobieller Abbau von D-(+)-Biotin (nach McCoRMICK 1975)

\subsubsection{Biotin in der Wiederkäuerfütterung}

HAYES ET AL. (1966) beobachteten, dass bei Bullen die Aufnahme von Biotin nach Fütterung einer Ration aus viel Heu und wenig Mais größer war als bei umgekehrten Verhältnissen. MILLER ET AL. (1986) bestätigten die höhere Biotinaufnahme bei grundfutterreicher Ernährung im Vergleich zu kraftfutterreicher durch die im Vergleich zu Konzentraten höheren Biotingehalte in Grundfuttermitteln. Die Forschergruppe führte an duodenal- und ilealkanülierten Bullen 2 verschiedene Untersuchungen durch. Im ersten Versuchsblock wurden Testdiäten auf Basis verschiedener Getreidearten eingesetzt, im zweiten Block wurde eine konzentrathaltige mit einer konzentratarmen Ration verglichen. Die Biotinaufnahme war in Abhängigkeit der verschiedenen Getreidearten und ihrer Biotingehalte (vgl. Tabelle 2) im Versuch 1 unterschiedlich. Wie bereits unter 2.4.1 beschrieben, fiel bei der Auswertung der Chymusproben besonders auf, dass die Biotinsynthese im Pansen, gemessen als Differenz des mit dem Chymus am Dünndarm anflutenden und des mit dem Futter aufgenommenen Biotins, im Gegensatz zu der Synthese der andere erfassten B-Vitamine Niacin, Thiamin und Riboflavin, gering ausfiel, hingegen aber eine bemerkenswerte Synthese des Vitamins im Dünndarm stattfand. Die Auswertung des zweiten Versuchs mit den Testdiäten verschiedenen Konzent- 
ratgehaltes zeigte, dass die niedrigkonzentrierte Ration doppelt so viel Biotin am Duodenum anfluten liess wie die hochkonzentrierte. MILLER ET AL. (1986) betrachteten diesen Effekt jedoch in erster Linie als Folge der höheren Biotinkonzentration in der konzentratärmeren Ration und kamen abschliessend zu dem Ergebnis, dass die Produktion der erfassten BVitaminen nicht vom Grundfutter/Konzentrat-Verhältnis der verfütterten Ration beeinflusst wird.

ABEL ET AL. (2001) bestätigten nach in vitro-Untersuchungen mit der Pansensimulation RUSITEC die höhere Biotinzufuhr mit Grundfuttermitteln im Vergleich zu der mit Konzentraten, jedoch kam diese Forschergruppen zu anderen Ergebnissen bezüglich des Einflusses der Ration auf die ruminale Biotinsynthese als MILLER ET AL. (1986): Der Biotinüberschuss, also die Differenz zwischen den Biotingehalten in den Fermentationsrückständen und dem Futter, war nach Applikation konzentratreicher Rationen kleiner als nach der von grundfutterreichen, was entweder auf eine geringere Synthese oder einen höheren Eigenverbrauch durch die Mikroorganismen schließen ließ.

Auch SHAVER UND BAL (2000) widersprachen der Schlussfolgerung von MILLER ET AL. (1986) und bescheinigten einen Einfluss des Grundfutter-Konzentrat-Verhältnisses der Ration auf die mikrobielle Syntheseleistung von Vitaminen des B-Komplexes.

Wenn es zutrifft, dass konzentratreiche Rationen die Biotinsynthese im Pansen einschränken oder den Verbrauch von Biotin steigern, könnten Biotinsupplementierungen des Futters bei Hochleistenden Milchkühen, die mit kraftfutterbetonten Rationen versorgt werden, leistungssteigernd wirken (s. 2.2.3), während Tiere mit geringeren Leistungen grundfutterreicher versorgt werden und entsprechende Biotinsupplementierungen weniger wirkungsvoll ausfallen würden (WEISS UND ZIMMERLY 2000). Diese These bedarf jedoch noch der Überprüfung.

SEYMOUR (1998) vermutete, dass Rationen mit höherem Kraftfutteranteil die ruminale Biotinsynthese durch niedrige $\mathrm{pH}-$ Werte beeinträchtigen. Hier besteht nach Studien aus jüngerer Zeit auch die enge Verbindung zwischen der Fütterung konzentratreicher Rationen und dem Auftreten von Klauenschäden: Eine nach Fütterung leicht fermentierbarer Kohlenhydrate auftretende Pansenazidose kann zu einem subklinischen Biotinmangel führen und so Erkrankungen wie Laminitis fördern (SMART UND CYMBALUK 1997; MIDLA ET AL. 1998; SOCHA ET AL. 2000; Hedges ET AL. 2000; VoIGT ET AL. 2000).

FRIGG ET AL. (1993a) errechneten nach Versuchen mit weiblichen und männlichen wachsenden Rindern die tägliche Biotinaufnahme mit dem Futter (Heu) auf durchschnittlich ca. 2,5 mg. Für unsupplementierte Milchviehrationen gaben WEISS UND ZIMMERLY (2000) in Abhängigkeit von den jeweils aufgenommenen Futterkomponenten 4 bis $10 \mathrm{mg}$ pro Tag an.

In Tabelle 2 sind die Biotingehalte ausgewählter, in der Wiederkäuerfütterung zum Einsatz kommender Grund- und Kraftfuttermittel aufgeführt. Es wird deutlich, dass sich höhere Ge- 
halte an Biotin z.B. in Hefen oder Extraktionsschroten von Ölfrüchten, mittlere Gehalte in Raufuttermitteln wie Heu aus Luzerne oder Gras finden, während Getreidekörner zu den biotinärmeren Futterkomponenten zählen.

Für die ausgewiesen starke Variation der Biotingehalte bei mehreren Proben des gleichen Futtermittels gibt es verschiedene Gründe:

- Pflanzliche Produkte weisen je nach Sorte, Bodenfruchtbarkeit (MCCOY ET AL. 1958) und Klima Abweichungen auf.

- Abweichungen können durch verschiedene Bearbeitungsmethoden sowie im Verlauf der Lagerung entstehen, besonders bei fetthaltigen Futtermitteln (WHITEHEAD 1991).

- Verschiedene analytische Extraktions- und Messmethoden für Biotin können ebenfalls zu unterschiedlichen Werten führen. So können z.B. durch einen mikrobiologischen Analyseansatz mit Lactobacillus Plantarum bei der Analyse des gleichen Probenmaterials Abweichungen von bis zu 20\% um den Mittelwert auftreten (ROCHE 2002). 
Tabelle 2: Literaturübersicht zu Biotingehalten in ausgewählten Futtermitteln für Wiederkäuer

\begin{tabular}{|c|c|c|c|c|}
\hline \multirow{2}{*}{ Futtermittel } & \multicolumn{2}{|c|}{ Biotingehalt ( $\mu \mathrm{g} / \mathrm{kg})$} & \multirow{2}{*}{$\begin{array}{l}\text { Anzahl } \\
\text { Proben }\end{array}$} & \multirow{2}{*}{ Quelle } \\
\hline & Mittelwert & Variationsbreite & & \\
\hline \multicolumn{5}{|l|}{ Heu aus } \\
\hline Kammgras & 407 & - & 1 & THOMAS UND WALKER 1949 \\
\hline Wiesenschwingel & 162 & - & 1 & THOMAS UND WALKER 1949 \\
\hline Rotschwingel & 238 & - & 1 & THOMAS UND WALKER 1949 \\
\hline Deutschem Weidelgras & 384 & - & 1 & THOMAS UND WALKER 1949 \\
\hline Wiesenlieschgras & 168 & - & 1 & THOMAS UND WALKER 1949 \\
\hline Wiesenrispe & 266 & - & 1 & THOMAS UND WALKER 1949 \\
\hline Rotklee & 110 & & & MCDOWELL 1989 \\
\hline Luzerne, sonnengetrocknet & $\begin{array}{c}60 \\
200\end{array}$ & - & 1 & $\begin{array}{l}\text { HOFF-JÖRGENSEN ET AL. } 1952 \\
\text { MCDOWELL } 1989\end{array}$ \\
\hline \multirow[t]{2}{*}{ Luzerne, künstl. getrocknet } & 160 & - & 1 & HOFF-JÖRGENSEN ET AL. 1952 \\
\hline & 380 & - & 1 & PALAFOX UND REID 1961 \\
\hline Wiesenheu & 311 & - & 1 & ABEL ET AL. 2001 \\
\hline Grünmehl aus Luzerne & $\begin{array}{l}543 \\
320\end{array}$ & $196-779$ & 49 & $\begin{array}{l}\text { WHITEHEAD } 1991 \\
\text { AWT } 2001\end{array}$ \\
\hline Grünmehl & $\begin{array}{l}366 \\
220\end{array}$ & $227-459$ & 3 & $\begin{array}{l}\text { WHITEHEAD } 1991 \\
\text { AWT } 2001\end{array}$ \\
\hline Maiskolben & 40 & $40-60$ & 25 & HALL ET AL. 1952 \\
\hline Körnermais & $\begin{array}{c}111 \\
80 \\
79 \\
70 \\
52 \\
\end{array}$ & $\begin{array}{l}60-150 \\
56-115 \\
12-162 \\
\end{array}$ & $\begin{array}{l}11 \\
59\end{array}$ & $\begin{array}{l}\text { SCHREINER UND DE RITTER } 1975 \\
\text { MCDOWELL } 1989 \\
\text { WHITEHEAD } 1991 \\
\text { AWT } 2001 \\
\text { ROCHE } 2002 \\
\end{array}$ \\
\hline Futterrüben & 30 & - & 1 & HOFF-JÖRGENSEN ET AL. 1952 \\
\hline \multirow{4}{*}{ Weizen } & 140 & 140 & 2 & CALHOUN ET AL. 1958 \\
\hline & 110 & $100-130$ & 3 & SCHREINER UND DE RITTER 1975 \\
\hline & 110 & & & MCDOWELL 1989 \\
\hline & $\begin{array}{l}101 \\
100\end{array}$ & $70-276$ & 116 & $\begin{array}{l}\text { WHITEHEAD } 1991 \\
\text { AWT } 2001\end{array}$ \\
\hline \multirow[t]{4}{*}{ Gerste } & $\begin{array}{l}110 \\
170\end{array}$ & & 3 & $\begin{array}{l}\text { SCHREINER UND DE RITTER } 1975 \\
\text { MCDOWELL } 1989\end{array}$ \\
\hline & 140 & $80-246$ & 166 & WHITEHEAD 1991 \\
\hline & 150 & & & AWT 2001 \\
\hline & 141 & - & 1 & ABEL ET AL. 2001 \\
\hline \multirow[t]{5}{*}{ Hafer } & 200 & $170-240$ & 2 & LAMPEN ET AL. 1942 \\
\hline & 190 & $110-270$ & 2 & SCHREINER UND DE RITTER 1975 \\
\hline & 310 & & & MCDOWELL 1989 \\
\hline & 246 & $169-317$ & 49 & WHITEHEAD 1991 \\
\hline & 210 & & & AWT 2001 \\
\hline \multirow[t]{3}{*}{ Roggen } & $\begin{array}{l}50 \\
60\end{array}$ & & 1 & $\begin{array}{l}\text { HOFF-JÖRGENSEN ET AL. } 1952 \\
\text { McDOWELL } 1989\end{array}$ \\
\hline & 84 & $51-105$ & 5 & WHITEHEAD 1991 \\
\hline & 60 & & & AWT 2001 \\
\hline \multirow[t]{3}{*}{ Sojaextraktionsschrot } & 360 & & & MCDOWELL 1989 \\
\hline & 270 & $200-387$ & 120 & WHITEHEAD 1991 \\
\hline & 330 & & & AWT 2001 \\
\hline Rapsextraktionsschrot & $\begin{array}{l}984 \\
940\end{array}$ & $647-1180$ & 20 & $\begin{array}{l}\text { WHITEHEAD } 1991 \\
\text { AWT } 2001\end{array}$ \\
\hline \multirow[t]{4}{*}{ Bierhefe, getrocknet } & $\begin{array}{l}1180 \\
1080\end{array}$ & & 4 & $\begin{array}{l}\text { SCHREINER UND DE RITTER } 1975 \\
\text { MCDOWELL } 1989\end{array}$ \\
\hline & 634 & $165-1070$ & 9 & WHITEHEAD 1991 \\
\hline & 1050 & & & AWT 2001 \\
\hline & 462 & $90-1070$ & & ROCHE 2002 \\
\hline Biertreber & 245 & $152-484$ & 8 & WHITEHEAD 1991 \\
\hline
\end{tabular}

Leere Zellen weisen auf fehlende Angaben in der entsprechenden Literatur hin. 
Neben dem Biotingehalt ist die Bioverfügbarkeit, also die biologische Verwertbarkeit des Biotins, welche große Unterschiede zwischen den verschiedenen Futtermitteln aufweist, von Bedeutung für die praktische Fütterung. Dies gilt besonders bei der Fütterung monogastrischer Tieren, aber auch für die Versorgung von Wiederkäuern. Da aber bei Monogastriern die Biotinversorgung in höherem Maße als bei Wiederkäuern über das Futter erfolgen muss, wurden für sie auch die ersten Verfahren entwickelt, um die Bioverfügbarkeit des Biotins in den Einzelfuttermitteln zu bestimmen. Als Parameter beim Geflügel dienen z.B. das Kükenwachstum, die Aktivität der Pyruvatcarboxylase im Blut und der Biotingehalt im Eidotter (BUENROSTO UND KRATZER 1984).

Erste Vermutungen über eine niedrige Bioverfügbarkeit von Biotin in Weizen kamen auf, als Futterrationen auf Weizenbasis biotinmangelbedingte Läsionen bei Küken hervorriefen (FRIGG UND BRUBACHER 1976). Auch bei anderen Getreidesorten wurde eine niedrige Bioverfügbarkeit festgestellt. Demgegenüber erwies sich das Biotin aus Mais oder Sojabohnenmehl als bis zu $100 \%$ verfügbar.

In der folgenden Tabelle 3 ist zur Veranschaulichung dieser auftretenden Unterschiede die Bioverfügbarkeit ausgesuchter Futtermittel zusammengestellt.

Tabelle 3: Bioverfügbarkeit von Biotin in ausgewählten Futtermitteln bei Broilern (ROCHE 2002)

\begin{tabular}{|c|c|}
\hline \hline Futtermittel & Bioverfügbarkeit [\%] \\
\hline \hline Gras- / Luzernegrünmehl & 65 \\
\hline Mais & 100 \\
\hline Weizen & 5 \\
\hline Gerste & 20 \\
\hline Hafer & 40 \\
\hline \hline
\end{tabular}

Im Gegensatz zu den Verhältnissen bei monogastrischen Tieren ist über die Bioverfügbarkeit des Futterbiotins für den mikrobiellen Stoffwechsel im Pansen von Wiederkäuern bisher nur wenig bekannt. In vitro führte eine Biotinbindung an Protein durch Avidinzusätze zu herabgesetztem mikrobiellem Celluloseabbau und reduzierter Propionat- und Acetatproduktion (MILLIGAN ET AL. 1967). Dies kann als Hinweis dafür angesehen werden, dass die Art der Proteinbindung von Biotin im Futter die Verfügbarkeit für den mikrobiellen Stoffwechsel beeinflusst. Dabei ist zu berücksichtigen, dass Biotin für drei wichtige cellulolytische Bakterienstämme (Bacteroides succinogenes, Ruminococcus albus, Ruminococcus flavefaciens) und für einen bedeutenden saccharolytischen Stamm (Butyrivibrio fibrisolvens) als essentielles Vitamin gilt (BALDWIN UND ALLISON 1983). Auch Bakterien des Stammes Selenomonas rumi- 
nantium benötigen Biotin für die Decarboxylierung von Succinat zu Pyruvat (SCHEIFINGER 1975). In vivo wurden die Effekte von Biotinsupplementierungen auf den Abbau von Rohfaser und besonders Cellulose noch nicht untersucht (WEISS UND ZIMMERLY 2000).

Die Bioverfügbarkeit von Biotin bei Rindern, die in der bisher einzigen Untersuchung (FRIGG ET AL. 1993b) an einjährigen, wachsenden männlichen und weiblichen nichttragenden Rindern in einem 4-monatigen Versuch über abbaukintetische Eigenschaften von Biotin im Blutserum und die AUC (area under the curve) errechnet wurde, betrug zwischen 40 und $55 \%$. Dabei wurde der niedrigere Wert bei Tieren ermittelt, die vor Versuchsbeginn mit biotinsupplementiertem Futter versorgt worden waren, der höhere Wert stammte von Tieren ohne diese Biotinsupplementierung zum Futter.

Die Frage, ob eine geringe Bioverfügbarkeit des Biotins die Aktivität der für die Gluconeogenese bzw. den Pyruvatmetabolismus wichtigen Enzyme Pyruvatcarboxylase und PropionylCoA-Carboxylase (s. 2.2.1) beeinträchtigen kann, ist gegenwärtig offen (SEYMOUR 2001).

\subsubsection{Bedeutung der Protozoen}

Die Pansenprotozoen lassen sich in die vollständig begeißelten holotrichen und die nur teilweise begeißelten entodiniomorphen (ursprünglich auch oligotrich genannt) Ciliaten unterteilen. Daneben kommen in geringem Umfang auch Flagellaten im Pansen vor. Die Gattungen Entodinium, Diplodinium, Ophryoscolex und Polyplastron der entodiniomorphen Protozoen kommen in größerer Zahl vor, wobei die Gattung Entodinium 85 bis 99\% der gesamten Protozoenmasse stellen kann (LEINMÜLLER UND MENKE 1986). Insgesamt kommen nicht mehr als 5 bis 6 Gattungen gleichzeitig bei einem Tier vor (JOUANY 1978).

FFOULKES UND LENG (1984) beschrieben, dass die Protozoen im Gegensatz zu den Pansenbakterien in der Lage sind, sich aktiv im Pansen zu halten (Sequestration). So können sie sich z. B. an Pflanzenpartikel anheften (ORPIN UND LETCHER 1978), Holotricha-Arten können ganze Stärkegranula aufnehmen, so dass sie aufgrund ihrer hohen spezifischen Dichte auf den Pansenboden absinken (VALDEZ ET AL. 1977).

Ausgehend von der symbiontischen Beziehung zwischen Protozoen und methanogenen Bakterien und der Bedeutung der letztgenannten für die eingeschlagenen Reduktionswege sowie damit verbundene Carboxylierungs- und Decarboxylierungsschritte der Pansenfermentation (s. 2.2) sind bei verminderter Methanbildung, z.B. durch Defaunierung, Auswirkungen auf den Biotinstatus des mikrobiellen ruminalen Ökosystems zu erwarten.

Über den Biotinbedarf der Protozoen selbst gibt es bislang keine Informationen (WILLIAMS UND COLEMAN, 1992), während für einzelne Protozoenarten andere essentielle B-Vitamine identifiziert worden sind, so z.B. Vitamin $\mathrm{B}_{12}$ bzw. Cobalt für Entodinium ssp. (BONHOMME ET 
AL. 1982) und Niacin (ABDOULI ET AL. 1983) für Epidinium caudatum und Ophryoscolex caudatum.

Bisher gibt es keinen Hinweis darauf, dass Protozoen über Möglichkeiten zur Biosynthese von B-Vitaminen verfügen.

\subsection{Schlussfolgerungen für die eigenen Untersuchungen}

Die aufgeführten Funktionen von Biotin im Stoffwechsel spielen besonders im Hinblick auf lipo- und gluconeogenetische Stoffwechselprozesse beim Wiederkäuer eine wichtige Rolle, diese Arbeit soll aber besonders die Zusammenhänge zwischen Pansenstoffwechsel und Umsetzungen des Vitamins beim Wiederkäuer untersuchen.

Nach den Arbeiten von MILLER ET AL. (1986) sowie ABEL ET AL. (2001) sollen die Untersuchungen weitere Erkenntnisse über den Einfluss der Rationsgestaltung auf den ruminalen Biotinumsatz liefern, wobei ein Schwerpunkt aufgrund bisher fehlender Untersuchungsergebnisse in der Bestimmung des Einflusses der Protozoen liegt. 


\section{Material und Methoden}

In der vorliegenden Arbeit stehen die Einflüsse des Grundfutter/Konzentrat-Verhältnisses der gefütterten Ration, der Art der eingesetzten Futterkohlenhydrate sowie der Protozoenpopulation (Größe und Zusammensetzung) auf die Zusammenhänge zwischen den mikrobiellen Stoffwechselvorgängen im Pansen und dem Biotinstatus bzw. dem Biotinfluss in das Duodenum im Mittelpunkt des Interesses. Ihre Erfassung erfolgte durch systematische Untersuchungen in vitro (mit Hilfe der Pansensimulationstechnik RUSITEC) und in vivo (an darmkanülierten Milchkühen).

\subsection{In vitro-Untersuchungen}

\subsubsection{Versuchsplan für RUSITEC-Untersuchungen}

Um die Einflüsse der Fütterung und der ruminalen Mikrofauna, besonders der Protozoen auf die mikrobiellen Umsetzungen von Biotin im Pansen zu untersuchen, wurde ein Versuchsplan entworfen, der die Faktoren

- Raufutter- Konzentrat- Verhältnis

- Art des Kohlenhydratträgers im Konzentratanteil der Ration

- Faunierungsstatus

berücksichtigte.

Das Schema dieses Versuches ist in Tabelle 4 dargestellt.

Tabelle 4: $\quad$ Schema des Versuchsaufbaus der in vitro-Untersuchungen

\begin{tabular}{|c|c|c|c|c|}
\hline \hline $\begin{array}{c}\text { Fermenter } \\
(\mathbf{F})\end{array}$ & $\begin{array}{c}\text { Wiesenheu (H) } \\
\text { [\% der Ration] }\end{array}$ & $\begin{array}{c}\text { Weizen (W) } \\
\text { [\% der Ration] }\end{array}$ & $\begin{array}{c}\text { Mais (M) } \\
\text { [\% der Ration] }\end{array}$ & defauniert \\
\hline \hline $\mathbf{1}$ & 100 & & & nein \\
$\mathbf{2}$ & 100 & & & ja \\
\hline $\mathbf{3}$ & 66,7 & 33,3 & & nein \\
$\mathbf{4}$ & 66,7 & 33,3 & 33,3 & ja \\
\hline $\mathbf{5}$ & 66,7 & & 33,3 & ja \\
$\mathbf{6}$ & 66,7 & & & nein \\
$\mathbf{7}$ & 33,3 & 66,7 & & ja \\
$\mathbf{8}$ & 33,3 & 66,7 & 66,7 & nein \\
\hline $\mathbf{9}$ & 33,3 & & 66,7 & ja \\
\hline $\mathbf{1 0}$ & 33,3 & & & \\
\hline \hline
\end{tabular}

Nach diesem Schema wurden 5 Versuchsdurchgänge mit einer Laufzeit von je 15 Tagen durchgeführt. Die Dauer der Adaptationszeit wurde auf 10 Tage festgesetzt, um zu gewährleisten, dass sich das System auf steady-state-Bedingungen einstellte. Die sich anschlie- 
ßenden 5 Tage dienten der Sammlung von Probenmaterial, d.h. von Substratrückständen in den Nylonbeuteln nach 48 Stunden Inkubation und von Überlaufflüssigkeit, welches jeweils als Mischprobe der Biotinanalytik und der Bestimmung der SCFA (nur im Überlauf) zugeführt wurde.

\subsubsection{Pansensimulationstechnik (RUSITEC)}

CZERKAWSKI und BECKENRIDGE (1977) entwickelten das RUSITEC-System (Rumen Simulation Technique) zur Simulation des mikrobiellen Stoffwechsels pansenstämmiger Mikroorganismen. Dieses semi-kontinuierliche, offene Langzeit- in vitro-Verfahren ermöglicht Untersuchungen auch extremer Futterrationen, ohne ein Wirtstier belasten zu müssen.

Kernstück der Apparatur sind die Fermenter, die im Wasserbad bei $39^{\circ} \mathrm{C}$ stehend ständig mit Puffer versorgt werden. Perforierte Innenbehälter dienen zur Aufnahme substratgefüllter Nylonbeutel. Die Deckel dieser Behälter sind fest mit Hubstangen verschraubt, deren andere Enden an einer waagrechten Stange befestigt sind, welche über einen Motor aufwärts und abwärts bewegt werden. Dadurch werden die Innenbehälter mit einer Geschwindigkeit von ca. 500 Hüben pro Stunde bewegt.

Mit einer Schlauchpumpe wird eine Pufferlösung nach McDougALL (1948) in den unteren Teil der Fermenter geleitet. Die Zusammensetzung dieser Lösung ist aus Tabelle 5 ersichtlich.

Tabelle 5: $\quad$ Zusammensetzung des eingesetzten Puffers

\begin{tabular}{|c|c|}
\hline Salz & $\begin{array}{c}\text { Einwaage } \\
\left(\mathrm{mg} / 1.000 \mathrm{ml} \mathrm{H}_{2} \mathrm{O}\right) \\
\end{array}$ \\
\hline $\mathrm{NaHCO}_{3}$ & 6540 \\
\hline $\mathrm{Na}_{2} \mathrm{HPO}_{4} \times 12 \mathrm{H}_{2} \mathrm{O}$ & 6200 \\
\hline $\mathrm{KCl}$ & 376 \\
\hline $\mathrm{NaCl}$ & 310 \\
\hline $\mathrm{MgCl} \times 6 \mathrm{H}_{2} \mathrm{O}$ & 84 \\
\hline$\left(\mathrm{CH}_{3} \mathrm{COO}\right)_{2} \mathrm{Co} \times 4 \mathrm{H}_{2} \mathrm{O}$ & 76 \\
\hline $\mathrm{CaCl}$ & 35 \\
\hline
\end{tabular}

Im verschraubten Deckel der Fermenter befindet sich eine Öffnung, die über einen Schlauch mit einer Überlaufflasche verbunden ist. Die an diese Flaschen angeschlossenen Gassammelbeutel ermöglichen die getrennte Sammlung flüssiger und gasförmiger Fermentationsprodukte.

Die schematische Darstellung in Abbildung 5 zeigt den Aufbau des eingesetzten Simulationssystems. 


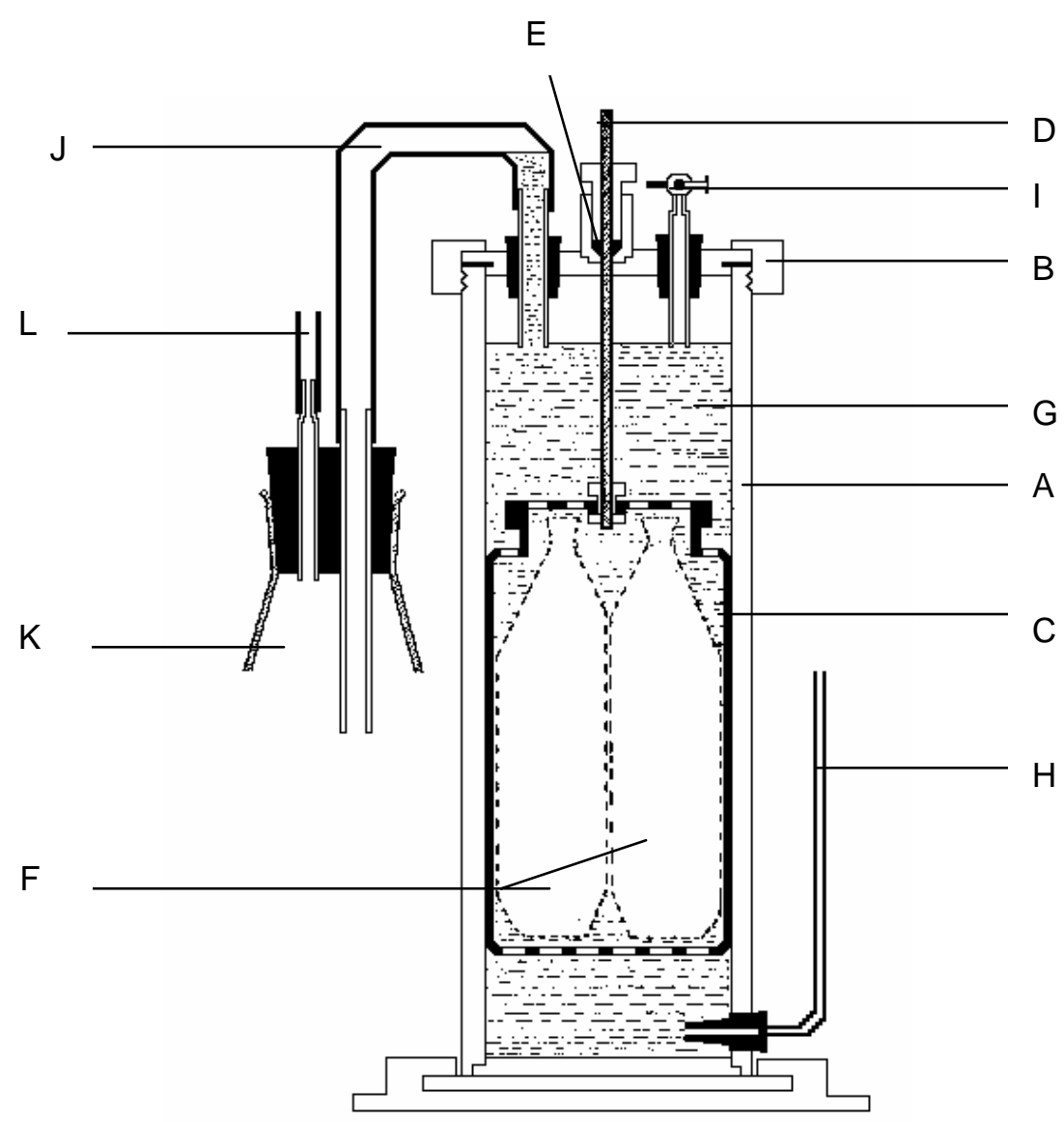

A Fermenter, Plexiglas mit Schraubdeckel und Gummidichtung

B Schraubverschluss des Fermenters mit gasdichter Gummidichtung

C perforierter Innenbehälter mit abschraubbarem Deckel

D Hubstange, mit Deckel von $C$ fest verschraubt

E geschraubte Dichtung (gasdicht)

F Nylonbeutel mit Substrat (beim Einsetzen ist 1 Beutel mit festem Panseninhalt gefüllt)

G Gemisch aus Pansenflüssigkeit und Puffer

H Pufferzulauf, verbunden mit Schlauchpumpe

F 1 - F 6 : Typ IPS-8, Fa. ISMATEC, Zürich, CH

F 7 - F 10: Typ 104 , Fa. Ole Dich, Hvidovre, DK

I Dreiwegehahn zur Probenentnahme

$\mathrm{J} \quad$ gasdichter Überlaufschlauch

K Überlaufgefäß, Volumen $800 \mathrm{ml}$

L Verbindungsschlauch zum Gassammelbeutel TECOBAG mit Zapfhahn, Volumen 5 I (Fa. Teseraux, Bürstadt,D)

Abb. 5: Schematischer Aufbau eines RUSITEC-Fermenters (CZERKAWSKI UND BECKENRIDGE 1977) 
Abbildung 6 zeigt ein RUSITEC-System mit 6 Fermentern, das bei den Versuchen zum Einsatz kam.

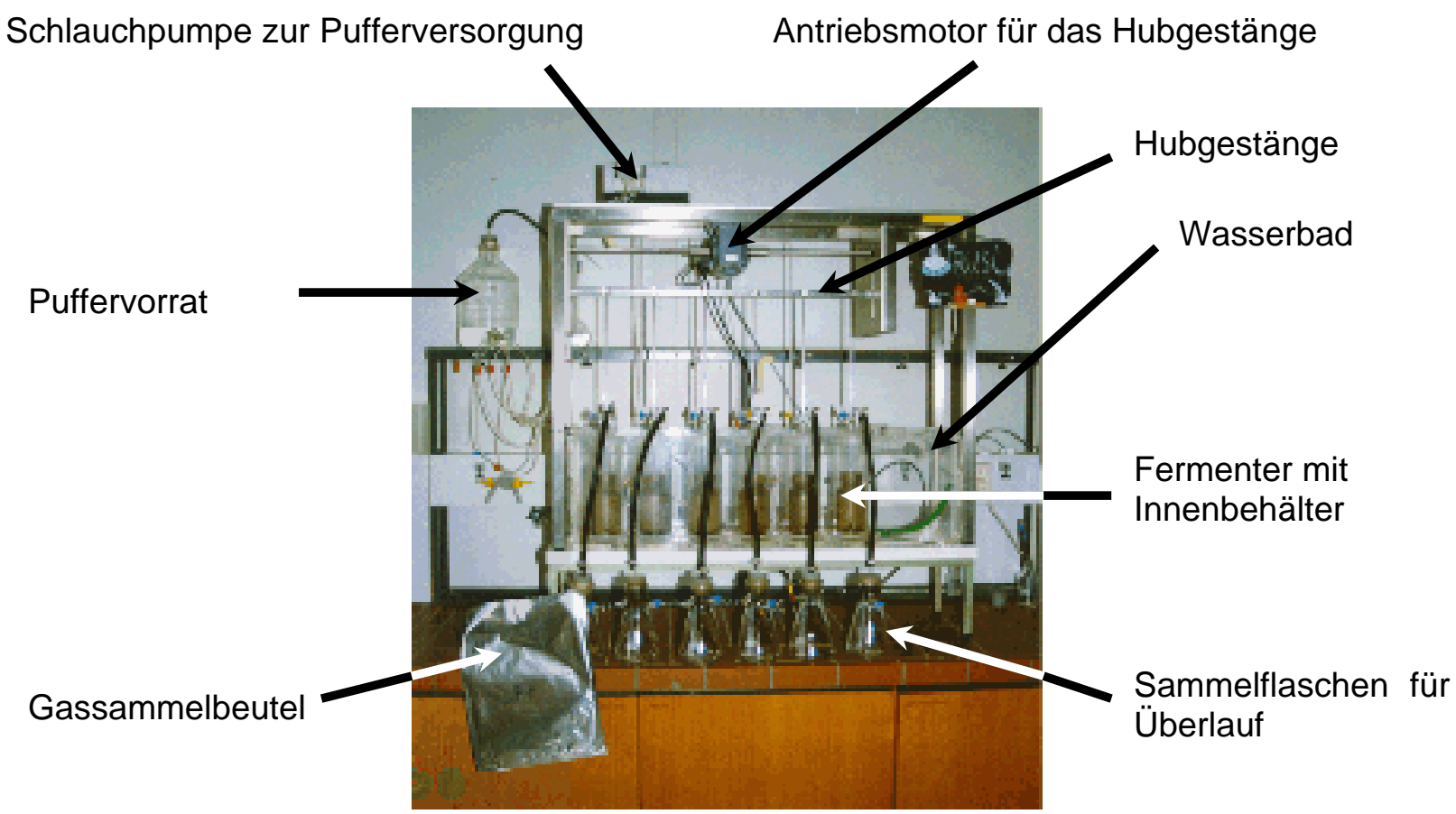

Zur besseren Übersicht sind die Fermenter nicht befüllt, der Thermostat für die Temperierung des Wasserbades wurde entnommen und die Gasbeutel bis auf den linken abgenommen.

\section{Abb. 6: RUSITEC-System}

Für die durchgeführten in vitro-Versuche stand kein Gerät zur Aufnahme von 10 laut Versuchsschema simultan zu betreibenden Fermentern zur Verfügung, so dass 2 Geräte verwendet werden mussten.

Sie glichen sich in technischer Hinsicht weitgehend, allerdings waren die Fermenter unterschiedlich groß: Während die Fermenter 1 bis 6 ein Volumen von je $1070 \mathrm{ml}$ fassten, betrug das der Fermenter 7 bis 10 je $740 \mathrm{ml}$.

Dieser Unterschied wurde bei allen notwendigen Einstellungen (Substrateinwaage, Pufferzulauf, Dosierung des Defaunierungs-Detergenzes) berücksichtigt, wie in Tabelle 6 dargestellt ist. Außerdem fand dieser Unterschied Berücksichtigung bei der Auswertung der Daten, besonders bei der Berechnung von Produktionsraten verschiedener Fermentationsprodukte aus deren Konzentrationen.

Im Rahmen der Diskussion dieser Arbeit wird noch einmal auf diese Thematik eingegangen (s. 5.1). 
Tabelle 6: Substrateinwaage, Pufferzulauf und Dosierung des DefaunierungsDetergenzes für alle 10 Fermenter

\begin{tabular}{|c|c|c|c|c|c|c|c|}
\hline \hline $\mathbf{F}$ & $\begin{array}{c}\text { Volumen } \\
\text { [ml] }\end{array}$ & $\begin{array}{c}\mathbf{H} \\
\text { [g FS] }\end{array}$ & $\begin{array}{c}\mathbf{W} \\
\text { [g FS] }\end{array}$ & $\begin{array}{c}\mathbf{M} \\
\text { [g FS] }\end{array}$ & $\begin{array}{c}\text { MinF. } \\
\text { [g FS] }\end{array}$ & $\begin{array}{c}\text { Pufferzulauf } \\
\text { [ml/d] }\end{array}$ & $\begin{array}{c}\text { Synperonic } \\
\text { NP9 [ml] }\end{array}$ \\
\hline \hline $\mathbf{1}$ & 1070 & 12,0 & & & 0,15 & 550 & 0 \\
$\mathbf{2}$ & 1070 & 12,0 & & & 0,15 & 550 & 2,68 \\
\hline $\mathbf{3}$ & 1070 & 8,0 & 4,0 & & 0,15 & 550 & 0 \\
$\mathbf{4}$ & 1070 & 8,0 & 4,0 & & 0,15 & 550 & 2,68 \\
\hline $\mathbf{5}$ & 1070 & 8,0 & & 4,0 & 0,15 & 550 & 0 \\
$\mathbf{6}$ & 1070 & 8,0 & & 4,0 & 0,15 & 550 & 2,68 \\
\hline $\mathbf{7}$ & 740 & 2,75 & 5,51 & & 0,103 & 380 & 0 \\
$\mathbf{8}$ & 740 & 2,75 & 5,51 & & 0,103 & 380 & 1,85 \\
\hline $\mathbf{9}$ & 740 & 2,75 & & 5,51 & 0,103 & 380 & 0 \\
$\mathbf{1 0}$ & 740 & 2,75 & & 5,51 & 0,103 & 380 & 1,85 \\
\hline \hline
\end{tabular}

$\mathrm{F}=$ Fermenter; $\mathrm{H}$ = Heu; $\mathrm{W}=$ Weizen, $\mathrm{M}=$ Mais; MinF. = Mineralfutter ; Mineralfutter-Zulage erfolgte in Höhe von $1,25 \%$ der Einwaage an Heu und/oder Weizen und/oder Mais

Die Mengen der eingesetzten Trockensubstanz sind im Anhang unter A1 aufgeführt.

Für die eingesetzten Substrate wurden die Gehalte an Weender Rohnährstoffen ermittelt. Sie sind Tabelle 7 zu entnehmen.

Tabelle 7: Gehalte an Trockensubstanz (\%), Weender Rohnährstoffen (\% in T) sowie den Zellwandfraktionen ADF und NDF (\% in T) der verwendeten in vitroSubstrate

\begin{tabular}{|c|c|c|c|c|c|c|c|c|}
\hline $\begin{array}{l}\text { Sub- } \\
\text { strat }\end{array}$ & $\begin{array}{c}\mathbf{T} \\
{[\%]}\end{array}$ & $\begin{array}{c}\mathrm{XA} \\
{[\% \mathrm{~T}]} \\
\end{array}$ & $\begin{array}{c}\mathrm{XL} \\
{[\% \mathrm{~T}]}\end{array}$ & $\begin{array}{c}\mathrm{XP} \\
{[\% \mathrm{~T}]}\end{array}$ & $\begin{array}{c}\text { XF } \\
{[\% \mathrm{~T}]}\end{array}$ & $\begin{array}{c}\text { ADF } \\
{[\% \mathrm{~T}]}\end{array}$ & $\begin{array}{l}\text { NDF } \\
{[\% \mathrm{~T}]}\end{array}$ & $\begin{array}{l}\mathrm{NfE} \\
{[\% \mathrm{~T}]}\end{array}$ \\
\hline $\mathbf{H}$ & 91,5 & 6,8 & 1,8 & 11,8 & 39,6 & 40,3 & 76,7 & 40,0 \\
\hline $\mathbf{W}$ & 89,7 & 1,7 & 2,1 & 13,6 & 3,2 & 2,5 & 15,7 & 79,4 \\
\hline M & 89,2 & 1,5 & 3,5 & 9,9 & 2,7 & 2,6 & 11,1 & 82,4 \\
\hline MinF. & 98,8 & 77,3 & 0 & 0 & 0 & 0 & 0 & 22,7 \\
\hline
\end{tabular}

$\mathrm{H}=$ Heu; $\mathrm{W}=$ Weizen; $\mathrm{M}=$ Mais; MinF. = Mineralfutter

Beim eingesetzten Mineralfutter handelte es sich um die Mischung Movikalin 22/3 der Fa. HEMO Mohr GmbH (Scheden, D) deren Zusammensetzung nach Angaben des Herstellers der Tabelle A3 des Anhangs zu entnehmen ist. 


\subsubsection{Spendertiere und deren Fütterung}

Als Spendertiere für den Pansensaft standen drei 11-jährige Ochsen der Rasse Jersey mit einem Gewicht von je ca. 600 kg zur Verfügung. Alle Tiere hatten eine permanente weitlumige Pansenfistel (innerer Durchmesser $10 \mathrm{~cm}$ ).

Die Fütterung erfolgte mit einer Ration aus $7 \mathrm{~kg}$ Heu und 500g Milchleistungsfutter (Typ MLF 26, Fa. HEMO Mohr GmbH, Scheden, D, mit 19,5 \% XP und 6,2 MJ NEL/kg) pro Tag. Auch diese Futtermittel wurden auf ihre Rohnährstoffgehalte analysiert.

Tabelle 8: Gehalte an Trockensubstanz (\%) und Weender Rohnährstoffen (\% in T) der bei der Fütterung der Spendertiere zum Einsatz gekommenen Futtermittel

\begin{tabular}{|c|c|c|c|c|c|c|}
\hline \hline $\begin{array}{c}\text { Futter- } \\
\text { mittel }\end{array}$ & $\begin{array}{c}\text { T } \\
{[\%]}\end{array}$ & $\begin{array}{c}\text { XA } \\
{[\% \text { T] }}\end{array}$ & $\begin{array}{c}\text { XL } \\
{[\% \text { ] }]}\end{array}$ & $\begin{array}{c}\text { XP } \\
{[\% \text { T] }}\end{array}$ & $\begin{array}{c}\text { XF } \\
{[\% \text { T] }}\end{array}$ & $\begin{array}{c}\text { NfE } \\
{[\% \text { T] }}\end{array}$ \\
\hline \hline Heu & 90,8 & 6,7 & 1,5 & 12,8 & 35,7 & 43,3 \\
\hline MLF 26 & 89,5 & 7,6 & 4,0 & 21,8 & 21,5 & 45,1 \\
\hline \hline
\end{tabular}

\subsubsection{Entnahme von Pansensaft und festem Panseninhalt}

Die Pansensaftentnahme erfolgte immer vor der Morgenfütterung 16 Stunden nach der letzten Futtervorlage.

Mit Hilfe einer $65 \mathrm{~cm}$ langen, starren Metallsonde, an deren vorderem Ende über eine Länge von $5 \mathrm{~cm}$ Löcher (Durchmesser $3 \mathrm{~mm}$ ) gebohrt waren und ein Nylonbeutel (40 $\mu \mathrm{m}$ Maschenweite) als Partikelfilter befestigt war, wurde der Pansensaft durch die geöffnete Pansenfistel aus dem ventralen Pansensack entnommen. Dazu wurde das zweite Ende des Rohres über einen Schlauch mit einer im Wasserbad bei $39^{\circ} \mathrm{C}$ stehenden Saugflasche als Auffanggefäß, in der über eine Wasserstrahlpumpe ein leichter Unterdruck erzeugt wurde, verbunden.

Zur weitgehendsten Eliminierung von Sauerstoff aus dem System wurde das Gefäß vor der Pansensaftentnahme 10 Minuten lang mit $\mathrm{N}_{2}$ begast, wodurch anaerobe Bedingungen geschaffen werden konnten.

Bei jeder Pansensaftentnahme für die Beschickung des RUSITEC-Systems dienten alle drei Ochsen zu möglichst gleichen Teilen als Spendertiere (jeweils ca. $3 \mathrm{I}$ ).

Vor der Entnahme aus der Saugflasche zur Befüllung der Fermenter wurde der Pansensaft mit Hilfe eines Magnetrührers homogenisiert, die Entnahme selbst erfolgte durch Einleitung von $\mathrm{N}_{2}$ in das geschlossene Gefäß. Der entstehende Überdruck drückte dann den Pansensaft heraus in einen Messzylinder, mit dessen Hilfe exakt gleiche Mengen Pansensaft für die Befüllung der Fermenter abgemessen wurden. 
Die Gewinnung des festen Panseninhalts erfolgte ebenfalls bei allen drei Tieren zu ungefähr gleichen Teilen. Dazu wurden aus dem ventralen Pansensack je 2 Hände voll Panseninhalt entnommen, manuell ausgepresst und dann in einen vorher mit $\mathrm{N}_{2}$ begasten Polyethylenbeutel gegeben. Anschließend wurde diese Masse im Beutel von außen durchgewalkt, um eine Durchmischung zu erreichen. Bis zur Einwaage in die Nylonbeutel wurde der feste Panseninhalt im Wasserbad warm gehalten.

\subsubsection{Defaunierung des Pansensaftes}

Die Defaunierung des Pansensaftes sollte ursprünglich durch Zusatz von Caprinsäure erfolgen (MATSUMO ET AL. 1991, DONG ET AL. 1997), aufgrund guter Ergebnisse, die sowohl am eigenen Institut erzielt wurden (DA COSTA GOMEZ 1999) als auch aus der Literatur ersichtlich sind (EADIE UND SHAND 1982, KREUZER 1986, DohmE ET AL. 1999) und der einfachen Applikation wurde dann aber das oberflächenaktive Detergens Synperonic NP9 eingesetzt, dessen effektive defaunierende Wirkung erstmalig von WRIGHT UND CURTIS (1976) beschrieben wurde. Von der sonst für industrielle Zwecke verwendete Substanz (Wirkstoff: Natrium-lauryldiethoxy-Sulfat, Fa. Deutsche ICl, Frankfurt a. M., D) wurden 2,68 bzw. 185 ml (d.h. in einer auf das Fermentervolumen bezogenen Konzentration von 0,25 \% (v/v)) am Tag der Beschickung des Simulationssystems direkt in den von Spendertieren gewonnenen Pansensaft in die entsprechenden Fermenter gegeben.

\subsubsection{Arbeitsabläufe beim Betrieb des RUSITEC -Systems}

Der in dieser Arbeit beschriebene RUSITEC-Versuch wurde nach folgendem täglichen Arbeitsplan durchgeführt:

1.Tag (nach Entnahme von festem und flüssigem Panseninhalt):

1. festen Panseninhalt in die Nylonbeutel (Maschenweite $100 \mu \mathrm{m}$ ) einwiegen (F1 - F6: 80g; F7 - F10: $55 \mathrm{~g}$ ), diese bis zum Gebrauch im Wasserbad bei $39^{\circ} \mathrm{C}$ und unter $\mathrm{N}_{2}$ Atmosphäre lagern

2. Pansensaft in den Fermenter füllen (F1 - F6: $690 \mathrm{ml}$; F7 - F10: $477 \mathrm{ml}$ )

3. je einen Beutel mit Substrat (Maschenweite $40 \mu \mathrm{m}$, Einwaage s. Tabelle 2) und festem Panseninhalt in den perforierten Innenbehälter geben, diesen verschließen

4. verschlossenen Innenbehälter in den Fermenter einführen

5. Fermenter mit vorbereitetem, auf $39^{\circ} \mathrm{C}$ erwärmten Puffer auffüllen, bei den Behältern 2,4,6,8 und 10 zusätzlich die Defaunierung durch Zugabe des entsprechenden Volumens Symperonic NP9 einleiten, anschließend verschließen 
6. im Fermenter befindliche Luftblasen durch fünfmaliges kräftiges Herabdrücken des Innenbehälters an der Hubstange entfernen; gleichzeitig wird dadurch die Durchfeuchtung des Substrats im Beutel beschleunigt

7. Fermenter in das Wasserbad stellen, Hubstange an der waagerechten, durch einen Motor bewegten Führungsstange befestigen

8. Pufferzulauf an Schlauchpumpe und Überlaufschlauch an Überlaufflasche anschließen; in letzterer befinden sich $2 \mathrm{ml}$ eine $\mathrm{HgCl}_{2}$-Lösung $\left(1,15 \mathrm{~g} \mathrm{HgCl}_{2} / 100 \mathrm{ml} \mathrm{H}_{2} 0\right)$ zur Vermeidung einer Nachfermentation außerhalb der Fermenter

9. das System durch den Dreiwegehahn im Deckel 2 Minuten lang mit $\mathrm{N}_{2}$ spülen, um die Luft aus der Überlaufflasche zu verdrängen

10. nach Beendigung der Begasung Gasssammelbeutel anschließen und öffnen

11. aus dem Fermenter am Dreiwegehahn im Deckel mit Hilfe einer $25 \mathrm{ml}$-Einwegspritze 10 ml Flüssigkeit zur Bestimmung des pH-Wertes, des Redoxpotenzials und der Protozoenzahl entnehmen

Der Arbeitsschritt 1 wurde zuerst für alle 10 Fermenter durchgeführt, so dass genügend NyIonbeutel mit festem Panseninhalt bereitlagen, danach erfolgte die Durchführung der Schritte 2 bis 11 für jeden Fermenter einzeln, bis alle benötigten Gefäße in Betrieb waren.

2.Tag:

1. aus jedem Fermenter eine Probe $(10 \mathrm{ml})$ des flüssigen Inhalts zur Bestimmung von $\mathrm{pH}$ Wert, Redoxpotenzial, $\mathrm{NH}_{3}-\mathrm{N}-$ Gehalt und Protozoenzahl entnehmen

2. im Fermenter befindliche Gasblasen durch fünfmaliges kräftiges Herabdrücken des Innenbehälters an der Hubstange entfernen

3. System über den Dreiwegehahn im Deckel mit $500 \mathrm{ml} \mathrm{N} \mathrm{N}_{2}$ spülen, um die Fermentationsgase möglichst vollständig im Gassammelbeutel aufzufangen

4. Gasbeutel verschließen und abnehmen

5. Fermenter aus dem Wasserbad nehmen und öffnen. Beutel mit festem Panseninhalt entnehmen und durch einen zweiten mit Substrat ersetzen

6. entnommenen Beutel in einem Plastikbeutel mit vorgewärmtem Puffer (F1 bis F6: 60 ml; F7 bis F10: 42 ml) gleichmäßig spülen und auswringen, Spülflüssigkeit in den Fermenter geben

7. Fermenter verschließen, das in ihm befindliche Gas durch fünfmaliges kräftiges Herabdrücken des Innenbehälters an der Hubstange entfernen

8. Überlaufgefäß leeren, Flüssigkeitsmenge bestimmen und Probe zur späteren SCFAAnalyse einfrieren 
9. -12. wie Schritte $7-10$ von Tag 1

\section{3. bis 15. Tag:}

wie am 2. Tag mit folgender Änderung bei den Schritten 5 und 6:

5. Fermenter aus dem Wasserbad nehmen und öffnen. Beutel mit Substrat, der 2 Tage zuvor eingelegt wurde, entnehmen und durch Beutel mit frischem Substrat ersetzen

6. entnommenen Beutel in einem Plastikbeutel mit vorgewärmtem Puffer (F1 bis F6: 60 ml; F7 bis F10: 42 ml) gleichmäßig spülen und auswringen, Spülflüssigkeit in den Fermenter geben; Beutelinhalt in der Adaptationszeit (Tag 1 bis 10) verwerfen, in der Sammelphase (Tag 11 bis 15) wiegen und bis zur späteren Analyse einfrieren

\subsubsection{Analytische Methoden}

\subsubsection{Bestimmung des $\mathrm{pH}$-Wertes}

Der pH-Wert der Fermenterflüssigkeit wurde täglich vor dem Wechsel der Substratbeutel in einer Probe von ca. 20 ml mit einer pH-Einstabmesskette (InLab 417 pH, Fa. Mettler Toledo, Steinbach, D) und pH-Meter (CG 811, Fa. Schott, Hofheim, D) erfasst. Die Messapparatur wurde täglich mit Standardpufferlösungen auf $\mathrm{pH} 4$ und pH 7 geeicht.

\subsubsection{Messung des Redoxpotenzials}

Nach der Erfassung des pH-Wertes wurde bei denselben Proben das Redoxpotenzial mit einer Einstabmesskette (N 6280, Fa. Schott) und einem daran angeschlossenen pH-Meter (CG 837, Fa. Schott) ermittelt. Die Eichung der Elektrode erfolgte täglich mit einer RedoxPufferlösung (Nr. 209881250, Fa. Mettler Toledo, Steinbach, D).

\subsubsection{Messung des $\mathrm{NH}_{3}-\mathrm{N}-$ Gehaltes}

Neben dem pH-Wert und dem Redoxpotenzial wurde täglich bei einer Probe der Fermenterflüssigkeit auch der Gehalt an $\mathrm{NH}_{3}-\mathrm{N}$ bestimmt. Dazu wurde eine Elektrode (NH 1100, Fa. Schott) mit angeschlossenem pH-Meter (CG 817, Fa. Schott) verwendet. Die Kalibrierung erfolgte täglich über eine Eichreihe auf Grundlage einer seriell verdünnten Ammoniumchlorid-Stammlösung (1.000 mg N / I).

Zur Überprüfung der mit der Elektrode erzielten Ergebnisse wurde in den ersten beiden Versuchsdurchgängen zusätzlich die Bestimmung des $\mathrm{NH}_{3}-\mathrm{N}$ nach CONWAY UND O'MALLEY (1942) durchgeführt. Da sich die Ergebnisse nicht unterschieden, wurde bei späteren Durch- 
gängen auf die Durchführung der aufwändigeren Labormethode verzichtet und nur mit der Elektrode gearbeitet.

\subsubsection{Messung der Fermentationsgase}

Die Bestimmung des Gasvolumens erfolgte bei den RUSITEC-Untersuchungen mit Hilfe eines 2000ml-Messzylinders aus Polyethylen, an dessen Unterseite eine Öffnung mit einem Dreiwegehahn angebracht worden war. Dieser Messzylinder wurde durch Untertauchen in einer wassergefüllten Wanne vollständig mit Wasser gefüllt und mit der Unterseite nach oben vorsichtig in diese Wanne gestellt.

Über einen Schlauch wurde der Dreiwegehahn mit dem Gassammelbeutel verbunden, anschließend konnte das Gas bei langsamem senkrechten Herausziehen des Zylinders aus dem Wasserbad durch den Saugdruck des Wassers aus dem Beutel gesaugt werden. Das Volumen des abgesaugten Gases wurde dann direkt an der Skala des Messzylinders abgelesen.

Die Berechnung der Gasvolumina in Mol erfolgte durch Umformung der allgemeinen Gasgleichung $(p * v=n * R * T) z u$

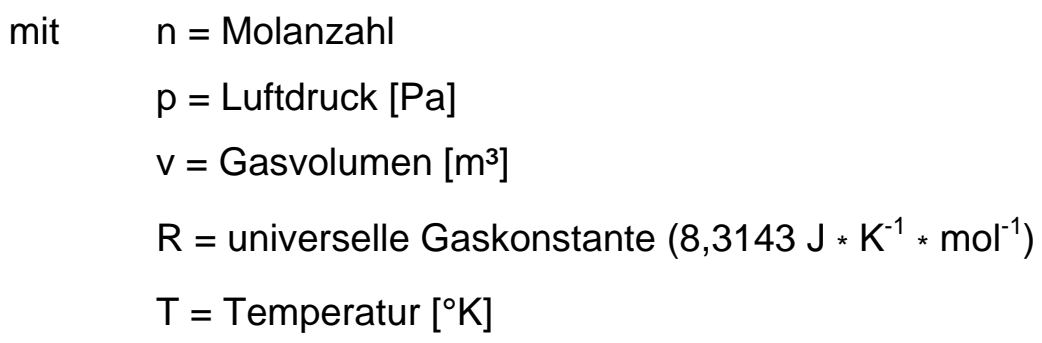

Die Gaszusammensetzung wurde gaschromatographisch unter den in Tabelle 9 dargestellten Bedingungen bestimmt. 
Tabelle 9: Chromatographiebedingungen zur Bestimmung der Zusammensetzung des Fermentationsgases.

\begin{tabular}{|l|l|}
\hline \hline Gerät & Shimadzu GC 8A (Fa. Shimadzu Europa, Duisburg, D) \\
\hline Detektor & Wärmeleitfähigkeitsdetektor (TCD) \\
\hline Injektortemperatur & $80^{\circ} \mathrm{C}$ \\
\hline Säulenofentemperatur & $40^{\circ} \mathrm{C}$, isotherm \\
\hline Detektortemperatur & $80^{\circ} \mathrm{C}$ \\
\hline Detektorstrom & $80 \mathrm{~mA}$ \\
\hline Säule & Porapak Q (80 / 100), 3 m x 4 mm \\
\hline Trägergas & Argon $40 \mathrm{ml} /$ min (Einstellung: $180 \mathrm{kPa})$ \\
\hline Probenmenge & 1 ml, manuelle Injektion \\
\hline Integrator & Schimadzu CR-1B \\
\hline \hline
\end{tabular}

Die Signale des Wärmeleitfähigkeitsdetektors wurden durch den Integrator in Form von Chromatogrammen aufgezeichnet. Die Flächen unter den Peaks wurden durch das Gerät berechnet und in der dimensionslosen Einheit Area ausgegeben.

Eine Eichung des Geräts erfolgte jeden Morgen nach Inbetriebnahme. Hierzu wurde dreimal $1 \mathrm{ml}$ eines speziell hergestellten Eichgasgemisches (Fa. Messer Griesheim, Kassel, D) der Zusammensetzung 65\% Kohlendioxid : 30\% Methan : 4\% Stickstoff : 1\% Sauerstoff verwendet. Um die Stabilität des Systems zu überprüfen, wurde die Eichung am Ende jeder Messreihe wiederholt.

\subsubsection{Bestimmung der Protozoenzahl}

Die Zählung der Protozoen erfolgte in Anlehnung an HARMEYER (1965). Dazu wurde in der Sammelphase täglich $1 \mathrm{ml}$ Probenflüssigkeit aus dem RUSITEC-System bzw. dem Pansen mit $1 \mathrm{ml}$ Protozoenlösung (Herstellung: 0,6 g Methylgrün, $8 \mathrm{~g} \mathrm{NaCl}, 100 \mathrm{ml}$ 35\%-ige Formaldehydlösung, $\mathrm{H}_{2} \mathrm{O}_{\text {dest. }}$ ad $1.000 \mathrm{ml}$ ) gemischt und bis zur Zählung in Dunkelheit gelagert. Zur Auszählung wurde dann eine Mischprobe pro Behandlung erstellt.

Die Zählung erfolgte mit einem Lichtmikroskop der Fa. Carl Zeiss Jena unter Verwendung eines Okulars mit Zählquadrat bei 160-facher Vergrößerung in einer modifizierten McMasterZählkammer (WETZEL 1951). Diese Zählkammer besitzt drei voneinander getrennte Einzelkammern mit Seitenlängen von 18 x 20 mm und einem Volumen von je 0,1568 mm³. 
Für die Bestimmung der Protozoenzahl einer Probe wurden die drei Abteilungen der Zählkammer möglichst blasenfrei mit $\mathrm{H}_{2} \mathrm{O}_{\text {dest. }}$-verdünnter Probenflüssigkeit gefüllt und mit einem Deckgläschen abgedeckt. Anschließend wurden in jeder Kammer die Protozoen auf der Fläche von 40 Zählquadraten ausgezählt, wobei darauf geachtet wurde, dass diese möglichst gleichmäßig über die gesamte Fläche der Kammer verteilt lagen. Um die Zahl der in einem Quadrat ausgezählten Protozoen auf einen Milliliter der Probenlösung aus dem Fermenter beziehen zu können, musste die Protozoenzahl mit dem Faktor 6377,55 (= 1.000 mm³ Fermenterflüssigkeit in der Protozoenlösung/ 0,1568 mm³ Kammervolumen) multipliziert werden. Die Berechnung der Protozoen pro Milliliter Probe erfolgte nach der Gleichung

$$
\text { Protozoen } / \text { ml Probe }=\frac{\text { Gesamtzahl der gezählten Protozoen x Faktor x Verdünnung }}{\text { Anzahl der gezählten Quadrate }}
$$

\subsubsection{Messung der flüchtigen Fettsäuren}

Die Messungen der kurzkettigen flüchtigen Fettsäuren (SCFA) erfolgten gaschromatographisch nach der Methode des internen Standards unter den in Tabelle 10 dargestellten Bedingungen.

Als Probenmaterial kam pro Fermenter eine Mischprobe aller Tagesproben des Überlaufs aus der Sammelperiode zum Einsatz. Bei der Zusammenstellung der Sammelprobe wurden die Schwankungen in der täglichen Überlaufmenge jedes Fermenters beachtet.

Die Berechnung der Konzentrationen der einzelnen flüchtigen Fettsäuren erfolgte durch den Vergleich der Peakflächen der Standardsubstanzen mit den Peakflächen der Probe unter Berücksichtigung des Korrekturfaktors des internen Standards. Die Zusammensetzung des Standardgemisches kann Tabelle 11 entnommen werden.

Dabei wurde zu Beginn einer jeden Messreihe in den drei Kalibrierungsanalysen des Standardgemischs nach folgender Gleichung ein Korrekturfaktor errechnet (ISTD = interner Standard):

$$
\text { Korrekturfaktor }=\frac{\text { Area ISTD } * \text { mol Substanz }}{\text { Area Subst. } * \text { mol ISTD }}
$$


Tabelle 10: Chromatographiebedingungen zur Bestimmung der SCFA

\begin{tabular}{|c|c|}
\hline Gerät & Shimadzu GC 14B (Fa. Shimadzu Europa, Duisburg, D) \\
\hline Detektor & Flammenionisationsdetektor (FID) \\
\hline Injektortemperatur & $200^{\circ} \mathrm{C}$ \\
\hline Säulenofentemperatur & $120^{\circ} \mathrm{C}$, isotherm \\
\hline Detektortemperatur & $200^{\circ} \mathrm{C}$ \\
\hline Synthetische Luft & $50 \mathrm{kPa}$ \\
\hline Säule & Gepackte Glassäule, 2,1m, Shimadzu (221-143668-21) \\
\hline Säulenfüllung & $\begin{array}{lllllllll}10 \% & \text { Carbowax } 20 & \text { MTPA } & \text { SP1000 } & \text { mit } & 1 & \% & \mathrm{H}_{3} \mathrm{PO}_{4} & \text { auf } \\
\text { Chromosorb WAW, } 80 / 100 & & & & & & & & \end{array}$ \\
\hline Trägergas & $\begin{array}{l}\text { Wasserstoff 5.0, } 100 \quad \mathrm{ml} / \mathrm{min} \text { (Einstellung: } 100 \mathrm{kPa}) \\
\text { gleichzeitig Brenngas für den FID }\end{array}$ \\
\hline Probenmenge & $1 \mu l$ \\
\hline Probenaufbereitung & $\begin{array}{l}5 \mathrm{ml} \text { zentrifugiertes Probenmaterial }+250 \mu \mathrm{l} \text { Ameisensäure (mit } \\
4 \% \text { 2-Methylvaleriansäure) }+750 \mu \mathrm{l} \text { Metaphosphorsäure }\end{array}$ \\
\hline Integrator & Merk D-2000 (Fa. Merk, Darmstadt, D) \\
\hline
\end{tabular}

Tabelle 11: Berechnungsgrundlage zur Herstellung eines SCFA-Standardgemischs

\begin{tabular}{|l|c|c|c|c|c|c|}
\hline \hline \multicolumn{1}{|c|}{ Säure } & $\begin{array}{c}\mathbf{m m o l} / \mathbf{2 5 0} \mathbf{~ m l} \\
\text { Standard }\end{array}$ & $\begin{array}{c}\boldsymbol{\mu} \mathbf{m o l} / \mathbf{~ m l} \\
\text { Standard }\end{array}$ & $\mathbf{g} / \mathbf{~ m o l}$ & $\begin{array}{c}\text { Gehalt } \\
(\mathbf{\%})\end{array}$ & $\mathbf{g} / \mathbf{~ m l}$ & $\begin{array}{c}\boldsymbol{\mu l} / \mathbf{2 5 0} \mathbf{~ m l} \\
\text { Standard }\end{array}$ \\
\hline \hline Essigsäure & 7,50 & 30,000 & 60,05 & 99,5 & 1,050 & 430 \\
Propionsäure & 5,00 & 20,000 & 74,08 & 99,0 & 0,990 & 378 \\
Iso Buttersäure & 0,25 & 1,000 & 88,11 & 98,0 & 0,947 & 24 \\
n-Buttersäure & 2,50 & 10,000 & 88,11 & 99,0 & 0,958 & 232 \\
Iso-Valeriansäure & 0,50 & 2,000 & 102,13 & 98,0 & 0,925 & 56 \\
n-Valeriansäure & 0,75 & 3,000 & 102,13 & 99,0 & 0,938 & 82 \\
2-Methylvaleriansäure & 3,89 & 15,557 & 116,16 & 98,0 & 0,922 & 500 \\
\hline \hline
\end{tabular}




\subsubsection{Bestimmung der mikrobiellen Proteinsynthese}

Nach COENEN (1988) lässt sich mit Hilfe des stabilen Isotops ${ }^{15} \mathrm{~N}$ und dem Prinzip der Dauerinfusion dieses Markers mit dem Puffer aus dem Verhältnis der ${ }^{15} \mathrm{~N}$-Anreicherung der Pufferlösung und des Ammoniumpools im Überlauf der Fermenter das synthetisierte Mikrobenprotein ableiten. Da hierfür aber steady-state-Bedingungen vorausgesetzt werden müssen, war es erforderlich, schon von Versuchsbeginn an 1,5 mg ${ }^{15} \mathrm{~N}$-Harnstoff als Marker (95\% Anreicherung, Fa. Chemotrade $\mathrm{GmbH}$, Leipzig, D) je Fermenter und Tag über den Puffer zu infundieren.

Die Probenaufbereitung erfolgte nach der Methode von BRANDT (1979). Dabei wurde der Ammonium- $\mathrm{N}$ aus $100 \mathrm{ml}$ zuvor bei $1.500 \mathrm{~g}$ für 10 Minuten zentrifugierter Überlaufflüssigkeit durch Destillation in eine Vorlage aus $0,1 \mathrm{n} \mathrm{H}_{2} \mathrm{SO}_{4}$, deren Menge für jede einzelne Probe entsprechend ihres $\mathrm{NH}_{4}{ }^{+}-\mathrm{N}-$ Gehaltes neu berechnet wurde, überführt.

Anschließend wurde die Destillatmenge mit einem rechnerischen Stickstoffgehalt von 1,5 mg auf durch Eindampdung auf $1 \mathrm{ml}$ reduziert, diese Menge zu gleichen Teilen in zwei Schiffchen aus Zinnfolie (Fa. Lüdi AG, Flawil, $\mathrm{CH}$ ) pipettiert und vollständig eingetrocknet.

Das Isotopenverhältnis $\left({ }^{15} \mathrm{~N} /{ }^{14} \mathrm{~N}\right)$ bzw. die ${ }^{15} \mathrm{~N}$-Anreicherung in der Probe wurde gegen einen Laborstandard als Blindwert im Isotopenlaboratorium für biologische und medizinische Forschung der Universität Göttingen massenspektrometrisch mit einem Elementaranalysator (MAT 251, Fa. Thermo Finnigan, San Jose, USA) nach dem Online-Verfahren bestimmt.

Die durch Mikroben synthetisierte Stickstoffmenge wurde nach COENEN (1988) berechnet:

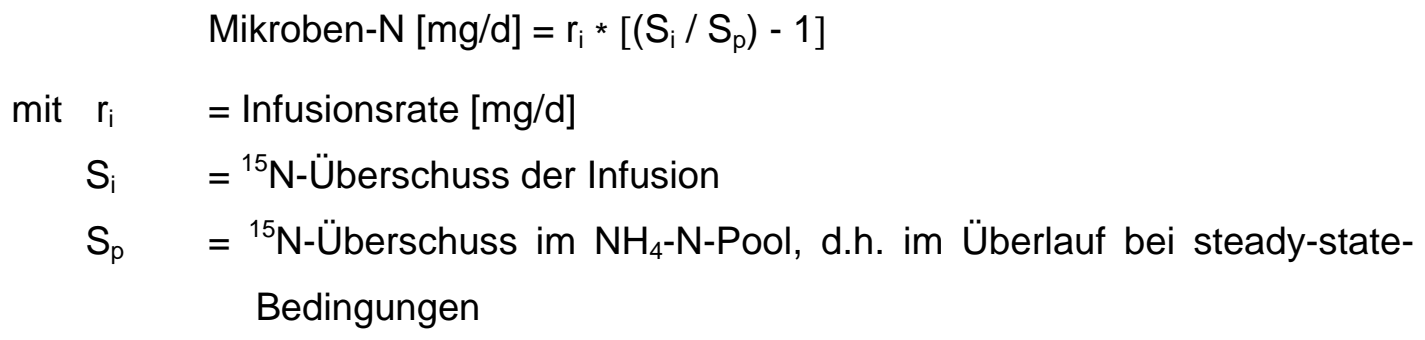

Unter Zugrundelegung eines Stickstoffgehaltes in der Trockenmasse der ruminalen Mikroorganismen von 8\% (CZERKAWSKI 1986) ließ sich die gebildete Mikrobenmasse errechnen. 


\subsection{In vivo-Untersuchungen}

\subsubsection{Versuchsaufbau}

Zur Untersuchung des Einflusses der Ration auf den ruminalen Biotinumsatz beim Rind wurden Duodenalchymusproben aus verschiedenen, am Institut für Tierernährung der Bundesforschungsanstalt für Landwirtschaft in Braunschweig durchgeführten Forschungsvorhaben (MATTHÉ 2001; LANGENHOFF 2002) verwendet. Ziel der Untersuchungen sollte es sein, die duodenalen Flussmengen von organischer Substanz, Rohprotein und Biotin nach Fütterung verschiedener Rationen zu bestimmen. Zusätzlich wurde der Anteil des Mikrobenproteins am Gesamtprotein des Chymus ermittelt.

Vergleichende Untersuchungen von ROHR ET AL (1984) haben gezeigt, dass zwischen einer Totalsammlung von Chymusmaterial und der unten beschriebenen markergestützten Stichprobenentnahme von Dünndarmsaft nur geringe Differenzen in der ermittelten Flussmenge am Duodenum bestehen.

Zur besseren Vergleichbarkeit wurden solche Rationen der in vivo-Versuche berücksichtigt, die den in den in vitro-Versuchen eingesetzten Rationen möglichst weitgehend entsprachen. Die Futterrationen der in vivo-Untersuchungen werden in Tabelle 12 näher charakterisiert.

Tabelle 12: Charakteristik der Futterrationen in den in vivo-Versuchen

\begin{tabular}{|c|c|c|}
\hline \hline Ration & Grundfuttermittel & Konzentrat \\
\hline \hline $\mathbf{1}$ & Hoch & Niedrig \\
\hline $\mathbf{2}$ & Hoch & Hoch (Weizen) \\
\hline $\mathbf{3}$ & Niedrig & Hoch (Mais) \\
\hline $\mathbf{4}$ & Niedrig & \\
\hline \hline
\end{tabular}

Aus Tabelle 13 sind die Anzahl der Tiere sowie die eingesetzten Futtermittel ersichtlich. 
Tabelle 13: Versuchstiere und Futterrationen in den in vivo-Untersuchungen (Angaben in Trockensubstanz pro Tier und Tag)

\begin{tabular}{|c|c|c|c|}
\hline \hline Ration & $\begin{array}{c}\text { Anzahl } \\
\text { Tiere }\end{array}$ & Grundfuttermittel & Kraftfutter $^{\mathbf{1}}$ \\
\hline \hline $\mathbf{1}$ & 2 & Wiesenheu; $10 \mathrm{~kg}$ & - \\
\hline $\mathbf{2}$ & 4 & Maissilage / 8,88 kg & Kraftfutter / 2,01 kg \\
\hline $\mathbf{3}$ & $\mathbf{3}$ & Grassilage / 7,48 kg & Kraftfutter „Weizen" / 10,03 kg \\
\hline $\mathbf{4}$ & $\mathbf{3}$ & Grassilage / 7,33 kg & Kraftfutter „Mais" / 10,13 kg \\
\hline \hline
\end{tabular}

${ }^{1}$ Die genaue Zusammensetzung der Kraftfutter ist Tabelle 14 zu entnehmen

Das Kraftfutter der Ration 2 entsprach einem bei hohem Maissilageeinsatz erforderlichen proteinreichen Ausgleichsfutter (s. Tab. 14). Die Rationen sollten damit einen annähernden Vergleich zwischen den Wirkungen der Grundfuttermittel auf Wiesenheu- (Ration 1) und Maissilagebasis (Ration 2) sowie mit den Rationen 3 und 4 einen Vergleich der Wirkungen von weizen- bzw. maisbetontem Kraftfutter (s. Tab. 14) in Kombination mit Grassilage als Grundfutter ermöglichen.

Tabelle 14: Zusammensetzung der Kraftfuttermischungen in den in vivo-Untersuchungen (Mischungsanteile in \%)

\begin{tabular}{|c|c|c|c|}
\hline \hline Komponente & $\begin{array}{c}\text { Kraftfutter } \\
\text { Ration 2 }\end{array}$ & $\begin{array}{c}\text { Kraftfutter Weizen } \\
\text { Ration 3 }\end{array}$ & $\begin{array}{c}\text { Kraftfutter Mais } \\
\text { Ration 4 }\end{array}$ \\
\hline \hline Weizen & 29 & 87 & - \\
\hline Mais & - & - & 87 \\
\hline Sojaextraktionsschrot & 65 & 11 & 2 \\
\hline Sojaöl & 1 & 2 & - \\
\hline Mineralfutter & 5 & - & 11 \\
\hline \hline
\end{tabular}

Zur Deckung des Vitamin- und Mineralstoffbedarfs erhielten die Tiere, die die Rationen 3 und 4 verfüttert bekamen, je $100 \mathrm{~g}$ der Mineralstoffmischung 1101 ADE Super 5 (Fa. Cimbria, jetzt Deutsche Vilomix, Hess. Oldendorf, D) und BASU-Kraft Nr. 0441 SM (Sondermischung Fa. BASU Mineralfutter $\mathrm{GmbH}$, Bad Sulza, D). Die gleichen Mineralstoffmischungen kamen auch bei Ration 2 zu gleichen Teilen zum Einsatz. Die Zusammensetzungen der Mineralstoffmischungen sind nach Herstellerangaben in Tabelle A3 im Anhang aufgeführt. 
Jede Ration wurde in einer zweigeteilten Periode von insgesamt je 49 Tagen gefüttert und umfasste 2 Sammelphasen für duodenale Chymusproben:

Teil I: 14 Tage Vorfütterung als Adaptation

5 Tage Erfassung pansenphysiologischer Parameter

2 Tage ohne Datenerfassung

5 Tage Sammlung duodenaler Chymusproben

Teil II: $\quad 9$ Tage fortgesetzte Fütterung der Versuchsration

(Wdh.) 5 Tage Erfassung pansenphysiologischer Parameter

2 Tage ohne Datenerfassung

5 Tage Sammlung duodenaler Chymusproben

2 Tage Pause bis zur nächsten Rationsvariante

Die Versuche zur Überprüfung des Einflusses von Mais oder Weizen als hauptsächliche Konzentratkomponente (Rationen 3 und 4) waren ursprünglich in Form eines vollständigen Cross Over über die Dauer von zwei Perioden geplant, in dem je zwei der 4 zur Verfügung stehenden Tiere das maisbetonte und die anderen zwei Tiere das weizenbetonte Kraftfutter vorgelegt bekommen sollten. Nach einer Periode sollte das Konzentrat gewechselt werden. Im ersten Versuchsviertel musste allerdings ein Tier aus dem Versuch genommen werden, da es die erforderliche Futtermenge nicht aufnahm. Da eine Ersatzkuh nicht zur Verfügung stand, wurde der Versuch als unvollständiger Cross Over weitergeführt.

Die folgende Tabelle 15 stellt das beschriebene Versuchsschema dar.

Tabelle 15: Versuchsschema zur Überprüfung des Einflusses von mais- und weizenbetonten Kraftfutterrationen

\begin{tabular}{|c|c|c|c|c|c|}
\hline \hline Ration & Kuh & $\begin{array}{c}\text { 1. Periode } \\
\text { I }\end{array}$ & $\begin{array}{c}\text { 1. Periode } \\
\text { II }\end{array}$ & $\begin{array}{c}\text { 2. Periode } \\
\text { I }\end{array}$ & $\begin{array}{c}\text { 2. Periode } \\
\text { II }\end{array}$ \\
\hline \hline $4 / 3$ & Ulane & $\begin{array}{c}\text { Grassilage }+ \\
\text { Mais-Konz. }\end{array}$ & $\begin{array}{c}\text { Grassilage }+ \\
\text { Mais-Konz. }\end{array}$ & $\begin{array}{c}\text { Grassilage + } \\
\text { Weizen-Konz. }\end{array}$ & $\begin{array}{c}\text { Grassilage + } \\
\text { Weizen-Konz. }\end{array}$ \\
\hline 3 / 4 & Leisa & $\begin{array}{c}\text { Grassilage }+ \\
\text { Weizen-Konz. }\end{array}$ & $\begin{array}{c}\text { Grassilage }+ \\
\text { Weizen-Konz. }\end{array}$ & $\begin{array}{c}\text { Grassilage + } \\
\text { Mais-Konz. }\end{array}$ & $\begin{array}{c}\text { Grassilage + } \\
\text { Mais-Konz. }\end{array}$ \\
\hline $4 / 3$ & Romke & $\begin{array}{c}\text { Grassilage }+ \\
\text { Mais-Konz. }\end{array}$ & $\begin{array}{c}\text { Grassilage }+ \\
\text { Mais-Konz. }\end{array}$ & $\begin{array}{c}\text { Grassilage + } \\
\text { Weizen-Konz. }\end{array}$ & $\begin{array}{c}\text { Grassilage + } \\
\text { Weizen-Konz. }\end{array}$ \\
\hline \hline
\end{tabular}

Die Versuche mit der grundfutterreichen und kraftfutterarmen Ration 2 umfassten ebenfalls zwei Perioden. In der ersten Periode kam jedoch eine Maissilage zum Einsatz, die aus einer anderen Maishybride als in der 2. Periode bereitet war. 
Die Ergebnisse der Futteranalysen sind Tabelle 16 zu entnehmen.

Tabelle 16: Gehalte an Trockensubstanz (\%), Weender Rohnährstoffen (\% in T) sowie Zellwandfraktionen ADF und NDF (\% in T) der in den in vivo-Versuchen eingesetzten Futtermittel

\begin{tabular}{|c|c|c|c|c|c|c|c|c|c|c|}
\hline \hline $\begin{array}{c}\text { Futter- } \\
\text { mittel }\end{array}$ & Ration & $\begin{array}{c}\text { Periode, } \\
\text { Teil }\end{array}$ & T & XA & XL & XP & XF & ADF & NDF & NfE \\
\hline \hline Heu & 1 & 1 & 87,7 & 7,5 & 1,3 & 13,8 & 37,3 & 36,4 & 73,3 & 40,1 \\
Heu & 1 & 2 & 88,7 & 5,7 & 1,7 & 12,8 & 29,3 & 29,7 & 60,8 & 50,5 \\
\hline Maissil. & 2 & 1 & 29,4 & 4,4 & 3,2 & 7,8 & 19,2 & 19,2 & 35,0 & 65,4 \\
Maissil. & 2 & 2 & 31,5 & 4,7 & 2,3 & 8,8 & 23,3 & 27,1 & 44,7 & 60,9 \\
Konz. & 2 & 1 & 87,2 & 9,5 & 3,3 & 34,3 & 5,0 & 5,9 & 16,5 & 47,9 \\
Konz. & 2 & 2 & 87,3 & 9,1 & 3,1 & 32,8 & 4,9 & 5,8 & 16,9 & 50,1 \\
\hline Grassil. & 3 & $1 / I$ & 35,6 & 14,1 & 2,8 & 14,1 & 30,1 & 33,0 & 53,2 & 38,9 \\
Grassil. & 3 & $1 /$ II & 37,0 & 11,2 & 2,5 & 15,9 & 32,6 & 35,2 & 57,3 & 37,8 \\
Konz. W & 3 & $1 / I$ & 86,4 & 3,3 & 3,1 & 16,9 & 3,1 & 3,6 & 16,1 & 73,6 \\
Konz. W & 3 & $1 / I$ & 87,2 & 3,2 & 3,2 & 17,9 & 3,0 & 3,4 & 14,4 & 72,7 \\
\hline Grassil. & 4 & $1 / I$ & 31,5 & 11,7 & 2,6 & 15,2 & 32,7 & 34,2 & 54,4 & 37,8 \\
Grassil. & 4 & $1 / I$ & 33,8 & 7,3 & 2,7 & 11,0 & 26,5 & 29,1 & 51,3 & 52,5 \\
Konz. M & 4 & $1 / I$ & 87,0 & 3,2 & 5,9 & 17,0 & 3,0 & 3,2 & 13,1 & 70,9 \\
Konz. M & 4 & $1 /$ II & 87,6 & 3,2 & 5,8 & 16,8 & 3,0 & 3,3 & 12,8 & 71,2 \\
\hline \hline
\end{tabular}

Maissil. = Maissilage; Konz. = Konzentrat; Grasssil. = Grassilage; Konz. W = weizenbetontes Konzentrat ; Konz. $\mathrm{M}=$ maisbetontes Konzentrat

\subsubsection{Versuchstiere und deren Haltung}

Die in vivo-Untersuchungen wurden an 6 verschiedenen Milchkühen der Rasse Deutsche Holstein durchgeführt. Alle Tiere waren mit einer weitlumigen Kunststoff-Kanüle $(10 \mathrm{~cm}$ innerer Durchmesser) im dorsalen Pansensack und einer T-Kanüle (Kunststoff, $2 \mathrm{~cm}$ innerer Durchmesser) am proximalen Duodenum (ca. $30 \mathrm{~cm}$ hinter dem Labmagenausgang) ausgestattet.

Die Tiere waren strohlos in Einzelanbindung aufgestallt. Die Liegefläche war dabei im vorderen Bereich mit einer Gummimatte ausgestattet, während das hintere Drittel des Standes mit einem Metallrost gestaltet war. Die Kühe konnten über Selbsttränken unbegrenzt Wasser aufnehmen und wurden zweimal täglich gefüttert und gemolken (5:30 Uhr und 15:30 Uhr). 


\subsubsection{Gewinnung von Duodenalchymusproben}

Während der 5-tägigen Sammelperioden wurde über die T-Kanüle Tag und Nacht alle 2 Stunden Chymus aus dem Duodenum entnommen (12 Stichproben in 24 Stunden). Dabei wurden pro Entnahmezeitpunkt und Tier 4 Kunststoffflaschen mit einem Volumen von je $100 \mathrm{ml}$ gefüllt.

Unmittelbar danach wurde bei allen 4 Proben der pH-Wert bestimmt. Die Probe mit dem jeweils niedrigsten pH-Wert (möglichst wenig Pankreas- und Gallensekrete) wurde in Tagessammelbehältern bei $-20^{\circ} \mathrm{C}$ eingefroren, die übrigen drei verworfen.

\subsubsection{Analytische Methoden}

\subsubsection{Bestimmung der duodenalen Flussmengen}

\subsection{Herstellung und Verabreichung des Chrommarkers}

Die Bestimmung der Flussmengen am Duodenum erfolgte mit $\mathrm{Cr}_{2} \mathrm{O}_{3}$ als Marker. Zur Herstellung des Markers nach ØRSKOV ET AL. (1971) wurden $30 \mathrm{~kg}$ Weizenmehl (Typ 550/68) mit 7,5 kg Chrom-(III)-oxid $\left(\mathrm{Cr}_{2} \mathrm{O}_{3}\right)$ und $375 \mathrm{~g}$ Aluminiumsulfat-Hydrat $\left(\mathrm{Al}_{2}\left(\mathrm{SO}_{4}\right)_{3} \times \mathrm{H}_{2} \mathrm{O}\right)$ gründlich vermischt und daraus unter Zugabe von Wasser ein Brei mit der Konsistenz von Hefeteig hergestellt. Diese Masse wurde bei $60^{\circ} \mathrm{C}$ getrocknet und über ein $3 \mathrm{~mm}$-Sieb vermahlen. Die für den Versuch benötigte Markermenge wurde anschließend auf Rundfilter eingewogen und mit einem Streifen Klebeband verschlossen. Die Konzentration an Chrom betrug 139,2 $\pm 0,9$ mg pro g Markersubstanz.

Die Verabreichung des Markers erfolgte nach der Methode von ROHR ET AL. (1979). Jeweils in den 10 Tagen vor Beginn der Sammelperiode wurde den Tieren zweimal täglich (um 5:45 und 17:45 Uhr) $50 \mathrm{~g}$ Marker durch die Pansenkanüle appliziert, damit sich ein Gleichgewicht zwischen Markerzufuhr und -ausscheidung einstellen konnte. Dazu wurde die Kanüle geöffnet, das Klebeband über der Kanülenöffnung vom Beutel entfernt, der nun offene Beutel eingegeben und mit Hilfe eines Kunststoffstabes vorsichtig mit dem Panseninhalt vermischt. Anhaftende Partikel am Stab wurden bei seiner Entnahme mit Wasser ebenso in den Pansen gespült wie etwaige Markeranhaftungen an der Kanüle.

Während der Chymussammeltage und am Tag davor erhielten die Tiere viermal täglich (um 5:45, 11:45, 17,45 und 23:45 Uhr) je $25 \mathrm{~g}$ Marker auf die gleiche Weise verabreicht. 


\subsection{Bestimmung der Chromkonzentration}

Für die Bestimmung der Chromkonzentration (modifiziert nach WILLIAMS ET AL. 1961) in den gefriergetrockneten Duodenalchymusproben wurde $1 \mathrm{~g}$ Material über Nacht bei $105^{\circ} \mathrm{C}$ im Trockenschrank getrocknet, nach Bestimmung der Trockensubstanz erfolgte die Veraschung der Probe bei $550^{\circ} \mathrm{C}$ im Muffelofen und die Ermittlung des Aschegehaltes. Die veraschte Probe wurde anschließend quantitativ in einen 250ml-Messkolben überführt und unter Zugabe von $3 \mathrm{ml}$ Phosphorsäure-Mangansulfatlösung und $4 \mathrm{ml}$ 4,5\%-iger Kaliumbromatlösung zum Kochen gebracht. Nach Abkühlen im Eisbad wurden zu der Lösung $25 \mathrm{ml}$ verdünnte Calciumchloridlösung gegeben und wiederum 5 Minuten gekocht. Nach Abkühlung erfolgte die Fällung des Braunsteins mit konzentrierter Natronlauge.

Nach Filtration der aufbereiteten Probe am nächsten Tag erfolgte die Ermittlung des Chromgehaltes durch ein Atomabsorptionsspektrometer (GBC 908 AA, Fa. Scientific Equipment Pty Ltd., Dandenong, AUS) mit Hilfe einer Standardkurve. Auf die gleiche Weise wurden in chromfreiem Chymus der Reagenzienblindwert (Blindprobe) sowie der Chromgehalt der eingesetzten Markersubstanz bestimmt.

\subsection{Berechnung der Trockensubstanzflüsse}

Die Berechnung der Trockensubstanzflüsse am Duodenum stellte die Grundlage für alle weiteren Nährstoffflussberechnungen dar und erfolgte wie in den folgenden Gleichungen dargestellt:

$$
\mathrm{T} \text { - Fluss am Duodenum }[\mathrm{kg} / \mathrm{d}]=\frac{\mathrm{mg} \text { Chrom pro Kuh und Tag }}{\mathrm{mg} \text { Chrom pro kg Chymus - T }} \quad / 1000
$$

mit mg Chrom pro Kuh und Tag $=$ mg Markersubst.-T $x$ mg Chrom pro g Markersubst.-T

Markersubst.-T

Chymus-T
= Trockensubstanz der Markersubstanz

$=$ Trockensubstanz des Chymus [kg]

\subsubsection{Messung der mikrobiellen Proteinsyntheseleistung}

Wie bei den in vitro-Versuchen wurde auch bei den Proben der in vivo-Versuche der Anteil des mikrobiellen Proteins am Gesamtprotein, hier als Anteil am Duodenalprotein, bestimmt. Die Messung wurde aber in diesem Falle unter Zuhilfenahme der Nah-Infrarot-Spektrometrie (NIRS) durchgeführt. Nach Einwaage in Probenzellen aus Aluminium mit schwarzem Überzug wurde jede Probe in doppelter Ausführung im Nah-Infrarot-Spektrometer (NIRSystems 
Model 6500 mit Autosampler, Fa. Foss Inc., Silver Springs, USA ) im Spektralbereich des eingesetzten PbS-Detektors (1100 bis 2500 nm) gescannt. Die Kalibration basierte dabei nicht auf ausgewählten Wellenlängen, sondern mittels Regression auf dem gesamten o.g. Spektralbereich. In 2-nm-Intervallen wurden die Daten gesammelt und als reziproker Logarithmus der reflektierten Energie (log 1/R) gespeichert und als prozentualer Anteil des Mikrobenproteins am Nicht-Ammoniak-Stickstoff (NAN) ausgegeben.

Da für die Anteile $\mathrm{NH}_{3}-\mathrm{N}$ am Gesamt- $\mathrm{N}$ im Duodenalchymus ein Wert von 5,2 $\pm 1,2 \%$ angenommen werden kann (SCHAFFT 1983; ENGLING 1988; KRASTANOVA 1993), liegt der NANAnteil bei $94,8 \%$ des Gesamt-Stickstoffs (Gesamt-N - 5,2\%).

3.2.4.2.1 Rechnerische Bestimmung der Mengen an nicht abgebautem Futterprotein (UDP) sowie fermentierter organischer Substanz (FOS)

Die Berechnung der Mengen an nicht abgebautem Futterprotein (UDP) und an fermentierter organischer Substanz (FOS) wurde wie folgt vorgenommen:

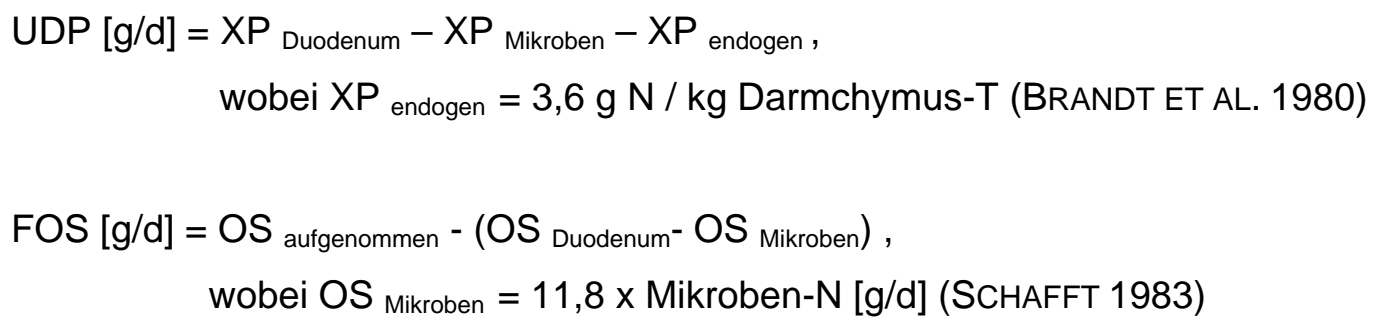

\subsection{Bestimmung des Biotingehaltes}

Die Bestimmung der Biotingehalte der eingesetzten Futtermittel und gewonnenen Proben aus den in vitro- und in vivo-Versuchen erfolgte wie bei FRIGG UND BRUBACHER (1976) beschrieben mit Hilfe eines mikrobiologischen Assays unter Verwendung von Milchsäurebakterien des Stammes Lactobacillus Plantarum ATCC 8014 nach Richtlinien der USamerikanischen Behörde FOOD AND DRUG ADMINISTRATION (FDA 1996). Die genauen Vorschriften der Biotinbestimmung aus Milch (hier angewandt für Überlaufflüssigkeit) sowie Futtermittel (hier angewandt für alle übrigen Proben) können dem Anhang unter A4 entnommen werden. 
Zur Bestimmung des Gehaltes aus dem Material nach der Inkubation in der Pansensimulation mussten die an den 5 Tagen der Sammelperiode gewonnenen Einzelproben der Überlaufflüssigkeit sowie der Inkubationsrückstände aus den Nylonbeuteln, welche zuvor gefriergetrocknet und auf $5 \mathrm{~mm}$ vermahlen wurden, zuerst zu einer Mischprobe gepoolt werden. Bei den Duodenalchymusproben aus den in vivo-Untersuchungen handelte es sich aufgrund der Methodik ihrer Gewinnung (s. 3.2.3) bereits um Mischproben, so dass dieser Schritt dort entfiel.

Anschließend wurde das Biotin durch Säurehydrolyse mit $1 \mathrm{M} \mathrm{H}_{2} \mathrm{SO}_{4}$ im Autoklaven $\left(120^{\circ} \mathrm{C}\right.$, 30 min) und anschließender enzymatischer Behandlung mit Papain (18 Stunden Inkubation bei $37^{\circ} \mathrm{C}$ ) aus der Probe gelöst, der Extrakt anschließend filtriert. Dieses Filtrat jeder Probe wurde darauf in drei verschiedenen Konzentrationen $(250 \mu \mathrm{l}, 500 \mu \mathrm{l}, 1.000 \mu \mathrm{l})$ und in je dreifacher Wiederholung mit vorgegebenen Mengen eines Nährmediums und $\mathrm{H}_{2} \mathrm{O}$ dest. in Reagenzgläser pipettiert, diese verschlossen und bei $120^{\circ} \mathrm{C}$ für 10 Minuten im Autoklav sterilisiert. Nach Abkühlung wurden die Gläser mit den Mikroorganismen beimpft und für 19 Stunden bei $37^{\circ} \mathrm{C}$ inkubiert. Das eingesetzte Nährmedium (Difco Biotin Assay Medium, Fa. Beton Dickinson, Sparks, USA) enthielt alle für die Laktobazillen notwendigen Nährstoffe mit Ausnahme von Biotin, das mit dem Probenextrakt hinzugegeben wurde. Das Zellwachstum stand demnach in Abhängigkeit vom Biotingehalt der Probe. Im Anschluss an die Inkubation, die durch eine Erhitzung der Proben für 3 Minuten auf $105^{\circ} \mathrm{C}$ beendet wurde, erfolgte die Messung der Trübung der gewachsenen Zellsuspension im Spektralphotometer (DU 65, Fa. Beckman, Fullerton, USA) bei einer Wellenlänge von $660 \mathrm{~nm}$.

Zur Quantifizierung des Biotingehaltes der Proben diente eine Eichkurve auf Basis einer seriell verdünnten Biotin-Stammlösung $(100 \mu \mathrm{g} / \mathrm{ml})$, die bei jedem Messdurchgang aus 32 Einzelwerten in 8 Konzentrationen (= 4 Wiederholungen pro Konzentration) erstellt wurde. Auf dieser Kurve waren die Extinktionswerte der Standards nach Inkubation mit LB Plantarum gegen die Biotinkonzentration aufgetragen.

Eine Überprüfung der Methodik erfolgte bei jeder Extraktion und Messung durch das Mitführen eines Standards mit definiertem Biotingehalt.

Neben den bereits erwähnten Richtlinien wurden auch die Vorgaben des Herstellers der für diese Methode benötigten mikrobiologischen Nährmedien (DIFCO 1998) berücksichtigt.

Die Ergebnisse der Bestimmung der Biotingehalte der eingesetzte Futtermittel in den in vitro- und in vivo-Untersuchungen sind in der folgenden Tabelle 17 aufgeführt. Die Werte stimmen weitgehend mit den Angaben der Literatur (s. Tab. 2) überein. 
Tabelle 17: Biotingehalte der in den in vitro- und in vivo-Untersuchungen eingesetzten Futtermittel

\begin{tabular}{|c|c|c|}
\hline Untersuchung & Futtermittel & Biotingehalt $(\mu \mathrm{g} / \mathrm{kg} \mathrm{T})$ \\
\hline \multirow{4}{*}{ in vitro } & $\mathrm{Heu}$ & 376 \\
\hline & Weizen & 135 \\
\hline & Mais & 135 \\
\hline & Mineralfutter & 190 \\
\hline \multirow{8}{*}{ in vivo } & $\begin{array}{c}\mathrm{Heu} \\
\text { (Ration1) }\end{array}$ & 255 \\
\hline & $\begin{array}{c}\text { Maissilage } \\
\text { (Ration 2, Periode1) }\end{array}$ & 182 \\
\hline & $\begin{array}{c}\text { Maissilage } \\
\text { (Ration 2, Periode 2) }\end{array}$ & 217 \\
\hline & $\begin{array}{l}\text { Kraftfutter } \\
\text { (Ration 2) }\end{array}$ & 285 \\
\hline & $\begin{array}{c}\text { Grassilage } \\
\text { (Ration 3) }\end{array}$ & 356 \\
\hline & $\begin{array}{c}\text { Grassilage } \\
\text { (Ration 4) }\end{array}$ & 450 \\
\hline & $\begin{array}{c}\text { Kraftfutter Weizen } \\
\text { (Ration 3) }\end{array}$ & 142 \\
\hline & $\begin{array}{c}\text { Kraftfutter Mais } \\
\text { (Ration 4) }\end{array}$ & 129 \\
\hline
\end{tabular}

\subsection{Mathematisch-statistische Auswertung der Versuchsergeb- nisse}

Die Untersuchungsergebnisse wurden varianzanalytisch mit der Methode der kleinsten Abweichungsquadrate (Least-Square-Means) nach HARVEY (1970) ausgewertet.

Dazu wurden in den RUSITEC-Untersuchungen für die täglich während der Sammelperioden erhobenen Parameter zunächst Mittelwerte pro Fermenter und Messperiode gebildet, so dass wie für die gepoolten Sammelproben pro Versuchsvariante 10 Beobachtungswerte (2 Fermenter x 5 Durchgänge) in die statistische Auswertung eingingen.

Diese Auswertung erfolgte für die Faktoren „Ration“ und „Faunierungsstatus“ nach folgendem Modell: 


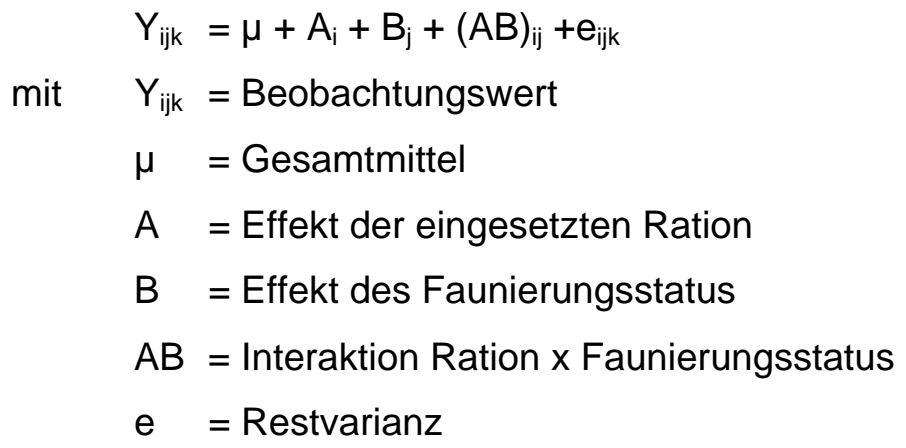

Mittels t-Test wurden zunächst geprüft, ob die verschiedenen Durchgänge einen Einfluss auf die gewonnenen Daten hatten. Das war jedoch nicht der Fall, sodass bei der Aufstellung des Modells für die varianzanalytische Auswertung auf eine Faktor „Durchgang“ verzichtet werden konnte.

Unterschiede zwischen den Gruppenmittelwerten wurden mit dem TUKEY-Test für multiple Mittelwertsvergleiche auf ihre Signifikanz überprüft $(p<0,05)$.

Um den Effekt der eingesetzten Getreideart bestimmen zu können, wurden die Werte aller Weizen- denen aller Mais-Rationen gegenübergestellt und mit dem t-Test überprüft.

In den In vivo-Versuchen wurde der Effekt einer Defaunierung nicht untersucht.

Zuerst wurden mit dem t-Test die Daten auf Tiereffekte oder auf Effekte verschieden langer Adaptationszeiten überprüft, die die Durchgänge und die Adaptationszeiten hatten jedoch keinen Einfluss. Im Gegensatz dazu bestanden Effekte der Tiere, die geblockt berücksichtigt wurden. Durch diese Prozedur wird bei der Varianzanalyse der Restfehler minimiert und die Aussagekraft der Analyse für die anderen Faktoren erhöht.

Schließlich wurde die Varianzanalyse lediglich mit dem Faktor „Ration“ nach folgendem Modell durchgeführt.

$$
Y_{i}=\mu+A_{i}+\beta_{j}+e_{i j}
$$

$$
\begin{aligned}
\text { mit } \quad Y_{i} & =\text { Beobachtungswert } \\
\mu & =\text { Gesamtmittel } \\
\text { A } & =\text { Effekt der eingesetzten Ration } \\
\beta & =\text { Effekt des Blockes „Tiere“ } \\
\text { e } & =\text { Restvarianz }
\end{aligned}
$$




\section{Untersuchungsergebnisse}

\subsection{In vitro-Versuche}

\subsubsection{Fermentationsparameter}

Die Ergebnisse der in den RUSITEC-Untersuchungen gemessenen Fermentationsparameter werden unter Berücksichtigung der Einflussfaktoren „Ration“, „Faunierungsstatus“, der Interaktion zwischen diesen beiden Faktoren und der Getreideart im Konzentrat in Tabelle 18 aufgezeigt. Die den Mittelwerten zugrunde liegenden Einzelwerte aus 5 Wiederholungen mit je 2 Fermentern pro Rationsvariante finden sich in Tabelle A6 des Tabellenanhangs.

Der Faktor „Ration" fasst jede der 5 Rationen mit den Varianten „fauniert" und „defauniert" zusammen ( $n=5 \times 2=10$ ). Der Faktor „Faunierungsstatus" stellt ohne Berücksichtigung der Rationszusammensetzung die faunierten den defaunierten Varianten gegenüber (jeweils 5 Rationen in 5 Wiederholungen: $n=5 \times 5=25$ ). Die Spalte "Interaktion Ration x Faunierungsstatus" zeigt die Signifikanz bestehender Wechselwirkungen zwischen den Faktoren „Ration" und „Faunierungsstatus". In der Spalte „Getreideart im Konzentrat" sind signifikante Unterschiede der Wirkungen der eingesetzten Getreideart ohne Berücksichtigung ihres Anteil an der Gesamtration oder des Faunierungsstatus aufgeführt (für beide Getreidearten je 2 Rationen fauniert und defauniert in 5 Wiederholungen: $\mathrm{n}=2 \times 2 \times 5=20$ )

Bei den angegebenen Produktionsraten handelt es sich teilweise um korrigierte Werte. Die Korrekturen mussten vorgenommen werden, da die eingegangenen technischen Grunddaten „Überlaufmenge" und „Fermentergröße" durch den Einsatz zwei verschiedener RUSITECGeräte nicht einheitlich waren (s. Tab. 6). Bei der Beschreibung der einzelnen Parameter im folgenden Text wird erläutert, wie die Werte ggf. korrigiert wurden.

Mit steigendem Konzentratanteil der Ration fielen die $\mathrm{pH}$-Werte signifikant ab, und zwar bei den Rationen mit Weizen signifikant stärker als bei denen mit Mais. Die Defaunation beeinflusste den $\mathrm{pH}$-Wert nicht. Es ergab sich eine signifikante Interaktion zwischen den Faktoren „Ration“ und „Faunierungsstatus“.

Die Gehalte an $\mathrm{NH}_{4}-\mathrm{N}$ in den Fermentern der Pansensimulation variierten in Abhängigkeit der zugeführten Substrate sehr stark: Während die weizenbetonte konzentratarme Ration im Vergleich zur reinen Heuration einen signifikant höheren $\mathrm{NH}_{4}-\mathrm{N}-\mathrm{Gehalt}$ verursachte, führte die maisbetonten Variante mit demselben Heu/Konzentrat-Verhältnis zu tendenziell geringeren Gehalten als mit der Heuration. Bei einer weiteren Steigerung des Konzentratanteils der Ration wurde dieser Unterschied noch deutlicher: Die konzentratreiche weizenbetonte Ration 
Tabelle 18: Einfluss der Ration und des Faunierungsstatus' auf Fermentationsparameter in der Pansensimulation RUSITEC

\begin{tabular}{|c|c|c|c|c|c|c|c|c|c|}
\hline \multirow{4}{*}{ Parameter } & \multicolumn{5}{|c|}{ Ration } & \multirow{3}{*}{$\begin{array}{l}\text { Getreideart } \\
\text { im } \\
\text { Konzentrat }\end{array}$} & \multicolumn{2}{|c|}{$\begin{array}{c}\text { Faunierungs- } \\
\text { status }\end{array}$} & \multirow{4}{*}{$\begin{array}{c}\text { Interaktion } \\
\text { Ration } \\
\mathbf{X} \\
\begin{array}{c}\text { Faunierungs- } \\
\text { status }\end{array}\end{array}$} \\
\hline & \multirow[t]{2}{*}{ 1/1 Heu } & \multicolumn{2}{|c|}{$\begin{array}{c}2 / 3 \mathrm{Heu}, \\
1 / 3 \text { Konzentrat }\end{array}$} & \multicolumn{2}{|c|}{$\begin{array}{c}1 / 3 \mathrm{Heu}, \\
2 / 3 \text { Konzentrat }\end{array}$} & & \multirow[t]{2}{*}{ fauniert } & \multirow[t]{2}{*}{ defauniert } & \\
\hline & & Weizen & Mais & Weizen & Mais & & & & \\
\hline & $n=10$ & $n=10$ & $n=10$ & $n=10$ & $n=10$ & $n=20$ & $n=25$ & $n=25$ & \\
\hline \multicolumn{10}{|l|}{ täglich $^{1}$} \\
\hline $\mathrm{pH}$ & $6,68^{d}$ & $6,57^{c}$ & $6,59^{c}$ & $6,35^{a}$ & $6,44^{b}$ & $*) * *$ & 6,54 & 6,51 & $*) * * *$ \\
\hline $\mathrm{NH}_{4}-\mathrm{N}[\mathrm{mmol} / \mathrm{l}]$ & $3,71^{b}$ & $4,85^{c}$ & $2,69^{b}$ & $5,63^{d}$ & $1,37^{a}$ & $* * *$ & $4,10^{b}$ & $3,24^{a}$ & \\
\hline Methan [mmol/d] & $6,60^{c}$ & $5,93^{b}$ & $5,43^{b}$ & $5,91^{b}$ & $5,13^{a}$ & ** & $6,56^{b}$ & $5,00^{a}$ & $* * *$ \\
\hline \multicolumn{10}{|l|}{ aus Sammelprobe ${ }^{1}$} \\
\hline Protozoen $\left({ }^{\star} 10^{3}\right) / \mathrm{ml}$ & $17,68^{a}$ & $82,20^{c}$ & $56,57^{b}$ & $26,29^{a}$ & $20,37^{a}$ & & $40,62^{b}$ & $0,02^{a}$ & \\
\hline C $2[\mathrm{mmol} / \mathrm{d}]$ & $39,57^{a}$ & $47,55^{a}$ & $43,54^{a}$ & $58,43^{b}$ & $43,12^{a}$ & * & 44,68 & 48,33 & \\
\hline C $3[\mathrm{mmol} / \mathrm{d}]$ & $17,61^{a}$ & $26,37^{a b}$ & $25,98^{a b}$ & $34,29^{b}$ & $32,62^{a b}$ & & $23,50^{a}$ & $31,18^{b}$ & \\
\hline iC $4[\mathrm{mmol} / \mathrm{d}]$ & $0,77^{\mathrm{b}}$ & $0,76^{a b}$ & $0,49^{a b}$ & $0,67^{\mathrm{ab}}$ & $0,39^{a}$ & ** & 0,65 & 0,59 & \\
\hline $\mathrm{nC} 4$ [mmol/d] & 5,81 & 7,51 & 5,76 & 7,45 & 7,36 & & $8,94^{b}$ & $4,67^{a}$ & \\
\hline iC 5 [mmol/d] & 1,44 & 2,09 & 1,77 & 2,75 & 2,08 & & $2,80^{b}$ & $1,31^{a}$ & \\
\hline $\mathrm{nC} 5[\mathrm{mmol} / \mathrm{d}]$ & $1,03^{b}$ & $1,67^{b c}$ & $0,91^{a b}$ & $2,12^{c}$ & $0,51^{a}$ & $* * *$ & 1,45 & 1,05 & \\
\hline$\Sigma$ SCFA [mmol/d] & $66,23^{a}$ & $85,95^{b}$ & $78,45^{a b}$ & $105,71^{c}$ & $86,08^{b}$ & $* *$ & 82,02 & 87,13 & \\
\hline Mikroben-N [mg/d] & $110,15^{a b}$ & $126,05^{b}$ & $101,74^{a}$ & $133,98^{c}$ & $84,97^{a}$ & $* * *$ & 108,29 & 114,20 & \\
\hline
\end{tabular}

Mittelwerte mit unterschiedlichen Indizes innerhalb einer Zeile unterscheiden sich signifikant.
1 : Art der Datenerfassung
$*): p<0,05 ; * *: p<0,01 ; * *: p>0,01$ 
hatte den höchsten $\mathrm{NH}_{4}-\mathrm{N}-$ Gehalt aller Rationen zur Folge, die maisreiche konzentratbetonte Ration den niedrigsten. Die Unterschiede zwischen den Wirkungen der Rationen mit Weizen oder Mais erwiesen sich als signifikant. Ebenfalls signifikant war die Absenkung des $\mathrm{NH}_{4}-\mathrm{N}-$ Gehaltes in den defaunierten im Vergleich zu den unbehandelten Fermentern.

Die täglich gebildete Methanmenge wurde zunächst auf eine einheitliche tägliche Substratmenge korrigiert, welche sich als Mittelwert der täglich in die Fermenter 1 bis 6 gegebenen Futtereinwaagen errechnete. Dazu wurden für jeden der 10 Fermenter aus den gemessenen Werten zunächst die in Methan auftretenden Anteile der Bruttoenergie des Futters berechnet, die dann auf einheitliche Futtermengen in allen Fermentern übertragen wurden. Den Berechnungen lagen folgende Bruttoeneriegehalte zugrunde:

$\begin{array}{lrr}\text { Heu } & 16,01 \mathrm{MJ} \text { GE / g } \\ \text { Weizen } & 16,24 \mathrm{MJ} \mathrm{GE} / \mathrm{g} \\ \text { Mais } & 16,68 \mathrm{MJ} \mathrm{GE} / \mathrm{g} \\ \text { Methan } & 55 \mathrm{~kJ} \mathrm{GE} / \mathrm{g} \quad \text { (GfE 1995; KIRCHGESSNER 1997) }\end{array}$

Die täglich gebildete Methanmenge unterschied sich zwischen den drei Futtervarianten signifikant: Sie nahm mit steigendem Konzentratanteil ab. Dabei bildeten die Rationen mit Weizen mehr Methan als die mit Mais, bei den Rationen mit hohem Konzentratanteil war dieser Unterschied signifikant. Die defaunierten Fermenter setzten signifikant weniger Methan frei als die faunierten.

Die Protozoen wurden durch die Defaunierung vollständig eliminiert bzw. mit wenigen Ausnahmen auf ein extrem niedriges Niveau gesenkt (vgl. Tab. A5). Der Einfluss der Ration auf die Protozoenkonzentration wird daher nur auf Basis der faunierten Fermenter dargestellt. Die Zahl der Protozoen, bei denen es sich zu einem überwiegenden Teil um entodiniomorphe Spezies handelte, erhöhte sich von der reinen Heuration zu den Rationen mit geringem Konzentratanteil signifikant und fiel bei den Rationen mit hohem Konzentratanteil wieder ab. Weizen führte im Vergleich zu Mais bei geringem Konzentratanteil zu einer höheren Protozoenkonzentration

Die Mengen an täglich gebildeten flüchtigen Fettsäuren wurden auf Basis einer einheitlichen täglichen Überlaufmenge, nämlich dem Mittelwert der Mengen der ersten 6 Fermenter berechnet und verhielten sich in Abhängigkeit der Rationen und des Faunierungsstatus' sehr unterschiedlich. Acetat (C2) und Propionat (C3) nahmen mit steigendem Kraftfutteranteil zu, jedoch ergaben sich nur für die Ration mit hohem Weizenanteil im Vergleich zur reinen Heuration signifikant höhere Werte. Umgekehrt verhielt es sich mit iso-Butyrat (iC4): Mit steigendem Konzentratanteil sanken die täglich freigesetzten Mengen, die zu beobachtenden Un- 
terschiede gegenüber der Heuration erwiesen sich jedoch nur bei hohem Maisanteil als signifikant unterschiedlich. Die Bildung von n-Butyrat (nC4) und iso-Valeriat (iC5) wurde von der Rationszusammensetzung nicht signifikant beeinflusst. Signifikante Unterschiede ergaben sich wiederum für die Gehalte an nC5 (n-Valeriat): Hier fielen die Werte mit steigendem Maisanteil in der Ration ab, während sie bei Weizenzulage stiegen. Dabei unterschied sich die Konzentration bei hohem Weizenanteil im Vergleich zur Heuration und zu den beiden Maisrationen signifikant. Die Getreideart wirkte sich signifikant auf die Gehalte an C2, iC4 und nC5 aus, die Defaunation bewirkte einen signifikanten Anstieg der täglich freigesetzten C3-Mengen sowie eine geringere Bildung von nC4 und iC5.

Die Gesamtmengen an täglich gebildeten SCFA stiegen mit zunehmendem Konzentratanteil der eingesetzten Ration an, mit Ausnahme der Ration mit niedrigem Maisanteil war dieser Anstieg gegenüber der reinen Heuration signifikant. Die Art des eingesetzten Getreides im Konzentrat hatte auch bei diesem Parameter einen signifikanten Einfluss, während sich der Faunierungsstatus nicht auswirkte.

Die Mengen an mikrobiell fixiertem Stickstoff (Mikroben-N) wurden für die Fermenter 7 bis 10 über die mikrobielle Effizienz der Zelltrockenmassebildung als Hilfsparameter abgeleitet.

Dazu wurde aus den Originaldaten für die SCFA-Produktion mit Hilfe einer von DEMEYER ET AL. (1995) angegebenen Gleichung ${ }^{1}$ die Mengen an fermentierter Hexose und der mittels ${ }^{15} \mathrm{~N}$-Dauerinfusion gewonnenen Ergebnisse unter Zugrundelegung von $8 \% \mathrm{~N}$ in der mikrobiellen Zelltrockenmasse (CZERKAWSKI 1986) die Mengen an gebildeter mikrobieller Zelltrockenmasse berechnet. Die Relation von gebildeter mikrobieller Trockenmasse zu fermentierter Menge an Hexose diente dann unter Berücksichtigung der korrigierten Produktionsraten an SCFA (s.o.) zur Berechnung der Mikroben-N-Mengen pro Tag für die Fermenter $7-10$, während für die Fermenter $1-6$ die unkorrigierten Originaldaten eingesetzt wurden.

Die Mengen an mikrobiell gebundenem Stickstoff stiegen mit der weizenreichen Ration signifikant über das Niveau der übrigen Rationen an. Auch mit der Ration mit niedrigem Weizenanteil wurde im Vergleich zu den maishaltigen Rationen mehr Stickstoff mikrobiell gebunden. Zwischen den Getreidearten konnte damit ein signifikanter Unterschied statistisch nachgewiesen werden. Der Faunierungsstatus wirkte sich dagegen nicht signifikant aus.

\footnotetext{
${ }^{1}$ fermentierte Hexose $[\mathrm{g} / \mathrm{d}]=162 \times[\mathrm{mmol}$ Acetat $/ 2+\mathrm{mmol}$ Propionat $/ 2+\mathrm{mmol}$ Butyrat $]$
} 


\subsubsection{Biotinumsatz in den in vitro-Untersuchungen}

Der Einfluss der Faktoren „Ration“ und „Faunierungsstatus“ auf den Biotinumsatz in der Pansensimulation ist in Tabelle 19 aufgezeigt. Die dazugehörigen Einzeldaten können der Anhangstabelle A7 entnommen werden

Die Werte des Faktors „Ration“ setzen sich wie bereits im Abschnitt 4.1.1 für die Fermentationsparameter beschrieben für jede der 5 Rationen aus je der faunierten und der defaunierten Variante zusammen ( $\mathrm{n}=5 \times 2=10)$. Für die Auswertung des Faktors „Faunierungsstatus" wurden aus den 5 Wiederholungen die Daten der 5 Rationen ohne Beachtung ihrer Zusammensetzung der Kategorie "fauniert" oder „defauniert“ zugeordnet ( $n=5 \times 5=25$ ). Da keine signifikanten Interaktionen zwischen den beiden Faktoren und keine signifikanten Effekte der eingesetzten Getreideart auftraten, beschränkt sich die Darstellung des Biotinumsatzes auf die Effekte der Ration und des Faunierungsstatus'.

Die Daten der Fermenter 7 bis 10 wurden zur Herstellung der Vergleichbarkeit mit den Daten der Fermenter 1 bis 6 volumenkorrigiert. Die jeweilige Vorgehensweise für die notwendigen Korrekturen der einzelen Parameter wird bei der Betrachtung der Ergebnisse einzeln dargestellt. Zuerst erfolgte die Berechnung der gemessenen Biotinmengen in Rückständen und Überläufen als Anteil der tatsächlich mit dem Futter zugeführten Biotinmengen, dann wurden unter Beibehaltung dieser errechneten Anteile die Korrektur der Biotinmengen in Beutelinhalt und Überlauffflüssigkeit auf eine einheitliche tägliche Substratmenge vorgenommen, wie sie auch für die mit dem Futter aufgenommene Biotinmenge beschrieben wurde.

Tabelle 19: Biotinumsatz in den in vitro-Untersuchungen $(\mu \mathrm{g} / \mathrm{d})$

\begin{tabular}{|c|c|c|c|c|c|c|c|}
\hline \multirow{4}{*}{ Probe } & \multicolumn{5}{|c|}{ Ration } & \multirow{2}{*}{\multicolumn{2}{|c|}{$\begin{array}{c}\text { Faunierungs- } \\
\text { status }\end{array}$}} \\
\hline & \multirow[b]{2}{*}{ 1/1 Heu } & \multicolumn{2}{|c|}{ 2/3 Heu, 1/3 Konz. } & \multicolumn{2}{|c|}{ 1/3 Heu, 2/3 Konz. } & & \\
\hline & & Weizen & Mais & Weizen & Mais & $\begin{array}{l}\text { fau- } \\
\text { niert }\end{array}$ & $\begin{array}{c}\text { defau- } \\
\text { niert }\end{array}$ \\
\hline & $n=10$ & $n=10$ & $n=10$ & $n=10$ & $n=10$ & $n=25$ & $n=25$ \\
\hline Futter vor Inkubation & 4,136 & 3,253 & 3,253 & 2,367 & 2,377 & 3,076 & 3,077 \\
\hline Fester Rückstand n.I. & 0,912 & 0,580 & 0,564 & 0,489 & 0,662 & 0,610 & 0,689 \\
\hline Überlauf & 1,848 & 1,922 & 1,973 & 1,643 & 1,925 & 1,714 & 1,995 \\
\hline Fester Rückstand + Überlauf n. I. & 2,760 & 2,503 & 2,537 & 2,132 & 2,587 & 2,324 & 2,684 \\
\hline Bilanz [out - in] & $-1,376^{a}$ & $-0,750^{a b}$ & $-0,716^{b}$ & $-0,234^{c}$ & $0,210^{d}$ & $-0,752$ & $-0,393$ \\
\hline
\end{tabular}

Konz. = Konzentrat; n. I. = nach Inkubation

Mittelwerte mit unterschiedlichen Indizes innerhalb einer Zeile unterscheiden sich signifikant mit $p<0,05$

Die mit dem Futter zugeführten Biotinmengen wurde für die Fermenter 7 bis 10 auf die durchschnittlich zugeführte Futtermenge der Fermenter 1 bis 6 linear korrigiert. Sie sanken 
mit steigendem Konzentratanteil der Ration signifikant. Vor der Inkubation waren die Gehalte im Futter der beiden Behandlungsarten „fauniert" und „defauniert" annähernd gleich.

Die Korrektur der Biotinmengen in den festen und flüssigen Fermentationsrückständen wurden folgendermaßen durchgeführt: Zuerst erfolgte die Berechnung der gemessenen Biotinmengen in Rückständen und Überläufen als Anteil der tatsächlich mit dem Futter zugeführten Biotinmengen, dann wurden unter Beibehaltung dieser errechneten Anteile die Korrektur der Botinmengen in Beutelinhalt und Überlauffflüssigkeit auf eine einheitliche tägliche Substratmenge vorgenommen, wie sie auch für die mit dem Futter aufgenommene Biotinmenge beschrieben wurde.

Nach der Inkubation lag der Biotingehalt in den Substratrückständen der reinen Heuration am höchsten und sank dann beim Einsatz der beiden Rationen mit geringem Kraftfutteranteil tendenziell ab, beim Einsatz der Rationen mit hohem Maisanteil stieg er wieder an, erreichte aber nicht den Wert der reinen Heuration. Die Futterrückstände wiesen nach Fermentation in defauniertem Inokulum gegenüber dem faunierten Status einen tendenziell höheren Biotingehalt auf.

Die Biotinmengen in der Überlauffflüssigkeit verhielten sich unabhängig von der zugeführten Konzentratmenge: Während bei der Ration mit niedrigem Weizenanteil der Gehalt im Vergleich zur reinen Heuration tendenziell zunahm, sank er bei der Ration mit hohem Weizenanteil unter das Niveau der reinen Heuration. Bei den Maisrationen dagegen stieg der Biotingehalt der Überlaufflüssigkeit mit steigendem Konzentratanteil. Diese Unterschiede zwischen den einzelen Rationen konnten statistisch nicht abgesichert werden. Die Gehalte in den defaunierten flüssigen Rückständen lagen nicht signifikant über denen der faunierten.

Die Summe der Biotinmengen in den festen Rückständen und Überläufen zeigten keine signifikanten Unterschiede, tendenziell führte dabei die konzentratarme Weizenration zu den niedrigsten Mengen an Biotin nach der Fermentation, die maisbetonte Konzentratration zu den höchsten. Der etwas höhere Gehalt in den Rückständen aus defaunierter Inkubation gegenüber denen aus faunierter erwies sich als nicht signifikant.

Die Biotinbilanz, berechnet als Differenz der in den Inkubationsrückständen auftretenden Biotinmengen und dem mit dem Futter zugeführten Biotin, nahm mit steigendem Konzentratanteil der Ration zu, die Unterschiede gegenüber der reinen Heuration erwiesen sich mit Ausnahme der grundfutterreichen Ration mit Weizenanteil als signifikant. Das maisreiche Substrat steigerte die Biotinbilanz gegenüber der maisärmeren Fütterungsvariante besonders stark, so dass sich auch ein signifikanter Unterschied zur weizenreichen Versorgung ergab. Die Defaunation hob die Bilanz ebenfalls etwas an, jedoch war der Unterschied zu den faunierten Ansätzen nicht signifikant. 


\subsection{In vivo-Untersuchungen}

Die Ergebnisse der in den in vivo-Untersuchungen erfassten Parameter werden unter Berücksichtigung des Faktors „Ration“ als Mittelwerte in Tabelle 21 dargestellt. Die diesen angegebenen Mittelwerten zugrunde liegenden Einzelwerte sind in der Anhangstabelle A8 aufgeführt. Die Ergebnisse der Erfassung der pansenphysiologischen Parameter werden in dieser Arbeit nicht angegeben, da sie in den Arbeiten von MATTHÉ (2001) und LANGENHOFF (2002) bereits veröffentlicht und diskutiert wurden.

Tabelle 20: Einfluss der Rationen auf duodenale Flussmengen an Trockensubstanz, Mikroben-N, fermentierter organischer Substanz, unabgebautem Futterprotein und Biotin in den in vivo-Versuchen

\begin{tabular}{|c|c|c|c|c|}
\hline \multirow{4}{*}{ Probe } & \multicolumn{4}{|c|}{ Ration } \\
\hline & \multirow{2}{*}{$100 \% \mathrm{Heu}$} & \multirow{2}{*}{$\begin{array}{c}\text { Maissilage + } \\
\text { Konzentrat }\end{array}$} & \multicolumn{2}{|c|}{$49 \%$ Grassilage, 51\% Konz. } \\
\hline & & & Weizen & Mais \\
\hline & $n=4$ & $n=8$ & $n=6$ & $n=6$ \\
\hline \multicolumn{5}{|l|}{ Futter-Aufnahme } \\
\hline $\mathrm{T}[\mathrm{kg} / \mathrm{d}]$ & $8,92^{a}$ & $10,89^{b}$ & $17,37^{\mathrm{c}}$ & $17,62^{\mathrm{c}}$ \\
\hline OS [kg/d] & $8,33^{a}$ & $10,28^{b}$ & $16,12^{c}$ & $16,29^{c}$ \\
\hline$X P[g / d]$ & $1186^{\mathrm{a}}$ & $1408^{b}$ & $2817^{c}$ & $2789^{c}$ \\
\hline Biotin [ mg/d] & $2,55^{a}$ & $2,35^{a}$ & $4,48^{b}$ & $4,26^{b}$ \\
\hline Biotin $[\mu \mathrm{g} / \mathrm{kg} \mathrm{T}]$ & $286^{c}$ & $217^{a}$ & $258^{b}$ & $242^{a b}$ \\
\hline \multicolumn{5}{|l|}{$\begin{array}{l}\text { Flussmengen bzw. Gehalte am } \\
\text { Duodenum }\end{array}$} \\
\hline T Duodenum, $[\mathrm{kg} / \mathrm{d}]$ & $4,93^{a}$ & $5,63^{a}$ & $9,89^{b}$ & $11,04^{c}$ \\
\hline T Duodenum [in \% der T-Aufnahme] & 55,3 & 51,7 & 56,9 & 62,6 \\
\hline $\mathrm{FOS}^{1}[\mathrm{~kg} / \mathrm{d}]$ & $5,94^{\mathrm{a}}$ & $7,83^{b}$ & $13,13^{d}$ & $11,59^{\mathrm{c}}$ \\
\hline XP [ $\mu \mathrm{g} / \mathrm{d}$ am Duodenum] & $1200^{a}$ & $1463^{b}$ & $3262^{c}$ & $3172^{c}$ \\
\hline Mikroben-N [g/d] & $120,0^{a}$ & $174,7^{b}$ & $395,1^{c}$ & $356,1^{c}$ \\
\hline Mikroben-N [g/kg OS-Aufn.] & $14,4^{a}$ & $17,0^{a}$ & $24,5^{b}$ & $21,9^{b}$ \\
\hline $\operatorname{UDP}^{2}[\mathrm{~g} / \mathrm{d}]$ & $276,5^{a}$ & $169,2^{a}$ & $333,3^{a}$ & $532,6^{b}$ \\
\hline Biotin [ $\mu \mathrm{g} / \mathrm{kg} \mathrm{T}$ Duodenum] & $376,1^{\mathrm{a}}$ & $782,8^{c}$ & $581,1^{b c}$ & $556,9^{a b}$ \\
\hline Biotin [ $\mu \mathrm{g} / \mathrm{d}$ am Duodenum] & $1834,7^{\mathrm{a}}$ & $4372,3^{b}$ & $5785,3^{\mathrm{bc}}$ & $6161,5^{c}$ \\
\hline Biotin [am Duod. in \% des Eintrags] & $72^{a}$ & $186^{b}$ & $129^{b}$ & $145^{b}$ \\
\hline Biotin [ $\mu \mathrm{g} / \mathrm{kg}$ T-Aufn.] & $206^{a}$ & $401^{b}$ & $333^{a}$ & $350^{a}$ \\
\hline Biotin [ $\mu \mathrm{g} / \mathrm{g}$ Mikroben-N] & 15,29 & 25,03 & 14,64 & 17,30 \\
\hline
\end{tabular}

Mittelwerte mit unterschiedlichen Indizes unterscheiden sich signifikant mit $p<0,05$

Konz. = Konzentrat; $\mathrm{T}=$ Trockensubstanz; OS = organische Substanz; $\mathrm{XP}=$ Rohprotein; Aufn. $=$ Aufnahme; $\mathrm{T}_{\text {Duodenum, }}=\mathrm{T}$ Flussmenge am Duodenum; UDP = unabgebautes Futterprotein ; FOS = fermentierte organische Substanz; Duod. = Duodenum

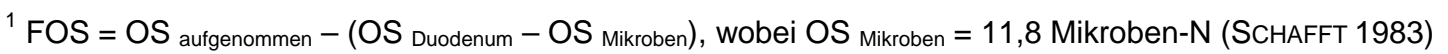

${ }^{2} \mathrm{UDP}=\mathrm{XP}$ Duodenum $-\mathrm{XP}$ Mikroben $-\mathrm{XP}$ endogen), wobei XP endogen $=3,6 \mathrm{gN} /$ Darmchymus- $\mathrm{T}$ (BRANDT 1980) 
Nach Verfütterung der reinen Heuration fiel der T-Fluss am Duodenum mit dem Chymus signifikant niedriger als bei den konzentrathaltigen Rationen und tendenziell niedriger als bei der Ration auf Maissilage-Basis aus. Die auf die aufgenommenen T-Mengen bezogenen TFlussmengen beliefen sich auf 52 bis $63 \%$ ohne signifikante Unterschiede zwischen den Versuchsgruppen.

Der Menge an fermentierter organischer Substanz (FOS) Tag lag bei der reinen Heuration mit 5,94 kg/d am niedrigsten und stieg über die Maissilageration und die Grassilageration mit Maiskonzentrat (7,83 bzw. 11,59 kg/d) bis zur Ration auf Grassilagebasis mit Weizenkonzentrat $(13,13 \mathrm{~kg} / \mathrm{d})$. Bezogen auf die aufgenommene T-Menge lag die Menge FOS bei der Heuration (67\%) in der gleichen Größenordnung wie bei den Rationen mit Konzentrat (66\% bei Weizen bzw. $76 \%$ bei Mais).

Ferner wurde bei reiner Heufütterung signifikant weniger Mikroben- $N$ im Duodenalchymus nachgewiesen als mit den konzentrathaltigen Rationen. Bei Bezug auf die OS-Aufnahme zeigten sich signifikante Unterschiede zwischen den höheren Gehalten der Rationen auf Grassilagebasis und den beiden anderen Rationen, wobei der Wert bei der Heuration der niedrigste war.

Die Mengen an im Pansen unabgebautem Futterprotein (UDP) lagen bei der Grassilageration mit Maiskonzentrat am höchsten und unterschieden sich signifikant von den Werten der anderen Rationen.

Die täglich mit dem Futter zugeführten Biotinmengen sollen aufgrund der unterschiedlichen Mengen an aufgenommenem Futter nur bezogen auf die T-Aufnahme betrachtet werden. So lag der Biotingehalt der T mit der reinen Heuration am höchsten und bei der Maissilageration am niedrigsten, die Gehalte der beiden Grassilagerationen lagen zwischen diesen beiden Extremwerten. Die Unterschiede zwischen der Maissilageration und der Ration auf Grassilagebasis mit Maiskonzentrat sowie zwischen den beiden Grassilagerationen mit weizen- oder Maiskonzentrat erwiesen sich als nicht signifikant.

Die im Duodenalchymus nachgewiesene Menge Biotin war, bezogen auf $1 \mathrm{~kg}$ T-Fluss, sehr variabel. Der signifikant höchste Wert wurde bei der Maissilageration ermittelt, während die drei anderen Rationen zwar auch relativ stark voneinander abwichen, diese Unterschiede statistisch jedoch nicht abgesichert werden konnten.

Gegenüber der aufgenommenen Biotinmenge lag der Biotinfluss am Duodenum bei reiner Heufütterung im Mittel um 0,70 mg/d niedriger (Reduktion um 28\%), dagegen bei Versorgung der Kühe mit eiweißergänzter Maissilage um 2,02 mg/d (86\% Steigerung), bei Fütterung der weizenreichen Grassilageration um 1,31 mg/d (29\% Zunahme) und mit der maisreichen Grassilageration um 1,90 mg/d (45 \% Steigerung) höher. 
Die am Duodenum anflutenden Biotinmengen standen sowohl mit der Menge an synthetisiertem Mikrobenprotein $\left(r^{2}=0,65\right)$ als auch mit der Menge FOS $\left(r^{2}=0,87\right)$ in Beziehung. 


\section{Diskussion}

\subsection{In vitro-Untersuchungen}

In vitro-Untersuchungen bieten die Möglichkeit, die mikrobiellen Umsetzungen im Pansen unter kontrollierten Laborbedingungen zu untersuchen (CZERKAWSKI 1986). Für die Überprüfung des Einflusses der Ration (Heu/Konzentrat-Verhältnis, Kohlenhydratträger im Konzentrat) und des Faunierungsstatus auf den Biotinumsatz während der Pansenfermentation wurde das kontinuierliche in vitro-System RUSITEC (Pansensimulationstechnik) gewählt (CZERKAWSKI UND BECKENRIDGE 1977), das schon seit vielen Jahren am Institut betrieben wird und in mehreren Promotionsvorhaben mit unterschiedlichen Fragestellungen Anwendung fand (BRINKMANN 1991; BEKENDORF 1993; BONGARTZ 1995; DA COSTA GOMEZ 1999). Nachteile des Systems liegen darin begründet, dass die Einflüsse des Spendertieres und der Pansensaftentnahme (z.B. Nüchterungsdauer des Tieres; Temperierung des Saftes; anaerobe Bedingungen in der Saugflasche) direkt in das System übernommen werden. Daher wurde versucht, die Spendertiere immer konstant zu füttern, vor der Pansensaftentnahme für die verschiedenen Durchgänge immer die gleiche Nüchterungsdauer einzuhalten und ferner bei der Pansensaftentnahme von jedem der drei Spendertiere die gleiche Menge Saft zu entnehmen.

Die Durchführung der Untersuchung erfolgte in 5 Wiederholungen, um zum einen genügend Daten für eine aussagekräftige Auswertung der Untersuchungsergebnisse zu bekommen, und zum anderen, um ausreichend Probenmaterial für die Biotinanalytik (für die Extraktion von Biotin aus einer Probe werden mind. $10 \mathrm{~g}$ bzw. $10 \mathrm{ml}$ Material benötigt; vgl. A4) und Rückstellproben zur Verfügung zu haben.

Ein möglicher Kritikpunkt an der Durchführung der in vitro-Untersuchungen ist die Verteilung der verschiedenen Testrationen auf die zwei unterschiedlichen Geräte mit unterschiedlichen Fermentervolumina. Es stellt sich die Frage, ob es trotz Berücksichtigung der Unterschiede in den Fermentergrößen der beiden Anlagen in den Substrateinwaagen, der Dosierung des Defaunierungsdetergenzes und der Pufferzufuhr (s. Tab. 6), sinnvoller gewesen wäre, in jedem der Geräte je eine Wiederholung der 5 verschiedenen Rationsvarianten zu untersuchen, um mögliche Einflüsse der Geräte auf Fermentationsparameter und Biotinumsetzungen auszuschließen. Mögliche Unterschiede zwischen der faunierten Variante in dem einen und der defaunierten Variante im anderen Gerät hätten dann aber nicht nur auf die An- oder Abwesenheit der Protozoen zurückgeführt werden können. Da vor Untersuchungsbeginn jedoch noch keine Erkenntnis darüber vorlag, ob und in welcher Größenordnung der Faunierungsstatus einen Einfluss auf die Biotinumsetzungen ausübt und dieser möglicherweise 
kleiner gewesen wäre als der Einfluss der verschiedenen Geräte, wurden die beiden im Hinblick auf den Faunierungsstatus möglichen Varianten derselben Ration in einem Gerät getestet.

\subsubsection{Fermentationsparameter}

Bevor die gewonnenen Ergebnisse der Fermentationsparameter diskutiert werden, soll anhand einiger Parameter auf die Plausibilität der Daten eingegangen werden, indem sie mit anderen Untersuchungsergebnissen verglichen werden.

Für eine effektive mikrobielle Proteinsynthese sollte der Gehalt an $\mathrm{NH}_{4}-\mathrm{N}$ nicht unter $50 \mathrm{mg}$ bzw. 2,78 mmol pro I Pansensaft liegen (SATTER UND ROFFLER 1975; SLYTER ET AL. 1979). In den eigenen Untersuchungen wurden in Abhängigkeit der Ration Gehalte zwischen 1,37 (also unter dem genannten Grenzwert) und 5,63 $\mathrm{mol} \mathrm{NH}_{4}-\mathrm{N}$ pro I Pansensaft bestimmt, wobei die mikrobielle Proteinsynthese (gemessen als mikrobiell fixierter Stickstoff) bei Einsatz der Rationen, bei denen die geringsten Mengen Ammonium- $\mathrm{N}$ anfielen, am geringsten ausfiel.

Als weiterer Parameter zur Beurteilung der gewonnenen Daten soll die Effizienz der mikrobiellen Synthese, die als Relation von mikrobieller Zelltrockenmasse zu fermentierter Hexose nach DEMEYER ET AL. (1995) errechnet wird, herangezogen werden. In den eigenen in vitroUntersuchungen ergaben sich pro kg fermentierter Hexose (errechnet anhand der Gleichung von DEMEYER ET AL. $1995^{2}$ ) durchschnittliche Produktionsraten an mikrobieller Zelltrockenmasse von $252 \mathrm{~g}(\mathrm{Heu}), 218 \mathrm{~g}$ (8g Heu + 4g Weizen), $187 \mathrm{~g}$ (8g Heu + 4g Mais), $231 \mathrm{~g} \mathrm{(4g}$ Heu $+8 \mathrm{~g}$ Weizen) und $170 \mathrm{~g}$ (4g Heu + 8g Mais). Die Größenordnung der mikrobiellen Synthesen entsprach damit Verhältnissen, wie sie auch unter in vivo-Bedingungen auftreten (STERN UND HOOVER 1979).

Die Anteile der einzelnen flüchtigen Fettsäuren an der Zusammensetzung der SCFA belaufen sich in vivo nach DEMEYER ET AL. (1995) auf ca. 70\% Acetat, 20\% Propionat und 10\% Butyrat, eine Literaturübersicht bei JOUANY ET AL. (1988) gibt für ausgewachsene Rinder Anteile von 52 - $64 \%$ Acetat,11 - 15\% Propionat und 21 - $27 \%$ Butyrat an. In den eigenen Untersuchungen wurde die Zusammensetzung der SCFA im Mittel aller Einzedaten mit 55\% Acetat, 32\% Propionat und 9\% Butyrat bestimmt und lag damit in vergleichbarer Größenordnung zu den Literaturangaben.

Die Methanbildung unterliegt sehr komplexen Vorgängen und soll daher nicht direkt als Maßstab zur Beurteilung der Plausibilität der gewonnenen Daten herangezogen werden. Vielmehr soll der bereits als Hilfsmaßstab bei der Volumenkorrektur der angefallenen Me-

\footnotetext{
${ }^{2}$ fermentierte Hexose $[\mathrm{g} / \mathrm{d}]=162 \times[\mathrm{mmol}$ Acetat $/ 2+\mathrm{mmol}$ Propionat $/ 2+\mathrm{mmol}$ Butyrat $]$
} 
thanmengen genutzte Anteil der methangebundenen Energie an der aufgenommenen Bruttoenergie betrachtet werden. BERGNER UND HOFFMANN (1996) geben diesen Anteil in Abhängigkeit der gefütterten Ration und damit des Musters der flüchtigen Fettsäuren mit ca. 7\% an. In den eigenen Untersuchungen wurden zwischen 2,7 und 4,4\% der zugeführten Bruttoenergie in Form von Methan umgesetzt. Betrachten man jedoch nur die Ergebnisse aus faunierter Inkubation, da diese den in vivo-Verhältnissen eher entsrechen, so liegt dieser Anteil in Abhängigkeit der Rationen zwischen 3,2 und 5,4\%.

\subsubsection{Einfluss der Ration}

Mit steigendem Konzentratanteil der Ration fiel der $\mathrm{pH}$-Wert signifikant ab. Dieser Effekt wurde in diversen Untersuchungen nach hohen Kraftfuttergaben aufgrund intensiver Fermentation nachgewiesen (MACKIE ET AL. 1984).

Die erfasste Menge des angefallenen Ammoniums, das beim Abbau von Futterproteinen und NPN-Verbindungen im Pansen entsteht (DEMEYER UND VAN NEVEL 1980), stieg bei den Rationen mit zunehmendem Weizenanteil signifikant an, während der Gehalt von $\mathrm{NH}_{4}-\mathrm{N}$ bei steigendem Maisanteil in der Ration signifikant abnahm. Diese Unterschiede zwischen den Rationen und auch den Getreidearten lassen sich mit dem Rohproteingehalten der Futtermittel begründen: Beim eingesetzten Weizen lag der Rohproteingehalt bei $13,5 \%$ in der Trockensubstanz, beim Heu lag dieser Anteil bei $11,8 \%$ und beim Mais bei nur 9,9\% (vgl. Tab. 7). Dadurch wurde mit den Maisrationen insgesamt weniger Futterprotein zugeführt als mit der Heu- und den Weizenrationen, während sich der im Vergleich zu Heu höhere XP-Anteil des Weizens in höheren $\mathrm{NH}_{4}$-Werten niederschlug.

Die Methanbildung wurde in den eigenen Untersuchungen mit steigendem Konzentratanteil in der Ration eingeschränkt. Der Zusammenhang liegt darin, dass bei steigendem Konzentratanteil der Ration die ruminale Fermentationsintensität und damit die Freisetzung von Wasserstoff zunimmt. Der vermehrt freigesetzte Wasserstoff kann zur Bildung von Propionat auf Kosten einer relativ verminderten Methanbildung genutzt werden (MACKIE ET AL. 1984). Diese Wechselbeziehung kann auch anhand er gebildeten Mengen an Propionsäure (C3) nachvollzogen weden: mit steigendem Konzentratgehalt stieg deren tägliche Freisetzung.

Die Protozoenzahl nahm mit steigendem Konzentratanteil der Ration zunächst zu. Diese Beobachtung deckt sich mit Ergebnissen von REICHL (1961) sowie ABE UND IRIKI (1978), die belegen, dass mit steigendem Anteil leicht fermentierbarer Kohlenhydrate in der Ration die Protozoenzahl zunimmt und dabei vor allem die großen entodiniomorphen Ciliaten der Gattungen Ophryoscolex und Polyplastron gefördert werden. Bei weiterer Erhöhung des Konzentratanteils in der Ration ging in den eigenen Untersuchungen die Zahl der Protozoen ten- 
denziell wieder zurück, was im Einklang mit Beobachtungen aus verschiedenen Untersuchungen steht (EADIE UND MANN 1970, LATHAM ET AL. 1971, GRAIN ET AL. 1979). Als Begründung werden in den angegebenen Veröffentlichungen hohe Stärkegaben mit der Folge eines Abfalls im pH-Wert für den Rückgang der Protozoenzahl bis hin zu einem vollständigen Ausfall der Fauna verantwortlich gemacht. In den eigenen in vitro-Untersuchungen wurden starke Schwankungen im pH-Wert durch kontinuierliche Pufferzufuhr jedoch ausgeschlossen, so dass der zu beobachtende Effekt hier ebenfalls mit Populationseffekten (Rückgang der einen zugunsten einer anderer Protozoenart, Verschiebungen in der Protozoen/Bakterien-Relation) zu erklären ist.

ITABASHI ET AL. (1984) beschrieben ferner den Zusammenhang zwischen den Protozoen und der Methanogenese: Bei einem Rückgang der Protozoenzahl geht auch die Zahl der methanogenen Bakterien, die sehr eng mit Protozoen der Entodinium-Arten verbunden sind, mit der Folge einer verminderten Methanbildung zurück. Dieser Effekt der sinkenden Methanmenge bei sinkenden Protozoenzahlen lässt sich deutlicher nach der Defaunierung erkennen.

Die mit steigendem Konzentratanteil in der Gesamtration zunehmenden Mengen von Acetat und Propionat entsprechen Ergebnissen von JOUANY (1996) sowie MACKIE ET AL. (1984). Die Steigerung der Fermentationsintensität lässt sich anhand der Gesamtmengen der SCFA belegen. Da die Fermentation der Stärke aus Weizen schneller abläuft als die der Maisstärke, ist bei den Rationen mit weizenhaltigem Kraftfutter die Menge an SCFA gegenüber den Rationen mit Maisanteil im Konzentrat z.T. deutlich erhöht.

Die Menge täglich gebildeten mikrobiellen Stickstoffs zeigte einen signifikanten Einfluss der eingesetzten Getreideart: Während der Wert bei den Rationen mit steigendem Weizenanteil signifikant anstieg, fiel er bei den Maisrationen tendenziell ab. Auch andere Autoren fanden beim Einsatz schwer fermentierbarer Stärke verminderte mikrobielle Syntheseleistungen (OLDHAM ET AL. 1979; LeBZIEN ET AL. 1983), wobei im vorliegenden Fall zusätzlich auch eine limitierte N-Versorgung mitgewirkt haben kann.

Bei der Berechnung der Effizienz der mikrobiellen Synthese ergaben sich, wie bereits erwähnt, Größenordnungen, die Verhältnissen unter in vivo-Bedingungen entsprechen. Die Effizienz der mikrobiellen Zellsynthese nahm mit steigenden Getreideanteilen in der Ration ab, wobei Mais deutlicher wirkte als Weizen. Die Ursachen hierfür liegen in der niedrigeren ruminalen Abbaubarkeit der Mais- im Vergleich zur Weizenstärke und möglicherweise im NMangel. 


\subsubsection{Einfluss der Defaunierung}

Eine bei Defaunierung auftretende Absenkung des pH-Wertes (WILLIAMS UND COLEMAN 1992) konnte in den eigenen Untersuchungen aufgrund der kontinuierlichen Zufuhr des starken Puffers nicht festgestellt werden. Sie lässt sich mit der von WHITELAW ET AL. (1972) beschriebenen $\mathrm{pH}$-stabilisierenden Wirkung der Protozoen im faunierten Pansensaft erklären: Die Protozoen nehmen ganze Stärkegranula auf und entziehen sie damit der sofortigen Fermentation durch die Bakterien.

In Untersuchungen von KURIHARA ET AL. (1978) an Hammeln war die Zahl der zellulolytischen Bakterien im Pansen faunierter Tiere gegenüber Tieren ohne Protozoen erhöht. Dagegen betrug der Anteil der amylolytischen Bakterien an der Gesamtpopulation im Pansen bei den defaunierten Tieren 65\%, während deren Anteil in faunierten Tieren nur 6\% betrug. Bei Verabreichung großer Mengen Konzentrat an defaunierte Tiere waren die $\mathrm{pH}$-Werte aufgrund der gesteigerten Bildung von Lactat niedriger als in einer Kontrollgruppe mit intakter Pansenfauna. Die Zahl der säureempfindlichen zellulolytischen Bakterien im Pansen wurde reduziert, während die der säuretoleranteren amylolytischen zunahm.

Die Methanogenese wurde, übereinstimmend mit Angaben aus der Literatur (DEMEYER UND VAN NEVEL 1979; USHIDA ET AL. 1986), durch die Defaunation deutlich herabgesetzt. Dies beruht auf der Reduktion der methanogenen Bakterien, die sehr eng mit Protozoen der Entodinium-Arten verbunden sind und bei deren Abtötung ebenfalls unwirksam gemacht werden (ITABASH ET AL. 1984). WHITELAW ET AL. (1984) sahen eine weitere Ursache nach Untersuchungen an defaunierten und unbehandelten Rindern in Unterschieden der Proportionen der gebildeten SCFA zueinander und einer damit einhergehenden Veränderung der Methanbildungsrate (s.u.). Zusätzlich verstoffwechseln Protozoen Sauerstoff und haben somit eine wichtige Rolle bei der Sauerstoffeliminierung im Pansen. HILLMAN ET AL. (1985) beobachteten bei defaunierten Schafen einen vorübergehenden Anstieg des ruminalen Sauerstofflevels nach der Fütterung. Das höhere Sauerstoffniveau führt nach ScOTT ET AL. (1983) zur Hemmung der Wasserstoffbildung und Methanogenese.

Die Reduktion der gebildeten Methanmenge durch den Einsatz des Defaunierungsdetergenzes um ca. 23\% deckt sich mit Resultaten von LeINMÜLLER UND MENKE (1986), die in ihren Untersuchungen einen Rückgang zwischen 10 und 20\% verzeichnen konnten.

Die erfasste Menge an $\mathrm{NH}_{4}-\mathrm{N}$ lag in den defaunierten Fermentern signifikant niedriger als in den faunierten. Diese Beobachtung deckt sich mit Werten aus der Literatur (VEIRA ET AL. 1981, 1983, 1984; MeYer ET AL. 1986; RomUlo ET AL. 1986). Protozoen spielen somit eine wichtige Rolle bei der Freisetzung von $\mathrm{NH}_{3}$, wobei der Grund dafür nicht nur in einer intensiveren Fermentation der Futterproteine durch die Pansenfauna, sondern vermutlich auch in 
einer höheren Wiederverwertung von Mikrobenprotein bakteriellen Ursprungs und einer kleineren Anzahl ammoniumnutzender Bakterien zu finden ist (LENG UND NOLAN 1984). Der dabei freigesetzte Stickstoff wird nur zu 50\% für Synthesezwecke verwendet, der Rest wird in das Medium abgegeben (COLEMAN 1975). JoUANY UND SENAUD (1982) vertraten zusätzlich die These, dass der Ammonium-Zuwachs bei Inkubation mit Protozoen nicht nur aus dem Abbau des von den Protozoen verdauten Bakterienproteins stammt, sondern auch auf eine geringere N-Aufnahme durch eine kleinere Bakterienpopulation zurückzuführen ist.

Beim Vergleich der SCFA-Zusammensetzung von faunierter mit defaunierter Fermenterflüssigkeit aus der Pansensimulation fallen die höheren Propionat- und niedrigeren iso-Butyratund n-Butyratanteile in den defaunierten Ansätzen auf. DEMEYER UND VAN NEVEL (1979) erhielten aus Untersuchungen mit Hammeln ähnliche Ergebnisse und zogen daraus den Schluss, dass Protozoen für die Butyratproduktion eine wichtige Rolle spielen, während Propionat überwiegend durch Bakterien gebildet wird. Andere Erklärungsansätze für den Zusammenhang zwischen pH-Wert und SCFA-Muster wie z.B. der von MACKIE ET AL. (1978), demzufolge bei niedrigem $\mathrm{pH}$-Wert die Zahl der säureempfindlichen, butyratbildenden Bakterien (Butyrivibrio, Eubacterium) absinkt, während die Entwicklung von lactat- und propionatproduzierenden Bakterien (Megasphera, Veillonella) begünstigt wird, können hier nicht herangezogen werden, da der $\mathrm{pH}$-Wert zwischen den defaunierten und den faunierten Fermentern nicht differierte.

Bei der Bildung von Acetat und Butyrat wird Wasserstoff frei, wohingegen die Bildung von Propionat mit einem Nettoverbrauch von $\mathrm{H}_{2}$ einhergeht. Da der Wasserstoff von den methanogenen Bakterien $\mathrm{zu} \mathrm{CH}_{4}$ umgewandelt wird, ist folglich bei Inkubation von Substrat in defauniertem Medium bei Bildung von mehr Propionat und weniger Butyrat die Menge an Wasserstoff und letztlich daraus gebildetem Methan geringer (WITHELAW ET AL. 1984). ØRSKOV ET AL. (1968) berechneten diesen Unterschied stöchiometrisch für typische SCFA-Proportionen und fanden heraus, dass die Methanbildung in faunierten Tieren bis zu zweimal höher ausfallen kann als in defaunierten.

Die Defaunierung wirkte sich nicht auf die Menge des mikrobiell gebundenen Stickstoffs aus. Auch die Effizienz der mikrobiellen Zellsynthese wurde nicht signifikant beeinflusst. Dieses den Erwartungen nicht ganz entsprechende Ergebnis lässt sich damit begründen, dass auch in den faunierten Varianten die Konzentration an Protozoen gering war. Der Verlust an mikrobieller Trockenmasse durch Verschwinden der Protozoen wurde vermutlich durch ein gesteigertes Bakterienwachstum kompensiert. Den Erklärungsansatz, dass nach der Defaunierung keine Bakterien von Protozoen konsumiert werden und dadurch der Mikrobenertrag steigt, beschrieben VAN NEVEL UND DEMEYER (1981). 


\subsubsection{Biotinumsatz}

\subsubsection{Einfluss der Ration}

Die den Biotingehalten der Rationen zugrunde liegenden Biotingehalte der eingesetzten Futtermittel (s. Tab. 19) deckten sich mit den Literaturangaben (vgl. Tab.2). Der Rückgang der mit dem Futter aufgenommenen Biotinmenge bei steigendem Konzentratanteil der Ration wurde auch schon von HAYES ET AL. (1966) sowie ABEL ET AL. (2001) beschrieben.

Die mit den festen und flüssigen Inkubationsrückständen aus dem Simulationssystem täglich ausgetragenen Biotinmengen entsprachen in ihrer Größenordnung den bereits in einer früheren Untersuchung mit Heu-Gerste-Rationen gemessenen Werten (ABEL ET AL. 2001). Allerdings wirkten sich in den eigenen Untersuchungen steigende Konzentratanteile anstelle von Heu im Gegensatz zu steigenden Gersteanteilen in der früheren Untersuchung nicht mindernd auf die Biotinausträge aus, vielmehr verhielten sich diese weitgehend unabhängig von den mit Heu, Weizen und Mais zugeführten Biotinmengen.

Die Bilanzmengen wurden für diese Versuche als Differenz zwischen den in den Inkubationsrückständen nachgewiesenen und den mit dem Futter zugeführten Biotinmengen bestimmt. Sie stiegen mit zunehmendem Konzentratanteil der Ration: Die reine Heuration führte zu einer deutlich negativen Biotinbilanz, die mit steigenden Getreideanteilen zunehmend ausgeglichen wurde und mit der maisreichen Ration einen positiven Wert erreichte. Auch dieses Ergebnis steht im Gegensatz zu der zitierten früheren Untersuchung mit Heu-GersteRationen, allerdings lagen dort die Biotingehalte in den Ausgangsrationen auch auf einem insgesamt niedrigeren Niveau.

\subsubsection{Einfluss der Defaunierung}

Es konnten keine signifikanten Einflüsse der Defaunierung auf die mikrobiellen Biotinumsetzungen in der Pansensimulation nachgewiesen werden.

Der tendenziell höhere Biotingehalt in den Fermentationsrückständen der defaunierten Ansätze könnte ein Anzeichen dafür sein, dass Biotin von den Protozoen benötigt wird. Dafür lassen sich jedoch, wie bereits unter 2.4.4 beschrieben, in der Literatur keine Hinweise finden. Auch könnte die Beobachtung der tendenziell geringfügig höheren Biotingehalte in den Rückständen aus den defaunierten Fermentern ein Hinweis sein, dass die Anzahl biotinsynthetisierender Bakterien oder ihre Syntheseleistung ansteigt, wenn keine Protozoen anwesend sind. Die Erklärung für den ersten Effekt (Anzahl Bakterien) liefern auch hier VAN NEVEL UND DEMEYER (1981), die wie bereits erwähnt, beschrieben, dass nach der Defaunierung keine Bakterien von Protozoen konsumiert werden und dadurch der Mikrobenertrag steigt. Auch über einen Einfluss auf die Syntheseleistung der biotinsynthetisierenden Bakte- 
rien, in unserem Fall auch speziell über den Einfluss einer Defaunierung oder der Rationsgestaltung, lässt sich in der Literatur kein Hinweis finden.

Bei der Interpretation des Ergebnisses bleibt zu beachten, dass die aufgetretenen Unterschiede signifikant nicht abgesichert werden konnten. Somit bedürften sie weiterer Überprüfung.

\subsection{In vivo-Untersuchungen}

Generell sind in vivo-Messungen kosten-, arbeits- und zeitintensive Verfahren. Außerdem bergen die geringen Tierzahlen, die Notwendigkeit des Einsatzes eines Markers sowie durch das Betreuungspersonal verursachte Effekte Fehlerquellen (STERN ET AL. 1977). Versuche mit Hilfe von Tieren, die operativ mit Fisteln oder Kanülen versehen worden sind, sind zudem oftmals mit Komplikationen verbunden. So beschrieben z.B. HARMON UND RICHARDS (1997), dass durch Umleitungskanülen die Darmperistaltik gehemmt wird und so auch besonders im Duodenum Chymusrückflüsse auftreten können. Einfache T-Kanülen, wie sie im vorliegenden Versuch Verwendung fanden, wirken sich am wenigsten nachteilig auf die Darmmotilität und den Chymusfluss aus. Allerdings erschweren T-Kanülen die Sammlung repräsentativer Proben, was eine hohe Anzahl Stichproben erforderlich macht.

Bei den in dieser Arbeit dargestellten Untersuchungen kam es zu keinem der beschriebenen Probleme.

Bevor die Ergebnisse der in vivo-Untersuchungen diskutiert werden, soll auch hier anhand einiger Beispiele kurz auf deren Plausibilität eingegangen werden.

Die am Duodenum geflossene T-Menge lag mit Anteilen an der aufgenommenen T-Menge von 52 bis $63 \%$ in gleichen Größenordnungen wie in früheren Untersuchungen (z.B. 61,9 bis $63,1 \%$ bei ROHR ET AL. 1984).

Die Effizienz der mikrobiellen Synthese (Berechnung s. 4.1.1) betrug für die reine Heuration $238 \mathrm{~g}$ mikrobielle Zelltrockenmasse pro $\mathrm{kg}$ FOS, bei Ration 2 lag sie bei $279 \mathrm{~g}$, und für die Rationen 3 und 4 bei 376 bzw. $378 \mathrm{~g}$. Der Wert der reinen Heuration stimmt mit dem der Heuration aus den in vitro-Untersuchungen überein, die anderen Werte liegen deutlich darüber, was an den verhältnismäßig höheren Mengen an mikrobieller Zelltrockenmasse liegt. Die Daten sind in den Größenordnungen vergleichbar.

Die Menge an aufgenommenem Biotin entsprach mit Werten zwischen 2,5 und 4,5 mg pro Tag der Größenordnung wie mit 2,5 mg/d von WEISS UND ZIMMERLY (2000) für Bullen ermit- 
telt und am unteren Rand der von FRIGG ET AL. (1993a) für Kühe angegebenen Menge (4 bis $10 \mathrm{mg} / \mathrm{d})$.

Die gebildeten Mengen an Mikrobentrockenmasse variierten sehr stark. Nur die Grassilagerationen mit Konzentratzulagen hatten mit 376 bzw. 378 g/kg FOS annähernd die Größenordnung des aus der von LEBZIEN UND VOIGT (1999) angegebenen mikrobiellen Proteinsynthese errechneten Mittelwertes von $362 \mathrm{~g} / \mathrm{kg}$ FOS. Der Wert der Heuration lag mit $238 \mathrm{~g} / \mathrm{kg}$ FOS ebenso deutlich darunter wie der der Maissilageration mit $279 \mathrm{~g} / \mathrm{kg}$ FOS, beide lagen aber deutlich über dem von LEBZIEN UND VOIGT (1999) angegebenen Minimalwert von 138 g/kg FOS (69 g Mikrobenprotein/kg FOS). Die Rationen auf Grassilagebasis erzielten einen höheren Ertrag an Mikrobenprotein, da mit ihnen die Futteraufnahme fast doppelt so hoch war als bei den beiden anderen Rationen (s. Tab. 13).

Die Biotinmengen am Duodenum standen mit der Menge an FOS in enger Beziehung. Entsprechend führte die Ergänzung der Grassilage mit weizenreichem Milchleistungsfutter zu einer stärkeren duodenalen Biotinanflutung als die Ergänzung mit dem maisreichen Milchleistungsfutter.

Ebenfalls konnte eine enge Beziehung zwischen der Menge an mikrobiell fixiertem Stickstoff und der duodenalen Biotinanflutung, jeweils bezogen auf einen Tag, festgestellt werden. 


\section{Schlussfolgerungen}

Die Ergebnisse der durchgeführten Untersuchungen mit Hilfe der Pansensimulationstechnik RUSITEC lassen schließen, dass eine verhältnismäßig hohe Biotinversorgung mit heureichen Rationen zu einem hohen Biotinverbrauch durch Pansenmikroorganismen führt. Dadurch ergeben sich negative Biotinbilanzen. Positive Biotinbilanzen sind mit getreidereichen und daher biotinärmeren Rationen zu erzielen. Unterschiedliche Wirkungen von Weizen und Mais sowie Einflüsse des Faunierungsstatus' auf die Biotinumsetzungen im Pansensimulationssystem ließen sich nicht nachweisen.

In Übereinstimmung mit den in vitro-Ergebnissen lässt sich aus den in vivo-Untersuchungen schließen, dass bei Fütterung reiner Heurationen an Kühe weniger Biotin am Duodenum der Tiere anflutet als mit dem Futter zugeführt wird. Dagegen kamen bei Fütterung Energie/Protein-ausgeglichener energiereicherer Rationen gegenüber den aufgenommenen Biotinmengen höhere Mengen am Duodenum an. Ein direkter Zusammenhang zwischen der Biotinzufuhr mit dem Futter und der Biotinanflutung am Duodenum der Kühe war nicht nachweisbar.

Diese beschriebenen Ergebnisse lassen direkte Vergleiche zwischen beiden methodische Ansätzen nur in einem gewissen Rahmen zu.

Die Effizienz der mikrobiellen Zellsyntheseleistungen war zwar bei beiden Methoden der Größenordnung nach vergleichbar, bei den konzentratreicheren Rationen waren jedoch unterschiedliche Ergebnisse zu verzeichnen: Mit steigenden Getreideanteilen nahm die pro kg fermentierter Hexose gebildete mikrobielle Zellmasse in den RUSITEC-Untersuchungen ab, während in den in vivo-Untersuchungen die mikrobielle Zellmasse pro kg FOS zunahm. Eine mögliche Ursache dafür könnte in den Unterschieden der Rationsgestaltung liegen: In den Simulationsuntersuchungen handelte es sich um den Austausch von Heu gegen Getreide, während in den in vivo-Untersuchungen getreidereiches Milchleistungsfutter zusätzlich zum Grundfutter gefüttert wurde.

Große Unterschiede bestanden außerdem bezüglich der von den isolierten Mikroorganismen in der Pansensimulation gebildeten und unter in vivo-Bedingungen aus dem Pansenstoffwechsel stammenden, am Duodenum anflutenden Biotinmengen. Bezogen auf den mikrobiell gebundenen Stickstoff lagen die Biotinmengen in vivo um ein Vielfaches höher. Mögliche Erklärungsansätze für die Unterschiede könnten in dem gegenüber in vitro-Bedingungen wesentlich engeren Verhältnis von Fest- zu Flüssigphase bei gleichzeitig im Vergleich zu in vivo-Verhältnissen erheblich vermindertem Flüssigkeitsumschlag in der Pansensimulation liegen. 
Insgesamt ist aus den Ergebnissen der Simulations- und der in vivo-Untersuchungen zu schließen, dass bei grundfutter- und damit biotinreicher Versorgung der Tiere ein hoher Verbrauch an zugeführtem Futterbiotin im mikrobiellen Pansenstoffwechsel auftritt, der zu einer niedrigen Biotinanflutung am Duodenum führt. Die Ergebnisse sowohl der Pansensimulations- als auch der in vivo-Untersuchungen weisen auf eine positive Beziehung zwischen dem Angebot an ruminal fermentierbarer Energie und der Biotinanflutung am Duodenum hin. Wenn auch mit der Pansensimulationstechnik weizen- bzw. maisspezifische Wirkungen nicht nachweisbar waren, so führte bei den Kühen die weizenreiche Futterration mit ruminal leicht abbaubarer Stärke zur mit Abstand höchsten und die maisreiche Ration mit ruminal schwerer abbaubarer Stärke zu deutlich niedrigerer duodenaler Biotinanflutung. Die Ergebnisse der in vivo-Untersuchungen verdeutlichen, dass große rations- und getreidespezifische Unterschiede in der duodenalen Biotinanflutung auftreten können, die die Beurteilung der Versorgungslage von Milchkühen mit Biotin erschweren, die jedoch im Hinblick auf eine leistungsgerechte Versorgung der Tiere beachtet werden sollten. 


\section{Zusammenfassung}

Für die vorliegende Arbeit wurden systematische Untersuchungen mit der Pansensimulationstechnik RUSITEC und an duodenalkanülierten Tieren durchgeführt, um zu bestimmen, ob und inwieweit der Biotinumsatz durch das Verhältnis von Grundfutter zu Konzentrat der gefütterten Ration, durch die abbaukinetischen Eigenschaften der eingesetzten Futterkohlenhydrate im Pansen sowie durch die Protozoenpopulation beeinflusst wird.

Bei den in vitro-Untersuchungen wurden 3 Rationen mit unterschiedlichen Heu/KonzenratVerhältnissen $(1 / 1 \mathrm{Heu} ; 2 / 3 \mathrm{Heu}+1 / 3$ Konzentrat; $1 / 3 \mathrm{Heu}+2 / 3$ Konzentrat) als Substrat eingesetzt, die Rationen mit Konzentratanteil wurden in Varianten mit Weizen und Mais als Kohlenhydratträger getestet. Außerdem wurde jede Futtervariante in fauniertem und defauniertem Medium inkubiert.

Für die in vivo-Untersuchungen zur Bestimmung der duodenalen Anflutung von Biotin mit dem Chymus wurden 4 verschiedene Rationen an duodenalkanülierte Tiere verfüttert. Die Rationen wurden so gewählt, dass ein annähernder Vergleich zwischen den Wirkungen der Grundfuttermittel auf Grasbasis und Maisbasis einerseits und der Wirkung von weizen- bzw. maisbetontem Kraftfutter in Kombination mit Grassilage als Grundfutter andererseits ermöglicht wurde.

Neben Abweichungen in Fermentationsparametern traten große Unterschiede bezüglich der von den Mikroorganismen in der Pansensimulation gebildeten und unter in vivo-Bedingungen aus dem Pansenstoffwechsel stammenden, am Duodenum anflutenden Biotinmengen auf. Bezogen auf den mikrobiell gebundenen Stickstoff lagen die Biotinmengen in vivo um ein Vielfaches höher.

Die Ergebnisse der Simulations- und der in vivo-Untersuchungen zeigen, dass keine direkte Beziehung zwischen dem Biotineintrag über das Futter und dem Austrag des Vitamins aus dem Pansen bzw. seiner Anflutung am Duodenum besteht. Tendenziell führt ein hoher Verbrauch an zugeführtem Futterbiotin im mikrobiellen Pansenstoffwechsel, der bei grundfutterreicher Fütterung auftritt, zu einer niedrigen Biotinanflutung am Duodenum. Die Ergebnisse der in vivo-Untersuchungen verdeutlichen, dass rations- und getreidespezifische Unterschiede in der duodenalen Biotinanflutung die Beurteilung der Versorgungslage von Milchkühen mit Biotin erschweren, jedoch hinsichtlich einer leistungsgerechten Versorgung der Tiere beachtet werden sollten. 


\section{Summary}

The aim of this study was to investigate in systematic examinations with the rumen simulation technique RUSITEC and in vivo with cows cannulated in the proximal duodenum whether and how the biotin turnover gets influenced by the roughage/concentrate ratio of the fed ration, by the quality of degradation kinetics of the used feed carbohydrates and by the protozoa population.

For the in vitro investigations there were used three rations with different hay/concentrate ratios (1/1 hay; $2 / 3$ hay $+1 / 3$ concentrate; $1 / 3$ hay $+2 / 3$ concentrate) for substrate, the rations with concentrates were tested in variants with wheat or maize as carbohydrate carriers. Besides each feed variant was incubated in faunated and defaunated inoculum.

For the in vivo examinations to determine the flooding of biotin at the duodenum with the digesta there were fed 4 different rations to the cows fitted with duodenum cannulae. They were thus chosen to make possible the comparison between the effect of roughages based on grass or maize on one hand and the effects of concentrates based on wheat or maize in combination to gras silage as roughage on the other hand.

Beside differences in parameters of fermentation there were great differences relative to the amount of biotin synthesized from the microbes in the rumen simulation and flooding at the duodenum under in vivo conditions, originating from rumen metabolism. Relative to microbially fixed nitrogen the amounts of biotin were multiple higher in vivo.

Altogether the results of both the simulation and in vivo investigations show that there is no direct relation between the biotin input by provided feed and biotin output from rumen respectively its duodenal flooding. Tendentiously high consumption of supplied feed biotin in microbial rumen metabolism occurring after high roughage feeding leads to a lower flooding of biotin at the duodenum. The results from the in vivo investigations show that there can occur big ration- and grain-specific differences in duodenal biotin flooding that render the judgement of providing situation for dairy cows with biotin more difficult, but that should be payed attention for to meet the individual pretensions of the animals resulting from their performances. 


\section{Literaturverzeichnis}

Abdouli, H.; SchAeFER, D.M.; PoPe, A.L., 1983: Effects of niacin supplementation on the rumen microbial population. J. Anim. Sci. 57 (Suppl. 1), 415

ABE, M.; IRIKI, T., 1978: Effects of diet on the protozoa population in permeable continuous cultures of rumen content. Br. J. Nutr. 39, 255 - 264

ABel, HJ., IMmig, I.; DA Costa Gomez, C.; Steinberg, W., 2001: Research note: Effect of increasing dietary concentrate levels on microbial biotin metabolism in the artificial rumen simulation system (RUSITEC). Arch. Anim. Nutr. 55, 371 - 376

AgraWALA, I.P.; HufFMAN, C.F.; LUECKE, R.W.; DunCAN, C.W., 1953: A quantitative study of rumen synthesis in the bovine in natural and purified diets. III. Riboflavin, panthothenic acid and niacin. J. Nutr. 49, $631-638$

ARINZE, J.C.; MISTRY, S.P., 1971: Activities of some biotin enzymes and certain aspects of gluconeogenesis during biotin deficiency. Comp. Biochem. Physiol. 38b, $285-294$

AWT, 2001: (Arbeitsgemeinschaft für Wirkstoffe in der Tierernährung) Vitamine in der Tierernährung. Agrimedia GmbH, Bergen/ Dumme

AXELROD, A.E., PRUZANSKY, J., 1955: The role of vitamins in antibody production. New York Acad. Sci. 63, $202-213$

BaezSaldana, A.; Diaz, G.; EspinozA, B.; Ortega, E., 1998: Biotin deficiency induces changes in subpopulations of spleen lymphocytes in mice. Am. J. Clin. Nutr. 67, 431 437

BALDWIN, R.L., 1965: Pathways of carbohydrate metabolism in the rumen. In: DoUGHERTY, R.W. (ED.): Physiology of digestion in the ruminant. Butterworth, Washington D.C., 379 389

BALDWIN, R.L.; Allison, M.J., 1983: Rumen metabolism. J. Anim. Sci. 57 (Suppl. 2), 461 477 
BEKENDORF, TH., 1993: In-vivo- und In-vitro-Untersuchungen zum Einfluss von Kohlenhydraten und Bicarbonat auf den Pansenstoffwechsel unter Berücksichtigung des Laktatumsatzes. Diss. sc. agr., Göttingen

BeRgneR, H.; HOFFMANN, L., 1996: Bioenergetik und Stoffproduktion landwirtschaftlicher Nutztiere. Harwood Academic Publishers, Chur, Philadelphia, Reading

Bergsten, C.; Greenough, P.R.; Gay, J.M.; Dobson, R.C.; Gay, C.C., 1999: A controlled field trial of the effects of biotin supplementation on milk production and hoof lesions. J. Dairy Sci. 82 (Suppl. 1), 34 (Abstract)

Bergsten, C.; Greenough, P.R.; Gay, J.M.; Seymour, W.M.; Gay, C.C., 2003: Effects of biotin supplementation on performance and claw lesions on a commercial dairy farm. J. Dairy Sci. 86 , 3953 - 3962

BITSCH, R.; BARTEL, K., 1994: Biotin - wissenschaftliche Grundlagen, klinische Erfahrungen und therapeutische Ansatzmöglichkeiten. In: $\mathrm{BITSCH}$, R. (ED.): Biotin. Wissenschaftliche Verlagsgesellschaft, Stuttgart. S. 5 - 135

BOECKX, R.L.; DAKSHINAMURTI, K., 1974: Biotin-mediated protein biosynthesis. Biochem. J. $140,549-556$

BONGARTZ, B, 1995: Untersuchungen an Schafen zum ruminalen Abbau und Abfluss freier und geschützter Nicotinsäure sowie zu deren Wirkungen auf Parameter des mikrobiellen Stoffwechsels im Pansensimulationssystem RUSITEC. Diss. Sc. agr., Göttingen

Bonhomme, A.; Durand, M.; QuintanA, C., Halpern, S., 1982: Influence du cobalt et de la vitamine $\mathrm{B}_{12}$ sur la croissance et la survive des ciliés du rumen in vitro et fonction de la population bacterienne. Reprod. Nutr. Dévelop. 22, 107 - 122

BONJOUR, J.-P., 1991: BIOTIN. IN: MACHLIN, L.J. (ED.): Handbook of vitamins. $2^{\text {nd }}$ edition. Marcel Dekker Inc., New York, Basel, $393-427$

Bonomi. A.; Quarantelli, A.; SABbioni, A.; SuperchI, P., 1996: Dairy cattle ration integration with rumen-protected biotin. Effects on production and reproductive efficiency (experimental contribution). La Rivista Di Scienza Dell’ Alimentazione 25 (1), 49 - 68 
BRADY, R.N.; RUIS, H.; MCCORMICK, D.B.; WRIGHT, L.D., 1966: Bacterial degradation of biotin. Catabolism of 14C-biotin and its sulfoxides. J. Biol. Chem. 241, $4717-4721$

BRANDT, M., 1979: Versuche zur Quantifizierung der mikrobiellen Proteinsynthese im Pansen (mit Hilfe von ${ }^{15} \mathrm{~N}$ ) bei Verwendung harnstoffhaltiger Rationen. Diss. sc. agr., Kiel

BRANDT, M.; RohR, K.; Lebzien, P., 1980: Bestimmung des endogenen Protein-N im Duodenalchymus von Milchkühen mit Hilfe von ${ }^{15} \mathrm{~N}$. Z. Tierphysiol., Tierernährg. u. Futtermittelkde. 44, 26

BRINKMANN, J., 1991: Verdauungsphysiologische In-vitro- und In-vivo-Untersuchungen zum Einfluss von freien, veresterten und verseiften Palmfettsäuren. Diss. sc. agr. , Göttingen

BROOKS, P.H.; SMITH, D.A.; IRWIN, V.C.R., 1977: Biotin-supplementation of diets; the incidence of foot lesions, and the reproductive performance of sows. Vet. Rec. 101, $46-50$

BRYANT, K.L.; KoRnEgAY, E.T.; KNIGHT, J.W; WebB, K.E.; NOTTER, D.R., 1985a: Supplemental biotin for swine. I. Influence on feedlot performance, plasma biotin and toe lesions in developing gilts. J. Anim. Sci. 60, $136-144$

BRyANT, K.L.; Kornegay, E.T.; KNIGHT, J.W; WebB, K.E.; NotTer, D.R., 1985b: Supplemental biotin for swine. II. Influence of supplementation to corn- and wheat-based diets on reproductive performance and various biochemical criteria of sows during four parities. J. Anim. Sci. 60, $145-153$

BRYANT, K.L.; Kornegay, E.T.; KNIGHT, J.W; WebB, K.E.; NOtTER, D.R., 1985c: Supplemental biotin for swine. III. Influence of supplementation to corn- and wheat-based diets on the incidence and severity of toe lesions, hair and skin characteristics and structural soundness of sows housed in confinement during four parities. J. Anim. Sci. 60, 154-162

BUENROSTO, J.L.; KRATZER, F.H., 1984: Use of plasma and egg yolk biotin of white leghorn hens to assess biotin availability from feedstuffs. Poultry Sci. 63, $1563-1570$

CAlhoun, W.K.; BeChTEL, W.G.; Bradley, W.B., 1958: The vitamin content of wheat, flour and bread. Cereal Chem. 35, 350 - 359 
Campell, J.; Greenough, P.R.; Petrie, L., 2000: The effects of dietary biotin supplementation on vertical fissures of the claw wall in beef cattle. Can. Vet. J. 41, $690-694$

CHEN, M.; WOLIN, M.J., 1977: Influence of $\mathrm{CH}_{4}$ production by Methanobacterium ruminantium on the fermentation of glucose and lactate by Selenomonas ruminantium. Appl. Environ. Microbiol. 34, 756 - 759

CHRISTNER, J.E.; SCHLESINGER, M.J.; COON, M.J., 1964: Enzymatic activation of biotin. J. Biol. Chem. 239, $3997-4002$

COENEN, G., 1988: In vitro-Untersuchungen mit dem RUSITEC-System zum Einfluss unterschiedlicher Fett-Stärke-Kombinationen auf verschiedene Fermentationsparameter von Pansenmikroben. Diss. sc. agr. , Göttingen

COLEMAN, G.S., 1975: The interrelationship between rumen ciliate protozoa and bacteria. In: MCDONALD, I.W.; WARNER, A.C.I (EDS.): Digestion and metabolism in the ruminant. Proc. $4^{\text {th }}$ Int. Symp. Ruminant metabolism, Sydney, $149-164$

Comben, N.; ClaRK, R.J.; SUtheRLAND, D.J.B., 1984: Clinical observations on the response of equine hoof defects to dietary supplementation with biotin. Vet. Rec. 115, 642 - 645

CONWAY, E.J.; O'MALLEY, E., 1942: Microdiffusion methods. Ammonia and urea using buffered absorbents (revised methods for ranges greater than $10 \mu \mathrm{g} \mathrm{N}$ ). Biochem. J. 36, 655 $-661$

CZERKAWSKI, J.W.; BRECKENRIDGE, G., 1977: Design and development of a long-term rumen simulation technique (RUSITEC). Br. J. Nutr. 38, 371 - 384

CzerkaWSKI, J.W., 1986: An introduction to rumen studies. Pergamon Press, Oxford, New York, Toronto, Sydney, Frankfurt

DA CostA Gomez, C., 1999: In vitro-Untersuchungen zur reduktiven Acetogenese im Pansen. Diss. sc. agr., Göttingen

DAKSHINAMURTI, K.; LITVAK, S., 1970: Biotin and protein synthesis in rat liver. J. Biol. Chem. $245,5600-5605$ 
DAKSHINAMURTI, K.; ChAUHAN, J., 1989: Biotin. Vitamines and hormones 45, 337 -384

Delost, P.; TERROINE, T., 1955: Les troubles endocriniens dans la carence en biotine. Arch. Sci. Physiol. 10, 17 - 52

DEMEYER, D.I.; NEVEL, C.J. VAN, 1979: Effect of defaunation on the metabolism of rumen microorganisms. Br. J. Nutr. 42, $515-524$

DemeYeR, D.I.; VANDE WOestyne, M.; PRINS, R., 1995: Mikrobiologie der Verdauung. In: Abel, HJ; Flachowsky, G.; Jeroch, H.; Molnar, S. (EDS.) Nutztierernährung. Gustav Fischer Verlag, Jena, $185-206$

DIFCO, 1998: Difco manual, $11^{\text {th }}$ Edition, Sparks/Maryland

DISTL, O. ; SCHMID, D.1994: Einfluss einer Zufütterung von Biotin auf die Klauenform, -härte und -gesundheit bei Milchkühen. Tierärztliche Umschau 49, 581 - 588

Dohme, F.; Machmüller, A.; Estermann, B.L.; Pfister, P.; Wasserfallen, A., Kreuzer, M., 1999: The role of the rumen ciliate protozoa for methane suppression caused by coco-nut oil. Letters in Applied Microbiology 29, 187 - 192

Dong, Y.; BAE, H.D.; McAllister, T.A.; MAthison, G.W.; Cheng, K-J., 1997: Lipid-induced depression of methane production and digestibility in the artificial rumen system (RUSITEC). Can. J. Anim. Sci. 77, $269-278$

DROCHNER, W., 1984: Proc. $2^{\text {nd }}$ TAD Veterinary Symposium „Cattle and pig diseases“, Cuxhaven, $99-109$

Du Vigneuad, W.; Melville, D.B.; Folkers, K.; Wolf, D.E.; Mozingo, R., 1942: The structure of biotin: A study of desthiobiotin. J. Bio. Chem. 146, $475-485$

EADIE. J.M., MANN, S.O., 1970: Development of the rumen microbial population: high starch diets and instability. In: PHILLIPSON, A.T. (ED.): Proc. $3^{\text {rd }}$ Int. Symp. Physiology of digestion and metabolism in the ruminant. Oriel Press. Newcastle upon Tyne, 335 - 347 
EADIE, J.M.; SHAND, W.J., 1982: The effect of Synperonic NP9 upon ciliate-free and faunated sheep. Proc. Nutr. Soc. 40, 113A

ENGLING, F.P., 1988: Überprüfung verschiedener Gärfutter unter ernährungsphysiologischen Aspekten: Ein Beitrag zur Erweiterung der Basis wirtschaftseigener Futtermittel in der Milchviehfütterung. Diss. sc. agr. , Göttingen

FDA, 1996: (FoOd AND DRUg Administration / ANGYAL, G. (ED.)) Methods for the microbiological analysis of selected nutrients. AOAC International, Gaithersburg/Maryland

FfloukES, D.; LeNG, R.A., 1984: Dynamics of protozoa in the rumen of cattle. Anim. Prod. Austr. 15, 679

Fitzgerald, T.; Norton, B.W.; Elliot, R.; Podlich, H.; Svendsen, O.L., 2000: The influence of long-term supplementation with biotin on the prevention of lameness in pasture fed dairy cows. J. Dairy Sci. 83, $338-344$

FLACHOWSKY, G., 1999: Zur Vitaminversorgung von Milchkühen. Übers. Tierernährg. 27, $29-64$

FRIGG, M.; BrUBACHER, G., 1976: Biotin deficiency in chicks fed a wheat based diet. Int. J. Vit. Nutr. Res. 46 (3), $314-321$

FRIGG, M.; RoHR, H.P.; 1978: Stereological composition of the liver of biotin deficient and control chicks. Int. J. Vit. Nutr. Res. 48 (4), 348 - 351

FRIGG, M.; HARTMANN, D.; StRAUB, O.C., 1993a: Biotin kinetics in serum of cattle after intravenous and oral dosing. Int. J. Vitam. Nutr. Res. 63, $36-40$

FRIGG, M.; StRAUB, O.C.; HARTMANN, D., 1993b: The bioavailability of supplemental biotin in cattle. Int. J. Vitam. Nutr. Res. 63, $122-128$

Fritsche, A.; MAthIS, G.A.; Althaus, F.R., 1991: Pharmakologische Wirkung von Biotin auf Epidermiszellen. Schweiz. Arch. Tierheilk. 133, 277 - 283 
Geyer, H.; Schulze, J.; Streiff, K.; TAgwerker, F.; Völker, L., 1984: Der Einfluss des experimentellen Biotinmangels auf Morphologie und Histochemie von Haut und Klauen des Schweines. Zbl. Vet. Med. (A) 31, $519-538$

GfE, 1995: Ausschuss für Bedarfsnormen der Gesellschaft für Ernährungsphysiologie. Zur Energiebewertung beim Wiederkäuer. Proc. Soc. Nutr. Physiol. 4, $121-123$

GIRARD, C.L., 1998: B-complex vitamins for dairy cows: a new approach. Can. J. Anim. Sci. 78 (S), $71-90$

Grain, J.; Groliere, C.A.; Senaud, J.; Puytorac, P. De; Zainab, B.; JouAny, J.P., 1979: Ciliate implantation in the rumen: Influence of inoculated genus and type of diet. Ann. Rech. Vet. 10, $264-267$

GYÖRGY, P.; ZILLIKEN, F.-W.,1974: Biotin. In: AMMON, R.; DIRSCHERL, W. (EDS.): Fermente, Hormone, Vitamine und die Beziehungen dieser Wirkstoffe zueinander. 3. Auflage. Band III/I. Georg-Thieme-Verlag, Stuttgart, $766-807$

HALL, H.H.; CURTIS, J.J.; SheKLEION, M.C., 1952: The B-complex vitamin composition of corn cobs. Cereal Chem. 29, $156-160$

HARMEYER, J., 1965: Zur Methodik experimenteller Untersuchungen an Pansenprotozoen. Zbl. Vet. Med. (A) 12, $841-880$

HARMON, D.L.; RICHARDS, C.J., 1997: Considerations for gastrointestinal cannulations in ruminants. J. Anim. Sci. 75, $2248-2255$

HARVEY, W.R., 1970: Estimation of variance and covariance components in the mixed model. Biometrics 26, $485-504$

Hayes, B.W.; Mitchell JR., G.E..; LitTle, C.O.; Bradley, N.W., 1966: Concentrations of Bvitamins in ruminal fluid of steers fed different levels and physical forms of hay and grain. J. Anim. Sci. 25, $539-542$ 
Hedges, V.J.; Blowey, R.W.; Packington, A.J.; O’Callaghan, C.J.; Green, L.E., 2001: A longitudinal field trial of the effect of biotin on lameness in dairy cows. J. Dairy Sci. 84, 1969 - 1975

HILLMAN, K.; LLOYD, D.; WILLIAMS, A.G., 1985: Use of a portable quadrupole mass spectrometer for the measurement of dissolved gas concentrations in bovine rumen liquor in situ. Current Microbiol. 12, $335-340$

HochSTETTER, T.; 1998: Die Hornqualität der Rinderklaue unter Einfluss der Biotinsupplementierung. Diss. Vet. Med., Berlin

Hoff-Jörgensen, E.; MoustgaARd, J; Möller, P., 1952: The content of B-vitamins in some ordinary Danish feedstuffs. (The application of an improved medium for vitamin determination with L. casei). Acta Agric. Scand. 2, 305 - 311

Huguchi, H.; Maeda, T.; KuWAno, A.; KaWAl, K.; Kasamatsu, M.; Nagahata, H., 2002: Effect of biotin supplementation on serum biotin concentration and physical property of hoof horn in Holstein cows. Proc. $22^{\text {nd }}$ World Buiatrics Congress, Hannover, 241

Hunkeler, A.; Lischer, Ch.-J.; GeYer, H.; OSSEN, P., 1996: The effect of biotin in the treatment of uncomplicated claw lesions with exposed corium in dairy cows. Proc. $9^{\text {th }}$ Internat. Symp. on disorders of the ruminant digit, Jerusalem

HYMES, J.; WOLF, B., 1996: Biotinidase and its role in biotin metabolism. Clin. Chim. Acta 255, $1-11$

ITABASHI, H.; KOBAYASHI, T.; MATSUMOTO, M., 1984: The effects of rumen ciliate protozoa on energy metabolism and some constituents in rumen fluid and blood plasma of goats. Japan. J. Zootech. Sci. 55, $248-256$

IWAHARA, S.; MCCORMICK, D.B.; WRIGHT, L.D.; LI, H.-C., 1969: Bacterial degradation of biotin. III. Metabolism of ${ }^{14} \mathrm{C}$-Carbonyl-labeled biotin. J. Biol. Chem. 244 (6), $1393-1398$

JOSSEK, H.; ZENKER, W.; GeYER, H., 1995: Hoof horn abnormalities in Lippizaner horses and the effect of dietary biotin on macroscopic aspects of hoof horn quality. Equine Vet. 27 (3), $175-182$ 
JOUANY, J.P., 1978: Contribution à l'étude des protozoaires ciliés du rumen: leur dynamique, leur rôle dans la digestion et leur intérèt pour le ruminant. Thèse doct., Clermont-Ferrand

JOUANY, J.P.; SENAUD, J., 1982: Influence des ciliés du rumen sur la digestion de différents lucides chez le mouton. I. Utilisation des glucides pariétaux (cellulose et hemicelulose) et de I’amidon. Reprod. Nutr. Dévelop. 22, 735 - 752

JOUANY, J.P.; DEMEYER, D.I.; GRAIN, J., 1988: Effect of defaunating the rumen. Anim. feed Sc. Techol. 21, $29-265$

JOUANY, J.P., 1996: Effect of rumen protozoa on nitrogen utilization by ruminants. J. Nutr. 126, 1335S - 1346S

Jungermann, K.; Möller, H., 1984: Gluconeogenese. In: Jungermann, K.; Möller, H.: Biochemie. 1. Auflage. Springer-Verlag, Berlin, Heidelberg, New York, $300-304$

KEMPSON, S.A., 1990: Ultrastructural observation on the response of equine hoof defects to dietary supplementation with farrier's formula. Vet. Rec. 127, $494-498$

KIRCHGESSNER, M., 1997: Tierernährung. Leitfaden für Studium, Beratung und Praxis. 10. Auflage. Verlagsunion Agrar, Frankfurt/Main, München, Münster-Hiltrup, Wien, Wabern, S. 121

KLÜNTER, A.-M., STEINBERG, W., 1993: Effect of supplementation of biotin on the concentration of biotin in plasma and milk in the dairy cow. Proc. Soc. Nutr. Physiol. 1, 67 (Abs.)

KOFLER, J., 2001: Beziehung zwischen Fütterung und Gliedmaßenerkrankungen bei Rindern - Diagnostik, Therapie und Prophylaxe. Proc. 28. Viehwirtschaftliche Fachtagung, Bundesanstalt für alpenländische Landwirtschaft (BAL), Gumpenstein

KOLB, E, 1989: (ED.): Lehrbuch der Physiologie der Haustiere. 5. Auflage. VEB Gustav Fischer Verlag, Jena

Kolb, E.; Seehawer, J.; Steinberg, W., 1999: Significance, utilization and application of Bvitamins in ruminants. 2. Niacin, pantothenic acid and biotin, folic acid and vitamin B12. Der praktische Tierarzt 80, $207-220$ 
KOPINSKI , J.S.; LEIBHOLZ, J.; BYRDEN, W.L., 1989: Biotin studies in pigs. 3. Biotin absorption and synthesis. Br. J. Nutr. 62, $767-772$

KRASTANOVA, M., 1993: Untersuchungen zum Einsatz von "geschütztem" Rapsschrot in der Milchviehfütterung. Diss. sc. agr., Göttingen

KREUZER, M., 1986: Methodik und Anwendung der Defaunierung beim wachsenden Wiederkäuer. J. Vet. Med. Ser. A 33, 721 - 745

KÜMPER, H., 1998: Entstehungsweise, Therapie und Prophylaxe von Gliedmaßenerkrankungen bei Kühen. 4: Seminar der 3. Berlin-Brandenburgischen Rindertage, 08.10.1998, Berlin

KURIHARA, Y.; TAKECHI, T.; SHIBATA, P., 1978: Relationship between bacteria and ciliate protozoa in the rumen of sheep fed on a purified diet. J. Agric. Sci. Camb. 90, 373-381

LAMPEN, J.O.; BAHLER, G.P.; PETERSON, W.H., 1942: The occurrence of free and bound biotin. J. Nutr. 23, $11-17$

LANGENHOFF, M., 2002: Futtermittelkundliche Bewertung von zwei Silomaishybriden bei Wiederkäuern. Diss. med. vet., Hannover

LARDinois, C.C.; Mills, R.C.; ElvehJem, C.A.; HART, E.B., 1944: Rumen synthesis of the vitamin B complex as influenced by ration composition. J. Dairy Sci. 27, 579 - 583

LATHAM. M.J.; ShARPE, E.; SUTTON, J.D., 1971: The microbial flora of the rumen of cows fed hay and high cereal rations and its relationship to the rumen fermentation. J. Appl. Bact. $34,425-434$

Lebzien, P.; RohR, K.; SchAFFT, H., 1983: Vergleichende Untersuchungen über die NUmsetzungen im Verdauungstrakt von Milchkühen bei Verfütterung von Weizen bzw. Körnermais. Landbauforschung Völkenrode 33, 57 - 64

LeBZIEN, P.; VoIGT, J., 1999: Calculation of utilizable crude protein at the duodenum of cattle by two different approaches. Arch. Anim. Nutr. 52, $363-369$ 
LeHNinger, A.L., 1987: Biochemie. 2. Auflage. Verlag Chemie, Weinheim, Deerfield Beach, Basel

LENG, R.A., NOLAN, J.V., 1984: Nitrogen metabolism in the rumen. J. Dairy Sci. 67, 1072 1089

LEINMÜLLER, E.; MeNKE, K.-H., 1986: Wirkungen einer Defaunierung des Panseninhalts. Übers. Tierernähr. 14, $75-100$

Lischer, Ch. J.; Koller, U.; Geyer, H.; Mülling, Ch.; Schulze, J.; OSSENT, P., 2002: Effect of therapeutic dietary biotin on the healing of uncomplicated sole ulcers in dairy cattle $-\mathrm{a}$ double blinded controlled study. Vet. J.,163, $51-60$

LOTTHAMMER, K.H., 2000: Beziehungen zwischen Leistungsniveau, Gesundheit, Fruchtbarkeit und Nutzungsdauer bei Milchrindern. Tier und Ernährung 1/2000

LYNEN, F., 1967: The role of biotin-dependent carboxylations in biosynthetic relations. Biochem. J. 102, $381-400$

MAckie, R.I.; GILChrist, F.M.C.; Roberts, A.M.; Hannah, P.E.; SchWARTZ, H.M., 1978: Microbiological and chemical changes in the rumen during stepwise adaption of sheep to high concentrate diets. J. Agric. Sci. Camb. 90, $241-254$

MACKIE, R.I.; GILCHRIST, F.M.C.; HEATH, S., 1984: An in vivo study of ruminal microorganisms influencing lactate turnover and its contribution to volatile fatty acid production. J. Agric. Sci. Camb. 103, $37-51$

MAgerison, J.K.; WinkLeR, B.; PenNY, B., 2002: The effect of supplementary biotin on milk production in Holstein cows. Proc. $22^{\text {nd }}$ World Buiatrics Congress, Hannover, 219

Majee, D.N.; Schwab, E.C.; Bertics, S.J.; Seymour, W.M.; Shaver, R.D., 2003: Lactation performance by dairy cows fed supplemental biotin and a B-vitamin blend. J. Dairy Sci. 86, $2106-2112$

MATTHÉ, A., 2001: Nährstoffumsetzungen im Verdauungstrakt des Rindes nach Einsatz unterschiedlicher Mengen an Mais- oder Weizenstärke. Diss. agr. , Giessen 
MAYNARD, L.; LOOSLI, J.K.; HINTZ, H.F.; WARNER, R.G., 1979: Animal nutrition. $7^{\text {th }}$ edition. McGraw-Hill Book Co. Inc. . New York, London

MATsumoto, M; Kobayashi, T.; TAKenAKA, A.; ITABASHI, H., 1991: Defaunation effects of medium-chain fatty acids and their derivates on goat rumen protozoa. J. Gen. Appl. Microbiol. 37, $439-445$

McCoRmICK, D.B., 1975: Biotin. Nutr. Rev. 33 (4), 97 - 102

McCoy, T.A.; BostWICK, D.G.; DEVICH, A.C., 1958: Some effects of Phophorus on the development, the B-vitamin content and the inorganic composition of oats. Plant Physiol. 26, $784-791$

McDougALL, E.I., 1948: Studies on ruminant saliva. 1. The composition and output of sheep's saliva. Biochem. J. 43, 99 - 109

MCDOWELL, L.R., 1989: Vitamins in animal nutrition. Comparative aspects to human nutrition. Academic Press Inc. . San Diego, London. 275 - 292 und 475 - 476

MCELROY, L.W., JUKES, T.H., 1940: Formation of the anti egg white injury factor (biotin) in the rumen of the cow. Proc. Soc. Expt. Biol. And Med. 45, $296-297$

MEYER, J.H.F.; WALT, S.I. VAN DER; SCHWARTZ, H.M., 1986: The influence of diet and protozoal numbers on the breakdown and synthesis of protein in the rumen of sheep. J. Anim. Sci. $62,509-520$

MeYer, K.; Köster, A.; Mülling, Ch.; Scaife, J.R.; BiRnie, M.; BudRas, K.-D., 2002: Influence of biotin supplementation on the fatty acid pattern in bovine claw horn and its role for function and integrity of the bovine hoof. Proc. $22^{\text {nd }}$ World Buiatrics Congress, Hannover, 240

MidLA, L.T.; Hoblet, K.H.; WeISS, W.P.; Moeschberger, M.L., 1998: Supplemental dietary biotin for prevention of lesions associated with aseptic subclinical laminitis (pododermatitis aseptica diffusa) in primiparous cows. Am. J. Vet. Res. 59, 733 - 739 
MILLER, B.L.; MEISKE, J.C.; GOODRICH, R.D., 1986: Effects of grain source and concentrate level on B-vitamin production and absorption in steers. J. Anim. Sci. 62,473 - 483

Milligan, L.P.; ASPLUND, J.M.; RobBleE; A.R., 1967: In vitro studies on the role of biotin in the metabolism of rumen microorganisms. Can. J. Anim. Sci. 47, $57-64$

Mock, D.M., 1999: Biotin status: which are valid indicators and how do we know? J. Nutr. $129,498 S-503 S$

Mock, D.M.; QUIRK, J.G.; Mock, N.I., 2002: Marginal biotin deficiency during normal pregnancy. Am. J. Clin. Nutr. 75, $295-299$

MüLLING, CH., 1998: The use of nutritional factors in prevention of claw diseases - biotin as an example for nutritional influences on formation and quality of hoof horn. Proc. $11^{\text {th }} \mathrm{In}$ tern. Symp. on disorders of the ruminant digit, Parma, $78-80$

Mülling, Ch.; Bragulla, H.H.; Reese, S.; Budras, K.D.; Steinberg, W., 1999a: How structures in bovine hoof epidermis are influenced by nutritional factors. Anat. Histol. Embryol. 28, $103-108$

Mülling, Ch.; Bragulla, H.H.; BudRas, K.D., 1999b: Biotinmangel bei Kälbern. In: SCHUBERT, R.; FLACHOWSKY, G.; BITSCH, R.; JAHREIS, G., (EDS.): Vitamine und Zusatzstoffe in der Ernährung von Mensch und Tier. 7. Symposium, Jena, 89 - 96

NEVEL, C.J. VAN; DEMEYER, D.I., 1981: Effect of methane inhibitors on the metabolism of rumen microbes in vitro. Arch. Tierernähr. 31, $141-151$

NYHAN, W.L., 1987: Inborn errors of biotin metabolism. Arch. Derm. 123, 1696a - 1698a

OldhAM, J.D.; SUtTON, J.D.; McAlLAN, A.B., 1979: Protein digestion and utilization by dairy cows. Ann. Rech. Vet. 10, $290-293$

ORPIN, C.G.; LETCHER, A.L., 1978: Some factors controlling the attachment of rumen holotrich protozoa Isotricha intestinalis and I. prostoma to plant particles in vitro. J. Gen. Microbiol. $106,33-40$ 
ØRSkOV, E.R.; FlATt, W.P.; MOE, P.W., 1968: Fermentation balance approach to estimate extent of fermentation and efficiency of volatile fatty acid formation in ruminants. J. Dairy Sci. 51, $1429-1435$

ØRSkOV, E.R.; FraSER, C.; McDonALD, I., 1971: Digestion of concentrates in sheep. 3. Effects of rumen fermentation of barley and maize diets on protein digestion. Br. J. Nutr. 26, $477-486$

PALAFOX, A.L.; REID, D.F., 1961: Amino acid and vitamin content of selected poultry feedstuffs produced in Hawaii. Agric. Exp. Stat. Tech. Bull. No. 48

Paulose, C.S.; ThliVeris, J.A.; VISWANATHAN, M.; DAKShINAMURTI, K., 1989: Testicular function in biotin-deficient adult rats. Horm. Metab. Res. 21, $661-665$

Petrelli, F.; Moretti, P.; Campanati, G., 1981: Studies on the relationship between biotin and the behaviour of $B$ and $T$ lymphocytes in the guinea pig. Experimentia 37, $1204-$ 1206

Pötzsch, C.J.; Collins, V.J.; Blowey, R.W.; PACkington, A.J.; GReen, L.E., 2003: The impact of parity and duration of biotin supplementation on white line disease lameness in dairy cattle. J. Dairy Sci. 86,2577 - 2582

REICHL, J., 1961: Relations of the occurrence of protozoa in the sheep rumen to feed and feed utilization. Proc. $1^{\text {st }}$ Int. Congr. Protozoology, 537 - 541

ROCHE , 2002: http://www.roche-vitamins.com/home/what/what-anh/what-anh-vitamins/whatanh-biotin

Rohr, K.; Brandt, M.; Castrillo, O.; Lebzien, P.; Assmus, G., 1979: Der Einfluss eines teilweisen Ersatzes von Futterprotein durch Harnstoff auf den Stickstoff- und Aminosäurefluss am Duodenum. Landbauforschung Völkenrode 29, 32 - 40

Rohr, K.; Brandt, M.; Lebzien, P.; SchafFT, H., 1984: Measurement of duodenal flow in dairy cows by either total collection or spot sampling, using a special cannula. Can. $\mathrm{J}$. Anim. Sci. 64 (Suppl.), $116-117$ 
RomULO, B.; BIRD, S.H.; LENG, R.A., 1986: The effects of defaunation on digestibility and rumen fungi counts in sheep fed high fibre diets. Proc. Austral. Soc. Anim. Prod. 16, $327-$ 330

RUSSEL, J.B.; WALLACE, R.J., 1988: Energy yielding and consuming reactions. In: HOBSON, P.N.(ED.): The rumen microbial ecosystem. Elsevier Applied Science, London, New York, $185-215$

SAID, H.M.; REDHA, R., 1987: A carrier-mediated system for transport of biotin in rat intestine in vitro. Am. J. Physiol. 252, G 52 - G 55

SATTER, L.D.; RofFLER, R.E., 1975: Nitrogen requirement and utilization in dairy cattle. J. Dairy Sci. 58, $1219-1237$

SCHAFFT, H., 1983: Untersuchungen zur Quantifizierung des Abbaus von Futterrohprotein in den Vormägen von Milchkühen. Diss. sc. agr., Göttingen

SCHEIFINGER, C.C.; WOLIN, M.J., 1973: Propionate formation from cellulose and soluble sugars by combined cultures of Bacteroides succinogenes and Selenomonas ruminantium. Appl. Microbiol. 26, $789-795$

SCHEIFINGER, C.C., 1974: Propionate formation from cellulose and soluble sugars through interspecies interaction of Bacteroides succinogenes and Selenomonas ruminantium. PhD Thesis, University of Illinois, Urbana

SCHEIFINGER, C.C.; LINEHAN, B.; WolIN, M.J., 1975: $\mathrm{H}_{2}$ production by Selenomonas ruminantium in the presence and absence of methanogenic bacteria. Appl. Microbiol. 29, $480-$ 500

SCHMID, M.; GEYER, H., 1994: Longterm investigation for the assessment of hoof horn quality in cattle before and during biotin supplementation. Proc. $20^{\text {th }}$ Congress of the Europ. Assoc. of Vet. Anatomist, Zürich, 159

SCHREINER, J.; De RitTeR, E., 1975: Biotin content of feedstuffs. J. Agric. and Food Chem. 23, $1157-1162$ 
Scott, M.L.; NeSheim, M.C.; Young, R.J., 1982: Nutrition of the chicken. Scott, Ithaca, New York, $119-276$

ScotT, R.I.; YARlett, N.; Hillman, K.; Williams, T.N.; Williams, A.G.; Lloyd, D., 1983: The presence of oxygen in rumen liquor and its effects on methanogenesis. J. Appl. Bacteriol. $55,143-149$

SEYMOUR, W.M., 1998: Role of biotin in ruminant nutrition examined. Feedstuffs 70, $14-18$

SEYMOUR, W.M., 2001: Biotin, hoof health and milk production in dairy cows. Proc. $12^{\text {th }}$ Annual Florida Ruminant Nutrition Symposium, $70-78$

SHAVER, R.D.; BAL, M.A., 2000: Effect of dietary thiamine supplementation on milk production by dairy cows. J. Dairy Sci. 83, $2335-2340$

Slyter, L.A.; TheURER, B.C.; SOWE, J.; NoON, T.H., 1979: Effect of ruminal ammoniac concentration on nitrogen utilization by steers. J. Anim. Sci. 48, $906-912$

SMART, M.; CYMBALUK, N.F., 1997: Role of nutritional supplements in bovine lameness - review of nutritional toxicities. In: GREenough, P.R.; WEAVER, A.D.(EDS.): Lameness in cattle. $3^{\text {rd }}$ edition. W.B. Sanders, Philadelphia, $145-161$

SochA, M.T.; TOMLINSON, D.J.; JoHnSON, A.B., 2000: Improved hooves through improved trace mineral nutrition. Proc. $11^{\text {th }}$ Intern. Symp. on disorders of the ruminant digit, Parma, $67-69$

SPENCER, R.P.; BRODY, K.R., 1964: Biotin transport by small intestine of rat, hamster and other species. Am. J. Physiol. 206, $653-657$

SteinBeRG, W.; KLÜNTER, A.-M.; SCHÜEP, W., 1994: Plasma kinetics and excretion of biotin in dairy cows after intravenous and intraruminal application. Proc. Soc. Nutr. Physiol. 3, 226

STERN, M.D.; HOOVER, W.H., 1979: Methods for determining and factors affecting rumen microbial protein synthesis: A review. J.Anim. Sci. 49, 1590 - 1603 
SteRn, M.D.; BACH, A.; CALSAMIGLIA, S., 1997: Alternative techniques for measuring nutrient digestion in ruminants. J. Anim. Sci. 75, $2256-2276$

ThOMAS, B.; WALKER, H.F., 1949: The B-vitamins in grass. Empire J. Exp. Agric. 17, 170 178

TRIBBLE, L.F.; HANCOCK, J.D.; ORR, D.E., 1983: Value of supplemental biotin on reproductive performance of sows in confinement. J. Anim. Sci. 59 (Suppl. 1), 245

USHIDA, K.; MIYATAKI, A.; KAWASHIMA, R., 1986: Effect of defaunation on ruminal gas and SCFA production in vitro. Japan. J. Zootech. Sci. 57, 71 - 77

Valdez, R.E.; Alvarez, F.J.; Ferreiro, H.M.; Guerra, F.; lopez, J.; Priego, A.; Blackburn, T.H.; LENG, R.A.; PRESTON, T.R., 1977: Rumen function in cattle given sugar cane. Trop. Anim. Prod. 2, $260-272$

VEIRA, D.M.; IVAN , M.; JUI, P.Y., 1981: The effects of partial defaunation on rumen metabolism in sheep. Can J. Anim. Sci. 61, $1086-1087$

VEIRA, D.M.; IVAN, M.; JUI, P.Y., 1983: Rumen ciliate protozoa: effects on digestion in the stomach of sheep. J. Dairy Sci. 66, $1015-1022$

VEIRA, D.M.; IVAN, M.; JUI, P.Y., 1984: The effects of ciliate protozoa on the flow of amino acids from the stomach of sheep. Can. J. Anim. Sci. 64 (supplement), $22-23$

Voigt, J.; Steger, H., 1967: Zur quantitativen Bestimmung von Ammoniak, Harnstoff und Ketokörpern in biologischem Material mit Hilfe eines modifizierten Mikrodiffusionsgefäßes. Arch. Tierernährung 17, $289-293$

Voigt, J.; HAgemeister, H.; KuHla, S.; Schoenhusen, U.; Weber, G.M., 2000: The effect of biotin supplementation on claw health in dairy cattle kept under field conditions. Proc. $11^{\text {th }}$ Intern. Symp. on disorders of the ruminant digit, Parma, $292-294$

WAKIL, S.J.; GIBSON, D.M., 1960: Studies on the mechanism of fatty acid synthesis. VII. The participation of protein-bound biotin in the biosynthesis of fatty acids. Biochim. Biophys. Acta 41, $122-129$ 
Watanabe, T.; Endo, A., 1984: Teratogenic effects of avidin-induced biotin deficiency in mice. Teratology 30, 91- 94

WebB, N.G.; Penny, R.H.C.; Johnston, A.M., 1984: Effect of a dietary supplement of biotin on pig hoof horn strength and hardness. Vet. Rec. 114, 185 - 189

Wegner, M.I., Booth, A.N., ElvehJem, C.A.; HART, E.B., 1941: Rumen synthesis of vitamin B complex on natural rations. Proc. Soc. Expt. Biol. And Med. 47, 90 - 94

WeISS, W.P, ZIMMERLY, C.A., 2000: Effects of biotin on metabolism and milk yield of dairy cows. Proc. $62^{\text {nd }}$ Cornell Nutrition Conference for Feed Manufacturers, $22-30$

WERTZ, P.W.; DOWNING, D.T., 1983: Ceramides of pig epidermis: Structure determination. J. Lipid Res. 24, 759 - 765

WETZEL, R., 1951: Verbesserte McMaster-Zählkammer zum Auszählen von Wurmeiern. Tierärztl. Umsch. 6, $209-210$

WHITEHEAD, C.C., 1991: Biotin in der Tierernährung. F.Hoffmann- La Roche AG, Basel

Whitelaw, F.G.; EADIE, J.M.; MANN, S.O.; ReID, R..S., 1972: Some effects of rumen ciliate protozoa in cattle given restricted amounts of a barley diet. Br. J. Nutr. 27, 425-437

WhitelaW, F.G.; EADIE, J.M.; BRUCE, L.A.; SHAND, J.W., 1984: Methane formation in faunated and ciliate-free cattle and its relationship with rumen volatile fatty acid proportions. Br. J. Nutr. 52, $261-275$

Williams, A.G., Coleman, G.S., 1992: The rumen protozoa. Brock/Springer Series in Contemporary Bioscience. Springer Verlag, Berlin, Heidelberg, New York

WILLIAMS, C.H.; DAVID, D.J.; JISMAA, O.; 1962: The determination of chromic oxide in faeces samples by atomic absorption spectrophotometry. J. Agric. Sci. 59,381 - 385

Wolf, B.; HEARD, G.; McVoY, J.R.S.; RAETZ, H.M., 1984: Biotinidase deficiency: the possible role of biotinidase in the processing of dietary protein-bound biotin. J. Inherit. Metab. Dis. 7 (suppl. 2), $121-122$ 
Wood, H.G.; BARDEN, R.E., 1977: Biotin enzymes. Ann. Rev. Biochem. 46, 385 - 413

WRIGHT, D.E.; CURTIS, M.W., 1976: Bloat in cattle. XLII. The action of surface-active chemicals on ciliate protozoa. N. Z. J. agric. Res. 19, $19-23$

ZEMPLENI, J., MOCK, M.D., 1999: Biotin biochemistry and human requirements. J. Nutr. Biochem. 10, $128-138$

ZemPLENI, J., Mock, M.D., 2000: Marginal biotin deficiency is teratogen. Proc. Soc. Exp. Biol. Med. 223, 14

ZIMMERLY, C.A.; WEISS, W.P., 2001: Effects of supplemental dietary biotin on performance of Holstein cows during early lactation. J. Dairy Sci. 84, 498 - 506

ZinN, R.A., OWEnS, F.N.; StUART, R.L., Dunbar, J.R.; NORMANN, B.B., 1987: B-vitamin supplementation of diets for feedlot calves. J. Anim. Sci. 65, $267-277$ 


\section{Anhang}

A1 Mittlere Substrateinwaage der in vitro-Untersuchungen [g T/d]

\begin{tabular}{|c|c|c|c|c|c|c|c|c|c|c|c|}
\hline \multicolumn{2}{|c|}{ Fermenter } & \multirow{2}{*}{1} & \multirow{2}{*}{2} & \multirow{2}{*}{3} & \multirow{2}{*}{4} & \multirow{2}{*}{5} & \multirow{2}{*}{6} & \multirow{2}{*}{7} & \multirow{2}{*}{8} & \multirow{2}{*}{9} & \multirow{2}{*}{10} \\
\hline Durchg. & Subs. & & & & & & & & & & \\
\hline 1 & $\begin{array}{l}H \\
W \\
M\end{array}$ & 10,91 & 10,91 & $\begin{array}{l}7,27 \\
3,59\end{array}$ & $\begin{array}{l}7,27 \\
3,59\end{array}$ & $\begin{array}{l}7,27 \\
3,69\end{array}$ & $\begin{array}{l}7,27 \\
3,69\end{array}$ & $\begin{array}{l}2,50 \\
4,94\end{array}$ & $\begin{array}{l}2,50 \\
4,94\end{array}$ & $\begin{array}{r}2,50 \\
5,09\end{array}$ & $\begin{array}{l}2,50 \\
5,09\end{array}$ \\
\hline 2 & $\begin{array}{l}H \\
W \\
M\end{array}$ & 10,93 & 10,93 & $\begin{array}{l}7,31 \\
3,61\end{array}$ & $\begin{array}{l}7,31 \\
3,64\end{array}$ & $\begin{array}{l}7,30 \\
3,73\end{array}$ & $\begin{array}{l}7,29 \\
3,73\end{array}$ & $\begin{array}{l}2,50 \\
4,94\end{array}$ & $\begin{array}{l}2,50 \\
4,94\end{array}$ & $\begin{array}{r}2,50 \\
5,09\end{array}$ & $\begin{array}{l}2,50 \\
5,09\end{array}$ \\
\hline 3 & $\begin{array}{l}H \\
W \\
M\end{array}$ & 10,92 & 10,95 & $\begin{array}{l}7,29 \\
3,60\end{array}$ & $\begin{array}{l}7,30 \\
3,60\end{array}$ & $\begin{array}{l}7,28 \\
3,70\end{array}$ & $\begin{array}{l}7,28 \\
3,70\end{array}$ & $\begin{array}{l}2,51 \\
4,94\end{array}$ & $\begin{array}{l}2,50 \\
4,94\end{array}$ & $\begin{array}{r}2,50 \\
5,09\end{array}$ & $\begin{array}{l}2,50 \\
5,09\end{array}$ \\
\hline 4 & $\begin{array}{l}\mathbf{H} \\
\mathbf{W} \\
M\end{array}$ & 10,93 & 10,93 & $\begin{array}{l}7,28 \\
3,60\end{array}$ & $\begin{array}{l}7,29 \\
3,60\end{array}$ & $\begin{array}{l}7,29 \\
3,71\end{array}$ & $\begin{array}{l}7,29 \\
3,71\end{array}$ & $\begin{array}{l}2,50 \\
4,94\end{array}$ & $\begin{array}{l}2,50 \\
4,94\end{array}$ & $\begin{array}{l}2,50 \\
5,09\end{array}$ & 2,50 \\
\hline 5 & $\begin{array}{l}H \\
W \\
M\end{array}$ & 10,91 & 10,91 & $\begin{array}{l}7,28 \\
3,59\end{array}$ & $\begin{array}{l}7,27 \\
3,59\end{array}$ & $\begin{array}{l}7,28 \\
3,70\end{array}$ & 3,70 & $\begin{array}{l}2,50 \\
4,94\end{array}$ & $\begin{array}{l}2,50 \\
4,94\end{array}$ & $\begin{array}{r}2,50 \\
5,09\end{array}$ & 5,09 \\
\hline
\end{tabular}

Durchg. = Durchgang, Subs. $=$ Substrat, $\mathrm{H}=\mathrm{Heu}, \mathrm{W}=$ Weizen, $\mathrm{M}=$ Mais

A2

Mittlere Mengen an festen Inkubationsrückständen der in vitroUntersuchungen [g T/d]

\begin{tabular}{|c|c|c|c|c|c|c|c|c|c|c|}
\hline \hline Fermenter & $\mathbf{1}$ & $\mathbf{2}$ & $\mathbf{3}$ & $\mathbf{4}$ & $\mathbf{5}$ & $\mathbf{6}$ & $\mathbf{7}$ & $\mathbf{8}$ & $\mathbf{9}$ & $\mathbf{1 0}$ \\
\cline { 1 - 4 } Durchg. & & & & & & & & & & \\
\hline \hline $\mathbf{1}$ & 7,49 & 7,73 & 6,47 & 6,68 & 7,09 & 7,55 & 3,59 & 3,62 & 4,46 & 4,50 \\
\hline $\mathbf{2}$ & 8,10 & 7,64 & 7,30 & 7,13 & 7,48 & 7,66 & 3,75 & 3,69 & 4,50 & 4,41 \\
\hline $\mathbf{3}$ & 7,76 & 7,39 & 6,77 & 7,05 & 7,06 & 7,29 & 3,85 & 3,97 & 4,43 & 4,31 \\
\hline $\mathbf{4}$ & 7,84 & 7,76 & 6,97 & 6,96 & 7,51 & 7,86 & 4,50 & 3,89 & 4,43 & 4,35 \\
\hline $\mathbf{5}$ & 7,75 & 8,13 & 7,43 & 7,47 & 7,78 & 7,88 & 3,77 & 4,10 & 4,45 & 4,53 \\
\hline \hline
\end{tabular}


Zusammensetzung der eingesetzten Mineralstoffmischungen (nach Angaben der Hersteller)

\begin{tabular}{|c|c|c|c|c|}
\hline & ersuch & in vitro & & \\
\hline $\begin{array}{r}\text { Name o } \\
\mathrm{He}\end{array}$ & $\begin{array}{l}\text { er Mischung } \\
\text { rsteller }\end{array}$ & $\begin{array}{l}\text { Movikalin 22/3, } \\
\text { Hemo Mohr }\end{array}$ & $\begin{array}{c}\text { basu-kraft } 0441 \\
\text { Basu }\end{array}$ & $\begin{array}{l}\text { ADE Super, } \\
\text { Vilomix }\end{array}$ \\
\hline $\begin{array}{c}\text { Inhaltsstoffe } \\
\text { [\%] }\end{array}$ & $\begin{array}{l}\text { Calcium } \\
\text { Natrium } \\
\text { Magnesium } \\
\text { Phosphor } \\
\text { Ca:P }\end{array}$ & $\begin{array}{c}22 \\
11 \\
3 \\
3 \\
7,5: 1\end{array}$ & $\begin{array}{c}- \\
10 \\
3 \\
- \\
-\end{array}$ & $\begin{array}{c}17,5 \\
10 \\
3 \\
5 \\
3,5: 1\end{array}$ \\
\hline $\begin{array}{c}\text { Zusatzstoffe } \\
\text { [mg/kg] }\end{array}$ & $\begin{array}{l}\text { Nikotinsäure } \\
\text { Eisen } \\
\text { Mangan } \\
\text { Zink } \\
\beta \text {-Carotin } \\
\text { Kupfer } \\
\text { Antioxidanz BHT } \\
\text { Jod } \\
\text { Selen } \\
\text { Kobalt } \\
\text { Vitamin E }\end{array}$ & $\begin{array}{c}- \\
- \\
4.000 \\
8.000 \\
- \\
- \\
- \\
80 \\
60 \\
80 \\
500\end{array}$ & $\begin{array}{c}60.000 \\
8.000 \\
8.000 \\
6.000 \\
6.000 \\
1.500 \\
1.000 \\
60 \\
- \\
- \\
6.000\end{array}$ & $\begin{array}{c}- \\
1.000 \\
4.000 \\
6.000 \\
- \\
1.300 \\
- \\
50 \\
50 \\
10 \\
4.000\end{array}$ \\
\hline $\begin{array}{l}\text { Vitamine } \\
\text { in } 1000 \text { I.E. }\end{array}$ & $\begin{array}{l}\text { Vitamin A } \\
\text { Vitamin D3 }\end{array}$ & $\begin{array}{l}500 \\
62,5\end{array}$ & $\begin{array}{c}1.000 \\
100\end{array}$ & $\begin{array}{c}1.000 \\
100\end{array}$ \\
\hline
\end{tabular}


A4 Analysenvorschrift zur Bestimmung der Biotinkonzentration in Milch (gilt auch für Pansensaft und Fermenterflüssigkeit aus der Pansensimulation) und Futtermitteln (gilt auch für feste Fermentationsrückstände aus der Pansenfermentation und getrockneten Duodenalchymus )

Übersicht

1. Bereich der Konzentration

2. Prinzip

3. benötigte Apparaturen

4. benötigte Reagenzien und Lösungen

5.Standardlösungen und Assay Medium

5.1 Biotin- Standard- Stammlösung

5.2 Lösungen zum Erstellen einer Eichreihe

5.3 Biotin Assay Medium

6. Vorbereitung der Mikroorganismen

7. Assay- Verfahrensweise

7.1 Vorbereitung der Probe (Säurehydrolyse, ggf. enzymatische Behandlung)

7.1.1 flüssige Proben

7.1.2 feste Proben

7.1.2.1 Proben ohne Mais

7.1.2.2 Proben mit Mais

7.2 Mikrobiologischer Assay

7.2.1 Eichreihe

7.2.2 Probe

7.2.3 Ansetzen und Sterilisation

7.2.4 Beimpfung

7.2.5 Messung der Trübung

8. Berechnungen

9. Zeitlicher Abriss des Ablaufs der Biotinbestimmung

\section{Bereich der Konzentration}

über $2 \mu \mathrm{g}$ Biotin pro Liter in den flüssigen, über $10 \mu \mathrm{g}$ pro $\mathrm{kg}$ in den festen Proben 


\section{Prinzip}

Mikrobiologische Bestimmung des Biotingehaltes mit Lactobacillus (LB) plantarum $\left(\right.$ ATCC $^{3}$ 8014). Das Biotin wird durch Säurehydrolyse und anschließende enzymatische Behandlung mit Papain aus der Probe gelöst. Nach Inkubation mit den Mikroorganismen wird die Trübung der gewachsenen Zellsuspension im Spektralphotometer bei einer Wellenlänge von $660 \mathrm{~nm}$ gemessen.

\section{3. benötigte Apparaturen}

3.1 Wasserfilteranlage (z.B. Serapur 90 CN, Fa. Seral)

3.2 Autoklav (z.B. LaboAutoclave MLS-3750 Fa. Sanyo)

3.3 Reagenzglas-Mixer (z.B. Reax 2000, Fa. Heidolph)

3.4 Brutschrank

3.5 Spektralphotometer, Messung bei 660 nm (z.B. DU - 65, Fa. Beckman)

3.6 Laborzentrifuge mit mindestens $4.000 \mathrm{U} / \mathrm{min}\left(4.000^{-\mathrm{min}}\right)$

$3.7 \quad \mathrm{pH}-$ Meter

3.8 automatische Eppendorf Multipette mit Combitips (5 ml steril / 12,5 ml / $50 \mathrm{ml}$ )

\section{4. benötigte Reagenzien und Lösungen}

alle Chemikalien sind vom Reinheitsgrad "zur Analyse", Wasser bezeichnet immer Wasser aus der Filteranlage $\{3.1\}$

4.1 D-(+) - Biotin (z.B. Fa. Merck 124514)

4.2 Difco ${ }^{\circledR}$ Bacto Assay Medium (Fa. Bacton Dickinson, Best.-Nr. 241910)

4.3 Difco ${ }^{\circledR}$ Bacto Microinoculum-Bouillon (Fa. Bacton Dickinson, Best.-Nr. 241910)

$4.4 \quad \mathrm{NH}_{3}$-Lösung $2 \%$

$80 \mathrm{~g}$ von 25-\%iger $\mathrm{NH}_{3}$-Lösung (z.B. Fa. Merck 105432), $\mathrm{H}_{2} \mathrm{O}$ ad $1.000 \mathrm{ml}$

$4.5 \mathrm{NaOH} 20 \%$

$20 \mathrm{~g} \mathrm{NaOH}$ (z.B. Fa. Merck 106445) in $80 \mathrm{ml} \mathrm{H}_{2} \mathrm{O}$ lösen

4.6 $1 \mathrm{M} \mathrm{H}_{2} \mathrm{SO}_{4}$

98,08 g (entspr. 53,3 ml) konzentrierte $\mathrm{H}_{2} \mathrm{SO}_{4}, \mathrm{H}_{2} \mathrm{O}$ ad $1.000 \mathrm{ml}$

4.7 flüchtiges Konservierungsmittel

folgende Reagenzien mischen:

1 Teil 1,2-Dichlormethan (z.B. Fa. Merck 159595)

1 Teil Chlorbenzol (z.B. Fa. Merck 801791)

\footnotetext{
${ }^{3}$ American Type Culture Collection, 12301 Parklawn Drive, Rockville, MD 20853, USA
} 
2 Teile 1-Chlorbutan (z.B. Fa. Merck 801640)

4.8 Citrat-Puffer $\mathrm{pH} \mathrm{5,5}$

- Lösung 1: $21 \mathrm{~g}$ Citronensäure (z.B. Fa Merck 818707), $\mathrm{H}_{2} \mathrm{O}$ ad $1.000 \mathrm{ml}$

- Lösung 2: $37,5 \mathrm{~g} \mathrm{Na}_{2} \mathrm{HPO}_{4}$ (z.B. Fa. Merck 106556), $\mathrm{H}_{2} \mathrm{O}$ ad $1.000 \mathrm{ml}$

- $44 \mathrm{ml}$ von Lsg. 1 und $56 \mathrm{ml}$ von Lsg. 2 mischen, $\mathrm{H}_{2} \mathrm{O}$ ad $1.000 \mathrm{ml}$

die Lösungen sind im Kühlschrank aufzubewahren (max. 2 Monate) und bei Bedarf zu mischen

4.9 Papain-Lösung

500 mg Papain ( >30.000 USP-U/mg, z.B. Fa. Merck 107144) in 50 ml Citratpuffer (s. \{4.8\}) lösen. Vor Gebrauch frisch bereiten!!

4.10 physiologische Kochsalzlösung

$9 \mathrm{~g} \mathrm{NaCl}$ (z.B. Fa. Merck 106404), $\mathrm{H}_{2} \mathrm{O}$ ad $1.000 \mathrm{ml}$

\section{Standardlösungen und Assay Medium}

\subsection{Biotin-Standard-Stammlösung}

25,00 mg D-(+) - Biotin (s.\{4.1\}) in Wasser unter Zugabe von $2 \mathrm{ml}$ 2\%- $\mathrm{NH}_{3}$-Lösung (s. \{4.4\}) zur besseren Löslichkeit in einem 250 ml-Messkolben lösen und Volumen genau einstellen. Biotin ist UV-empfindlich, daher braunen Messkolben verwenden.

Die Stammlösung ist 2 Monate bei $4{ }^{\circ} \mathrm{C}$ im Dunkeln haltbar, ihre Konzentration beträgt $1 \times 10^{-1} \mathrm{mg}$ Biotin / $\mathrm{ml}$.

\subsection{Lösungen zum Erstellen einer Eichkurve}

Standardlösungen für den Assay (jeden Messtag frisch ansetzen!)

\begin{tabular}{|l|c|c|c|}
\cline { 2 - 4 } \multicolumn{1}{c|}{} & gelöst in & Bezeichnung & Konzentration \\
\hline $5 \mathrm{ml}$ der Stammlösung (s.\{6.1\}) & $500 \mathrm{ml} \mathrm{H}{ }_{2} \mathrm{O}$ & Standard 1 & $1 \times 10^{-3} \mathrm{mg} / \mathrm{ml}$ \\
\hline $5 \mathrm{ml}$ Standard 1 & $500 \mathrm{ml} \mathrm{H} \mathrm{O}_{2}$ & Standard 2 & $1 \times 10^{-4} \mathrm{mg} / \mathrm{ml}$ \\
\hline $10 \mathrm{ml}$ Standard 2 & $100 \mathrm{ml} \mathrm{H}_{2} \mathrm{O}$ & $\underline{\text { Standard 3 }}$ & $1 \times 10^{-5} \mathrm{mg} / \mathrm{ml}$ \\
\hline $10 \mathrm{ml}$ Standard 3 & $100 \mathrm{ml} \mathrm{H}_{2} \mathrm{O}$ & Standard 4 & $1 \times 10^{-6} \mathrm{mg} / \mathrm{ml}$ \\
\hline
\end{tabular}

\subsection{Assay Medium}

Bacto Biotin Assay Medium (s.\{4.2\}), das als Lösung im mikrobiologischen Assay (s. \{7.2\}) mit einem Volumen von $5 \mathrm{ml}$ pro Reagenzglas eingesetzt wird, ist eine Nährlösung, die den Laktobazillen alle außer Biotin noch notwendigen Nähr- und Zusatzstoffe liefert.

Es wird mit einer Konzentration, die der von $75 \mathrm{~g}$ pro $1.000 \mathrm{ml} \mathrm{H}_{2} \mathrm{O}$ entspricht, eingesetzt. Dabei wird das exakt abgewogene Pulver zunächst mit ungefähr der Hälfte des Wassers vollständig gelöst, anschließend für 3 Minuten unter Rühren gekocht. Nach dem Abkühlen 
auf Raumtemperatur wird mit $\mathrm{H}_{2} \mathrm{O}$ auf das Endvolumen aufgefüllt, gut vermischt und durch Filterpapier (Rundfilter Schleicher \& Schüll 5971/22) filtriert.

\section{Vorbereitung der Mikroorganismen}

Wenn der Stamm der Milchsäurebakterien in Agar gehalten wird, muss am Vortag der Untersuchung mit der Isolierung aus dem Agar begonnen werden.

Dazu werden 1,48 g Difco Bacto Mikroinokulum-Bouillon (s. \{4.3\}) in $40 \mathrm{ml} \mathrm{H}_{2} \mathrm{O}$ gelöst und anschließend jeweils $5,7 \mathrm{ml}$ in 4 bereitstehende Reagenzgläser pipettiert. Die Reagenzgläser werden mit Metallkappen (z.B. Cap-O-Test) verschlossen und 15 Minuten bei $120^{\circ} \mathrm{C}$ im Autoklaven (s. $\left.\{3.2\}\right)$ sterilisiert.

Gleichzeitig werden auch 12 Reagenzgläser mit physiologischer Kochsalzlösung (s.\{4.10\}), die ebenfalls mit Metallkappen verschlossen sind, sowie $50 \mathrm{ml}$ physiologische Kochsalzlösung in einem mit Alu-Folie verschossenen Erlenmeyerkolben mitsterilisiert. Die Salzlösung wird später zum Waschen der Laktobazillen bzw. zum Ansetzen der Impflösung benötigt.

Nach dem Abkühlen wird jedes Reagenzglas mit Mikroinokulum-Bouillon mit je 2 Ösen LB plantarum aus dem Agar beimpft und für 19 Stunden bei $37^{\circ} \mathrm{C}$ bebrütet.

Beim Arbeiten mit LB plantarum gelten zur Vermeidung von Verunreinigungen strengste Hygienevorschriften:

- die Arbeitsfläche und die Hände sind direkt vor den Arbeitsgängen mit Ethanol zu reinigen

- die Impföse ist in der Flamme des Bunsenbrenners auszuglühen, muss vor dem Weiterarbeiten jedoch erst abkühlen

- die Öffnungen der Reagenzgläser sind sofort nach Abnahme und direkt vor dem Aufsetzen der Deckel in die Flamme des Bunsenbrenners zu halten.

Nach der Brutzeit werden die Röhrchen mit den gewachsenen Mikroorganismen bei mind. $2.500^{- \text {min }}$ für 10 Minuten zentrifugiert, der Überstand wird abgegossen und verworfen. Die sterile physiologischer Kochsalzlösung aus den Reagenzgläsern wird zu den Pellets gegeben, diese durch anschließendes Schütteln mit dem Reagenzglasschüttler aufgelöst und gewaschen.

Das Zentrifugieren und Waschen mit Kochsalzlösung wird noch einmal genauso wiederholt (stets unter Beachtung der Hygienevorschriften, s.o.).

Nach dem anschließenden 3. Zentrifugieren werden die Pellets in eine möglichst kleine Menge Salzlösung aufgenommen und in den mit Kochsalzlösung befüllten Erlenmeyerkolben überführt, dieser wird anschließend gut geschüttelt. 
Später wird jedes Reagenzglas mit Standard oder aufbereiteter Probe mit $100 \mu$ lieser Lösung beimpft. (s. $\{7.2 .4\})$

\section{Assay - Verfahrensweise}

7.1 Vorbereitung der Probe (Säurehydrolyse, ggf. enzymatische Behandlung)

\subsubsection{Flüssige Proben}

Die Probe muss zuerst, evtl. unter Zuhilfenahme eines Homogenisators, homogenisiert werden. Dann werden $10 \mathrm{ml}$ in einen $100 \mathrm{ml}$-Erlenmeyerkolben pipettiert.

Nach Zugabe von $50 \mathrm{ml} 1 \mathrm{M} \mathrm{H}_{2} \mathrm{SO}_{4}$ ( s. \{4.6\}) wird die Probe geschüttelt, das Gefäß mit Alu-Folie abgedeckt und im Autoklav (s.\{3.2\}) für 30 Minuten auf $120^{\circ} \mathrm{C}$ erhitzt.

Nach dem Abkühlen auf Raumtemperatur wird dann mit $20 \% \mathrm{NaOH}$ (s. $\{4.5\}$ ) ein pHWert von 7,5 eingestellt.

Nach der pH-Wert-Einstellung wird das Extrakt in einen 100ml-Messkolben überführt, das Volumen mit $\mathrm{H}_{2} \mathrm{O}$ exakt eingestellt und die Lösung durch Schütteln gut durchmischt. $5 \mathrm{ml}$ dieser Lösung werden in einen Erlenmeyerkolben pipettiert und mit $45 \mathrm{ml}$ der Papainlösung (s.\{4.9\}) sowie drei Tropfen des Konservierungsmittels (s. $\{4.7\})$ versetzt, mit Alu-Folie abgedeckt und für 18 Stunden bei $37^{\circ} \mathrm{C}$ inkubiert.

Um einen Blindprobe zu erstellen, wird dieser letztgenannte Vorgang mit $5 \mathrm{ml} \mathrm{H}_{2} \mathrm{O}$ statt des Extraktes parallel durchgeführt.

Nach Ablauf der Inkubationszeit wird die Lösung für 10 Minuten bei $120^{\circ} \mathrm{C}$ im Autoklav (s. \{3.2\}) sterilisiert und nach dem Abkühlen auf Raumtemperatur durch Filterpapier (z.B. Schleicher \& Schüll 5971/22 ) filtriert. Diese Lösung wird später für den mikrobiologischen Assay verwendet (s. \{7.2.2\}), ist aber auch zur späteren Analyse tiefgefriertauglich.

\subsubsection{Feste Proben}

\subsubsection{Proben ohne Mais}

Wenn die Probe pelletiert ist oder grobe Bestandteile enthält, muss sie zuerst in einer Mühle (s. \{3.9\}) zu feinem Puder zerkleinert werden. Dann werden exakt $10 \mathrm{~g}$ in einen $250 \mathrm{ml}$-Erlenmeyerkolben oder ein Becherglas gleichen Volumens gegeben. Hiernach erfolgt die Zugabe von $100 \mathrm{ml} 1 \mathrm{M} \mathrm{H}_{2} \mathrm{SO}_{4}$ ( s. \{4.6\}). Dabei ist auf eine gleichmäßige Verteilung und Durchfeuchtung des Probenmaterials zu achten. Das Gefäß wird anschließend mit Alu-Folie abgedeckt und im Autoklav (s. \{3.2\}) für 30 Minuten auf $120^{\circ} \mathrm{C}$ erhitzt. Nach dem Abkühlen auf Raumtemperatur wird mit $20 \% \mathrm{NaOH}$ (s. \{4.5\}) ein pH-Wert von 7,5 eingestellt.

Nach der pH-Wert-Einstellung wird das Extrakt in einen 500ml-Messkolben überführt und bis zur Markierung mit $\mathrm{H} 2 \mathrm{O}$ aufgefüllt. 
Jetzt wird eine bestimmt Menge dieser Lösung in einen Erlenmeyerkolben pipettiert, und zwar:

- bei einem erwarteten Biotingehalt der Probe unter $100 \mu \mathrm{g} / \mathrm{kg}$ liegt: $10 \mathrm{ml}$

- bei einem erwarteten Biotingehalt der Probe zwischen 100 und $300 \mu \mathrm{g} / \mathrm{kg}$ oder über $300 \mu \mathrm{g} / \mathrm{kg}$ Probe: $5 \mathrm{ml}$

Weniger als $5 \mathrm{ml}$ dieser Lösung werden in keinem Fall pipettiert!

Mit der entsprechenden Menge der Papainlösung (s.\{4.9\}) wird ein Gesamtvolumen von $50 \mathrm{ml}$ hergestellt, einige Tropfen des Konservierungsmittels (s. \{4.7\}) zugegeben, das Behältnis mit Alu-Folie abgedeckt und für 18 Stunden bei $37^{\circ} \mathrm{C}$ inkubiert.

Um einen Blindprobe zu erstellen, wird der letztgenannte Vorgang mit 5 bzw. $10 \mathrm{ml} \mathrm{H2O}$ statt des Extraktes parallel durchgeführt.

Anschließend wird die Lösung für 10 Minuten bei $120^{\circ} \mathrm{C}$ im Autoklav (s. $\{3.2\}$ ) sterilisiert und nach dem Abkühlen auf Raumtemperatur durch Filterpapier (z.B. Schleicher \& Schüll 5971/2 ) filtriert.

Diese Lösung wird später für den mikrobiologischen Assay verwendet (s. \{7.4.2\}), ist aber auch zur späteren Analyse tiefgefriertauglich.

\subsubsection{Proben mit Mais}

$10 \mathrm{~g}$ der Probe werden in einen $500 \mathrm{ml}$-Messkolben eingewogen, $100 \mathrm{ml} 1 \mathrm{M} \mathrm{H}_{2} \mathrm{SO}_{4} \mathrm{Zu}$ gegeben (s. \{ 4.6\}), das Gefäß mit Alu-Folie abgedeckt und im Autoklav (s. \{3.2\}) für 120 Minuten auf $120^{\circ} \mathrm{C}$ erhitzt. Nach dem Abkühlen auf Raumtemperatur wird mit $\mathrm{H}_{2} \mathrm{O}$ auf $500 \mathrm{ml}$ aufgefüllt, die Suspension geschüttelt und durch Filterpapier filtriert. Zu $10 \mathrm{ml}$ dieser klaren Lösung werden $10 \mathrm{ml} \mathrm{H}_{2} \mathrm{O}$ gegeben und der pH-Wert mit $20 \% \mathrm{NaOH}$ auf 6,8 eingestellt. Diese Lösung wird dann mit $\mathrm{H}_{2} \mathrm{O}$ auf $50 \mathrm{ml}$ aufgefüllt und für den mikrobiologischen Assay (s. \{7.4.2\}) verwendet

\subsection{Mikrobiologischer Assay}

Es werden Reagenzgläser mit einer Länge von 150 mm und einem Durchmesser von $15 \mathrm{~mm}$ verwendet.

\subsubsection{Eichreihe}

Für die Eichreihe mit Hilfe der Standardlösungen (s.\{5.2\}) wird jedes Volumen in vierfacher Wiederholung gemessen. Die Lösung Standard 4 wird in die Reagenzgläser E5 bis E24 pipettiert, die Lösung Standard 3 in die Gläser E25 bis E28 (E für Eichreihe). Zum Pipettieren wird die Eppendorf Multipette benutzt (s. \{3.8\}) 


\begin{tabular}{|l|c|c|}
\hline Volumen der Standardlösungen & Biotinkonzentration pro Glas] & Reagenzglas Nr. \\
\hline $0 \mathrm{ml}=$ Blindwert & $0 \mu \mathrm{g}$ & $\mathrm{E} 1-4$ \\
\hline $0,25 \mathrm{ml}$ von Standard 4 & $2,5 \times 10^{-5} \mu \mathrm{g}$ Biotin & $\mathrm{E} \mathrm{5-8}$ \\
\hline $0,5 \mathrm{ml}$ von Standard 4 & $5 \times 10^{-5} \mu \mathrm{g}$ Biotin & $\mathrm{E} \mathrm{9-12}$ \\
\hline $1 \mathrm{ml}$ von Standard 4 & $1 \times 10^{-4} \mu \mathrm{g}$ Biotin & $\mathrm{E} 13-16$ \\
\hline $2 \mathrm{ml}$ von Standard 4 & $2 \times 10^{-4} \mu \mathrm{g}$ Biotin & $\mathrm{E} \mathrm{17-20}$ \\
\hline $4 \mathrm{ml}$ von Standard 4 & $4 \times 10^{-4} \mu \mathrm{g}$ Biotin & $\mathrm{E} \mathrm{21-24}$ \\
\hline $800 \mu \mathrm{l}$ von Standard 3 & $8 \times 10^{-4} \mu \mathrm{g}$ Biotin & $\mathrm{E} \mathrm{25-28}$ \\
\hline
\end{tabular}

\subsubsection{Probe}

Bei den Proben mit unbekanntem Biotingehalt wird jede Probe mit drei verschiedenen Volumina in je dreifacher Ausführung gemessen:

\begin{tabular}{|c|c|c|}
\hline Probe & Volumen & Reagenzglas Nr. \\
\hline 1 & $0,25 \mathrm{ml}$ & $\mathrm{P} 1-3$ \\
\hline 1 & $0,5 \mathrm{ml}$ P -6 \\
\hline 1 & $1,0 \mathrm{ml}$ & $\mathrm{P} 7-9$ \\
\hline 2 & $0,25 \mathrm{ml} 10-12$ \\
\hline 2 & $0,5 \mathrm{ml}$ & $\mathrm{P} 13-15$ \\
\hline 2 & $1,0 \mathrm{ml}$ & $\mathrm{P} 16-18$ \\
\hline usw. & usw. & usw. \\
\hline
\end{tabular}

Für jedes Volumen wird für Korrekturzwecke auch ein Blindwert in dreifacher Ausführung bestimmt (vergl. \{7.1\}).

Es empfiehlt sich, zwischen dem letzten Reagenzglas der Eichreihe und dem ersten der Probe noch einmal zwei Gläschen mit dem Nullwert einzufügen, damit man sicher davon ausgehen kann, dass die Durchflussküvette des Photometers nicht noch Probenmaterial mit hoher Biotinkonzentration (= hoher Extinktion) enthält. Die Werte dieser beiden Röhrchen brauchen später nicht notiert zu werden.

\subsubsection{Ansetzen und Sterilisation}

Grundsätzlich wird zuerst immer $\mathrm{H}_{2} \mathrm{O}$ in die Reagenzgläser pipettiert, und zwar genau das Volumen, das zusammen mit der anschließend dazugegebenen Menge an Standard- bzw. Proben- oder Blindwertlösung ein Volumen von $5 \mathrm{ml}$ ergibt.

Dazu werden danach ebenfalls $5 \mathrm{ml}$ des fertigen Biotin Assay Mediums (s. \{4.3\}) gegeben, die Gläschen mit einer Metallkappe verschlossen, für 10 Minuten bei $120^{\circ} \mathrm{C}$ sterilisiert und auf Raumtemperatur abgekühlt. 


\subsubsection{Beimpfung}

Jedes Gläschen wird anschließend mit 0,1 ml der Bakteriensuspension beimpft, deren Herstellung in $\{6\}$ beschrieben ist. Dabei ist zügig zu arbeiten.

Nach der Beimpfung wird jedes Reagenzglas gut geschüttelt (s.\{3.3\}). Es folgt eine Inkubation für 19 Stunden bei $37^{\circ} \mathrm{C}$.

\subsubsection{Messung der Trübung}

Nach Ablauf der Inkubationszeit werden die Gläschen im Autoklaven (s. \{3.2\}) für 3 Minuten auf $105^{\circ} \mathrm{C}$ erhitzt, um das Wachstum der Mikroorganismen zu stoppen, und auf Raumtemperatur abgekühlt.

Der Inhalt jedes Gläschens wird mit dem Reagenzglasmixer (s.\{3.3\}) gut durchmischt und die Trübung mit dem Photometer (s.\{3.5\}) bei einer Wellenlänge von $660 \mathrm{~nm}$ gemessen.

\section{Berechnungen}

Aus den 4 Einzelwerten jeder Konzentration der Eichkurve wird ein Mittelwert gebildet, von dem der Mittelwert der Ergebnisse des Blindwertes abgezogen wird. Diese korrigierten Mittelwerte der Extinktion werden dann auf Logharitmuspapier gegen die entsprechende Biotinkonzentration abgetragen, so dass man eine Eichkurve erhält.

Aus den Einzelwerten der Proben aller drei getesteten Volumina wird ebenfalls ein Mittelwert gebildet, der um den jeweiligen dazugehörenden Blindwert korrigiert wird.

Nun kann, da die Extinktion bekannt ist, auf der Eichkurve die gesuchte Biotinkonzentration abgelesen werden.

\section{Zeitlicher Abriss des Ablaufs der Biotinbestimmung}

Im Folgenden gilt: fett gedruckter Text bezieht sich auf die Proben und deren Aufbereitung, normal gedruckter Text auf sonstige Tätigkeiten

\section{Tag}

- Überimpfen von LB plantarum aus dem Agar in vorbereitetes steriles MikroinokulumBouillon, anschließendes Bebrüten bei $37^{\circ} \mathrm{C}$ für 19 Stunden (s. $\{6\}$ )

- Extraktion des Biotins aus der Probe durch $\mathrm{H}_{2} \mathrm{SO}_{4}$ und enzymatische Behandlung mit Papain, anschließendes Bebrüten bei $37^{\circ} \mathrm{C}$ für 18 Stunden (s. $\{7.1\}$ ).

\section{Tag}

- Bereitstellung der Reagenzgläschen und Pipettieren der entsprechenden Wassermenge

- Autoklavieren ( $10 \mathrm{~min}, 120^{\circ} \mathrm{C}$ ), filtrieren und pipettieren. Blindwert nicht vergessen ( $\Rightarrow$ Papainlösung aufbewahren)!! (s. \{7.1\} und $\{7.2\}$ )

- Herstellen der Standardlösungen für die Eichreihe, Pipettieren in die Reagenzröhrchen (s. $\{7.2\})$ 
- Herstellung des Biotin Assay Mediums (s. \{5.3\}) und Pipettieren von je $5 \mathrm{ml}$ in jedes Glas, anschließend Autoklavieren (10 $\mathrm{min}, 120^{\circ} \mathrm{C}$, s. $\left.\{7.2 .3\}\right)$

- Fertigstellung der Impfsuspension durch wiederholtes Zentrifugieren und Waschen mit steriler physiologischer Kochsalzlösung (s. \{6\})

- Nach Abkühlung vom Autoklavieren Beimpfung aller Röhrchen mit 0,1 ml = 100 $\mu \mathrm{l}$ Zellsuspension (s. $\{7.2 .4\}$ ), anschließend gut mischen!!

- für 19 Stunden bei $37^{\circ} \mathrm{C}$ bebrüten

\section{Taq}

nach Ablauf der Inkubationszeit Wachstum der Mikroorganismen durch Sterilisation (3 min, $105^{\circ} \mathrm{C}$, s. $\left.\{7.2 .5\}\right)$ beenden, anschließend Extinktionen der vorher geschüttelten Lösungen am Photometer messen (s. \{7.2.5\}) und Konzentrationen des Biotins in den Proben bestimmen (s. $\{8\})$. 
es gilt: Ration 1 = 100\% Heu; Ration $2=67 \%$ Heu+ $33 \%$ Weizen; Ration $3=67 \%$ Heu+ $33 \%$ Mais; Ration $4=$ $33 \%$ Heu+ 67 \% Weizen; Ration 5= 33\% Heu+ $67 \%$ Mais; Faunierungsstatus: $f=$ fauniert; $d=$ defauniert

\begin{tabular}{|c|c|c|c|c|c|c|c|c|c|c|}
\hline \multicolumn{11}{|c|}{ Durchgang 1} \\
\hline Ration & \multicolumn{2}{|c|}{1} & \multicolumn{2}{|c|}{2} & \multicolumn{2}{|c|}{3} & \multicolumn{2}{|c|}{4} & \multicolumn{2}{|c|}{5} \\
\hline Faunierungsstatus & $f$ & $d$ & $f$ & $d$ & $f$ & d & $f$ & $d$ & $f$ & $d$ \\
\hline Überlaufmenge [ml/d] & 487 & 495 & 521 & 517 & 520 & 515 & 364 & 357 & 364 & 367 \\
\hline $\mathrm{pH}$-Wert & 6,63 & 6,72 & 6,54 & 6,52 & 6,58 & 6,52 & 6,30 & 6,05 & 6,38 & 6,29 \\
\hline $\mathrm{NH} 4-\mathrm{N}[\mathrm{mg} / \mathrm{l}]$ & 74,80 & 74,60 & 125,00 & 99,00 & 68,80 & 35,60 & 160,00 & 113,40 & 36,80 & 24,00 \\
\hline Methan[mmol/d] & 6,79 & 6,73 & 7,38 & 6,28 & 7,04 & 4,31 & 5,90 & 3,25 & 4,53 & 2,80 \\
\hline Protozoen [1.000/ml] & 16,90 & 0,00 & 64,73 & 0,11 & 57,57 & 0,00 & 35,18 & 0,00 & 26,36 & 0,00 \\
\hline $\mathrm{C} 2[\mu \mathrm{mol} / \mathrm{ml}]$ & 92,56 & 70,03 & 96,89 & 109,79 & 99,72 & 105,03 & 133,56 & 144,36 & 108,62 & 114,62 \\
\hline C3 $[\mu \mathrm{mol} / \mathrm{ml}]$ & 34,80 & 43,84 & 44,64 & 88,15 & 50,48 & 77,98 & 62,50 & 133,21 & 59,75 & 95,31 \\
\hline iC4[ $\mu \mathrm{mol} / \mathrm{ml}]$ & 2,28 & 2,34 & 2,61 & 0,92 & 1,07 & 1,02 & 1,24 & 0,71 & 1,01 & 0,66 \\
\hline $\mathrm{nC} 4[\mu \mathrm{mol} / \mathrm{ml}]$ & 15,00 & 8,36 & 23,49 & 4,69 & 18,31 & 5,88 & 31,77 & 4,79 & 28,92 & 3,55 \\
\hline $\mathrm{iC5}[\mu \mathrm{mol} / \mathrm{ml}]$ & 3,99 & 2,14 & 6,48 & 1,84 & 4,84 & 1,39 & 7,88 & 2,47 & 6,91 & 0,94 \\
\hline $\mathrm{nC5}[\mu \mathrm{mol} / \mathrm{ml}]$ & 2,77 & 0,87 & 3,64 & 1,49 & 2,67 & 0,59 & 5,57 & 2,57 & 2,81 & 0,76 \\
\hline$\Sigma$ SCFA $[\mu \mathrm{mol} / \mathrm{ml}]$ & 151,34 & 127,56 & 177,75 & 206,87 & 177,09 & 191,89 & 242,52 & 288,10 & 208,01 & 215,85 \\
\hline$\Sigma$ SCFA [mmol/d] & 73,70 & 63,14 & 92,61 & 106,95 & 92,09 & 98,82 & 88,28 & 105,73 & 74,05 & 79,22 \\
\hline Mikroben-N [mg/d] & 117,02 & 107,82 & 143,00 & 139,49 & 107,08 & 96,92 & 108,85 & 144,44 & 62,27 & 86,11 \\
\hline Zell-Trockenmasse [mg/d] & 1462,7 & 1347,7 & 1787,5 & 1743,6 & 1338,5 & 1211,5 & 1360,6 & 1805,5 & 778,4 & 1076,4 \\
\hline \multicolumn{11}{|c|}{ Durchgang 2} \\
\hline Ration & \multicolumn{2}{|c|}{1} & \multicolumn{2}{|c|}{2} & \multicolumn{2}{|c|}{3} & \multicolumn{2}{|c|}{4} & \multicolumn{2}{|c|}{5} \\
\hline Faunierungsstatus & $f$ & d & $f$ & d & $f$ & $d$ & $f$ & $d$ & $f$ & d \\
\hline Überlaufmenge [ml/d] & 456 & 481 & 473 & 485 & 490 & 481 & 359 & 363 & 351 & 384 \\
\hline $\mathrm{pH}-$ Wert & 6,69 & 6,64 & 6,60 & 6,56 & 6,59 & 6,57 & 6,36 & 6,13 & 6,38 & 6,36 \\
\hline $\mathrm{NH} 4-\mathrm{N}$ [mg/l] & 72,80 & 64,00 & 105,00 & 81,20 & 72,00 & 41,50 & 123,60 & 82,00 & 26,00 & 11,70 \\
\hline Methan [mmol/d] & 6,96 & 5,93 & 5,52 & 5,39 & 5,65 & 4,29 & 4,91 & 2,08 & 3,40 & 2,23 \\
\hline Protozoen [1.000/ml] & 17,54 & 0,00 & 82,20 & 0,00 & 50,06 & 0,00 & 26,29 & 0,00 & 22,64 & 0,00 \\
\hline $\mathrm{C} 2[\mu \mathrm{mol} / \mathrm{ml}]$ & 86,59 & 86,96 & 90,09 & 104,36 & 88,91 & 97,27 & 121,78 & 175,07 & 114,28 & 101,39 \\
\hline C3 $[\mu \mathrm{mol} / \mathrm{ml}]$ & 33,96 & 44,95 & 46,78 & 56,86 & 48,42 & 55,74 & 64,89 & 78,87 & 6,06 & 65,26 \\
\hline iC4 $[\mu \mathrm{mol} / \mathrm{ml}]$ & 1,09 & 1,10 & 1,77 & 1,21 & 1,23 & 1,15 & 1,59 & 0,77 & 1,05 & 1,02 \\
\hline $\mathrm{nC} 4[\mu \mathrm{mol} / \mathrm{ml}]$ & 14,87 & 10,47 & 18,26 & 11,15 & 16,67 & 9,67 & 23,86 & 5,26 & 20,65 & 6,59 \\
\hline $\mathrm{iC5}[\mu \mathrm{mol} / \mathrm{ml}]$ & 4,15 & 1,56 & 5,29 & 2,16 & 5,05 & 4,76 & 6,32 & 6,78 & 7,24 & 6,63 \\
\hline $\mathrm{nC5}[\mu \mathrm{mol} / \mathrm{ml}]$ & 2,17 & 2,42 & 3,87 & 2,17 & 3,04 & 1,11 & 6,15 & 2,36 & 1,45 & 0,33 \\
\hline$\Sigma$ SCFA $[\mu \mathrm{mol} / \mathrm{ml}]$ & 142,85 & 147,46 & 166,04 & 177,90 & 163,31 & 169,69 & 224,59 & 269,12 & 205,25 & 181,22 \\
\hline$\Sigma$ SCFA $[\mathrm{mmol} / \mathrm{d}]$ & 65,22 & 70,93 & 78,54 & 86,28 & 80,02 & 81,62 & 80,63 & 97,69 & 72,04 & 69,59 \\
\hline Mikroben-N [mg/d] & 105,61 & 113,80 & 125,01 & 121,97 & 105,30 & 91,59 & 102,87 & 137,35 & 58,59 & 67,09 \\
\hline Zell-Trockenmasse [mg/d] & 1320,1 & 1422,5 & 1562,6 & 1524,6 & 1316,2 & 1144,9 & 1285,9 & 1716,9 & 732,4 & 838,6 \\
\hline
\end{tabular}




\begin{tabular}{|c|c|c|c|c|c|c|c|c|c|c|}
\hline \multicolumn{11}{|c|}{ Durchgang 3} \\
\hline Ration & \multicolumn{2}{|c|}{1} & \multicolumn{2}{|c|}{2} & \multicolumn{2}{|c|}{3} & \multicolumn{2}{|c|}{4} & \multicolumn{2}{|c|}{5} \\
\hline Faunierungsstatus & $f$ & d & $f$ & d & $f$ & d & $f$ & $d$ & $f$ & d \\
\hline Überlaufmenge [ml/d] & 455 & 476 & 481 & 487 & 492 & 481 & 362 & 378 & 366 & 408 \\
\hline pH-Wert & 6,69 & 6,67 & 6,54 & 6,60 & 6,61 & 6,56 & 6,46 & 6,42 & 6,44 & 6,51 \\
\hline $\mathrm{NH} 4-\mathrm{N}[\mathrm{mg} / \mathrm{l}]$ & 66,80 & 59,60 & 92,20 & 78,80 & 61,40 & 32,60 & 101,40 & 81,40 & 27,80 & 24,40 \\
\hline Methan [mmol/d] & 6,42 & 5,87 & 6,15 & 5,50 & 6,91 & 4,22 & 4,75 & 2,68 & 3,65 & 3,23 \\
\hline Protozoen [1.000/ml] & 17,68 & 0,11 & 76,96 & 0,00 & 57,57 & 0,11 & 30,56 & 0,00 & 15,63 & 0,00 \\
\hline $\mathrm{C} 2[\mu \mathrm{mol} / \mathrm{ml}]$ & 82,20 & 85,68 & 99,75 & 88,46 & 73,75 & 81,07 & 95,59 & 104,39 & 71,94 & 68,19 \\
\hline C3 [ $[\mu \mathrm{mol} / \mathrm{ml}]$ & 31,18 & 38,61 & 46,85 & 53,10 & 46,77 & 71,18 & 72,16 & 71,72 & 68,16 & 75,80 \\
\hline iC4 $[\mu \mathrm{mol} / \mathrm{ml}]$ & 1,82 & 1,64 & 1,59 & 1,47 & 0,74 & 0,52 & 0,70 & 4,01 & 0,65 & 0,57 \\
\hline $\mathrm{nC} 4[\mu \mathrm{mol} / \mathrm{ml}]$ & 14,60 & 10,16 & 19,14 & 12,36 & 21,47 & 7,58 & 14,64 & 14,10 & 16,31 & 11,32 \\
\hline iC5 $[\mu \mathrm{mol} / \mathrm{ml}]$ & 4,26 & 2,39 & 6,85 & 3,49 & 6,01 & 1,81 & 10,08 & 3,79 & 6,73 & 1,76 \\
\hline $\mathrm{nC5}[\mu \mathrm{mol} / \mathrm{ml}]$ & 2,29 & 2,06 & 3,79 & 3,57 & 2,25 & 1,42 & 3,68 & 5,81 & 0,82 & 0,11 \\
\hline$\Sigma$ SCFA $[\mu \mathrm{mol} / \mathrm{ml}]$ & 136,34 & 140,53 & 177,97 & 162,41 & 150,99 & 163,58 & 195,84 & 203,83 & 164,61 & 157,74 \\
\hline$\Sigma$ SCFA [mmol/d] & 62,04 & 66,89 & 85,60 & 79,10 & 74,29 & 78,68 & 70,89 & 77,05 & 60,25 & 64,36 \\
\hline Mikroben-N [mg/d] & 95,55 & 102,81 & 115,53 & 111,83 & 97,71 & 89,74 & 87,97 & 90,44 & 50,32 & 61,32 \\
\hline Zell-Trockenmasse [mg/d] & 1194,4 & 1285,1 & 1444,1 & 1397,9 & 1221,4 & 1121,7 & 1099,6 & 1130,5 & 629,0 & 766,5 \\
\hline \multicolumn{11}{|c|}{ Durchgang 4} \\
\hline Ration & \multicolumn{2}{|c|}{1} & \multicolumn{2}{|c|}{2} & \multicolumn{2}{|c|}{3} & \multicolumn{2}{|c|}{4} & \multicolumn{2}{|c|}{5} \\
\hline Faunierungsstatus & $f$ & $d$ & $f$ & d & $f$ & d & $f$ & $d$ & $f$ & $d$ \\
\hline Überlaufmenge [ml/d] & 454 & 489 & 460 & 487 & 502 & 474 & 386 & 386 & 384 & 423 \\
\hline $\mathrm{pH}$-Wert & 6,67 & 6,68 & 6,58 & 6,55 & 6,61 & 6,61 & 6,59 & 6,33 & 6,51 & 6,58 \\
\hline $\mathrm{NH} 4-\mathrm{N}[\mathrm{mg} / \mathrm{l}]$ & 67,50 & 60,00 & 78,00 & 68,10 & 51,90 & 42,50 & 91,00 & 84,80 & 26,20 & 21,80 \\
\hline Methan [mmol/d] & 7,28 & 5,77 & 6,29 & 5,69 & 6,20 & 4,30 & 4,48 & 3,86 & 4,06 & 4,08 \\
\hline Protozoen [1.000/ml] & 16,79 & 0,00 & 92,10 & 0,00 & 63,35 & 0,00 & 19,77 & 0,00 & 14,99 & 0,00 \\
\hline $\mathrm{C} 2[\mu \mathrm{mol} / \mathrm{ml}]$ & 78,84 & 74,36 & 93,31 & 9,89 & 72,90 & 76,69 & 71,16 & 127,63 & 69,93 & 65,87 \\
\hline $\mathrm{C} 3[\mu \mathrm{mol} / \mathrm{ml}]$ & 29,68 & 38,55 & 45,00 & 55,38 & 38,67 & 45,18 & 49,24 & 59,26 & 52,67 & 56,35 \\
\hline iC4 [ $\mu \mathrm{mol} / \mathrm{ml}]$ & 1,77 & 1,54 & 1,74 & 1,60 & 1,55 & 1,40 & 1,51 & 1,16 & 0,96 & 0,86 \\
\hline $\mathrm{nC} 4[\mu \mathrm{mol} / \mathrm{ml}]$ & 14,44 & 8,44 & 21,99 & 12,98 & 15,58 & 10,49 & 13,39 & 12,08 & 18,89 & 15,73 \\
\hline $\mathrm{iC5}[\mu \mathrm{mol} / \mathrm{ml}]$ & 3,61 & 1,68 & 5,22 & 2,41 & 5,00 & 1,73 & 7,60 & 3,49 & 6,05 & 1,34 \\
\hline $\mathrm{nC5}[\mu \mathrm{mol} / \mathrm{ml}]$ & 2,37 & 1,49 & 3,56 & 4,02 & 1,97 & 1,59 & 3,52 & 6,46 & 1,59 & 0,64 \\
\hline$\Sigma$ SCFA $[\mu \mathrm{mol} / \mathrm{ml}]$ & 130,71 & 126,07 & 170,82 & 175,26 & 135,68 & 137,07 & 146,42 & 210,07 & 150,08 & 140,78 \\
\hline$\Sigma$ SCFA [mmol/d] & 59,34 & 61,65 & 78,58 & 85,35 & 68,11 & 64,97 & 56,52 & 81,09 & 57,63 & 59,55 \\
\hline Mikroben-N [mg/d] & 111,59 & 114,52 & 129,97 & 125,67 & 105,14 & 108,50 & 82,68 & 105,00 & 56,25 & 66,94 \\
\hline Zell-Trockenmasse [mg/d] & 1394,9 & 1431,5 & 1624,6 & 1570,9 & 1314,2 & 1356,3 & 1033,5 & 1312,5 & 703,1 & 836,7 \\
\hline
\end{tabular}




\begin{tabular}{|c|c|c|c|c|c|c|c|c|c|c|}
\hline \multicolumn{11}{|c|}{ Durchgang 5} \\
\hline Ration & \multicolumn{2}{|c|}{1} & \multicolumn{2}{|c|}{2} & \multicolumn{2}{|c|}{3} & \multicolumn{2}{|c|}{4} & \multicolumn{2}{|c|}{5} \\
\hline Faunierungsstatus & $f$ & $d$ & $f$ & d & $f$ & d & $f$ & $d$ & $f$ & d \\
\hline Überlaufmenge [ml/d] & 458 & 492 & 473 & 486 & 499 & 473 & 388 & 406 & 384 & 421 \\
\hline $\mathrm{pH}$-Wert & 6,67 & 6,74 & 6,63 & 6,61 & 6,63 & 6,61 & 6,42 & 6,47 & 6,46 & 6,53 \\
\hline $\mathrm{NH} 4-\mathrm{N}[\mathrm{mg} / \mathrm{l}]$ & 68,10 & 59,20 & 78,00 & 68,10 & 51,90 & 42,50 & 91,00 & 84,90 & 26,20 & 21,80 \\
\hline Methan [mmol/d] & 8,48 & 5,77 & 6,04 & 5,05 & 6,08 & 4,37 & 4,93 & 3,81 & 4,04 & 3,29 \\
\hline Protozoen [1.000/ml] & 19,51 & 0,00 & 95,03 & 0,21 & 54,32 & 0,00 & 19,66 & 0,00 & 22,22 & 0,11 \\
\hline $\mathrm{C} 2[\mu \mathrm{mol} / \mathrm{ml}]$ & 96,61 & 81,48 & 92,01 & 101,63 & 96,05 & 97,71 & 122,05 & 118,69 & 85,24 & 79,74 \\
\hline C3 $[\mu \mathrm{mol} / \mathrm{ml}]$ & 35,83 & 38,61 & 45,92 & 56,31 & 40,32 & 49,14 & 58,62 & 59,67 & 62,31 & 66,93 \\
\hline $\mathrm{iC} 4[\mu \mathrm{mol} / \mathrm{ml}]$ & 1,54 & 1,09 & 1,59 & 1,02 & 0,81 & 0,86 & 1,30 & 1,01 & 0,70 & 0,52 \\
\hline $\mathrm{nC} 4[\mu \mathrm{mol} / \mathrm{ml}]$ & 18,50 & 8,51 & 22,49 & 8,44 & 15,52 & 7,92 & 18,64 & 16,45 & 18,96 & 11,07 \\
\hline $\mathrm{iC5}[\mu \mathrm{mol} / \mathrm{ml}]$ & 5,09 & 1,85 & 6,10 & 3,29 & 5,40 & 2,28 & 6,61 & 3,73 & 4,45 & 1,27 \\
\hline $\mathrm{nC5}[\mu \mathrm{mol} / \mathrm{ml}]$ & 2,94 & 2,42 & 3,63 & 4,68 & 2,14 & 2,06 & 5,12 & 6,06 & 1,86 & 0,28 \\
\hline$\Sigma$ SCFA $[\mu \mathrm{mol} / \mathrm{ml}]$ & 160,51 & 133,95 & 171,74 & 175,37 & 150,24 & 159,96 & 212,34 & 202,61 & 173,52 & 159,81 \\
\hline$\Sigma$ SCFA [mmol/d] & 73,51 & 65,90 & 81,23 & 85,23 & 74,97 & 75,66 & 82,39 & 82,26 & 66,63 & 67,28 \\
\hline Mikroben-N [mg/d] & 121,19 & 111,59 & 127,36 & 120,68 & 110,50 & 98,35 & 91,83 & 88,91 & 70,64 & 84,70 \\
\hline Zell-Trockenmasse [mg/d] & 1514,9 & 1394,9 & 1592,0 & 1508,5 & 1381,2 & 1229,4 & 1147,9 & 1111,4 & 883,0 & 1058,7 \\
\hline
\end{tabular}


A6

Erfasste Einzelwerte der in vitro-Untersuchungen (volumenkorrigiert)

es gilt: Ration 1 = 100\% Heu; Ration 2 = 67\% Heu+ $33 \%$ Weizen; Ration 3 = 67\% Heu+ $33 \%$ Mais; Ration $4=$ $33 \%$ Heu+ 67 \% Weizen; Ration 5= 33\% Heu+ $67 \%$ Mais; Faunierungsstatus: $f=$ fauniert; $d=$ defauniert

\begin{tabular}{|c|c|c|c|c|c|c|c|c|c|c|}
\hline \multicolumn{11}{|c|}{ Durchgang 1} \\
\hline Ration & \multicolumn{2}{|c|}{1} & \multicolumn{2}{|c|}{2} & \multicolumn{2}{|c|}{3} & \multicolumn{2}{|c|}{4} & \multicolumn{2}{|c|}{5} \\
\hline Faunierungsstatus & $f$ & $d$ & $f$ & d & $f$ & d & $f$ & $d$ & $f$ & d \\
\hline $\mathrm{pH}$-Wert & 6,63 & 6,72 & 6,54 & 6,52 & 6,58 & 6,52 & 6,30 & 6,05 & 6,38 & 6,29 \\
\hline $\mathrm{NH} 4-\mathrm{N}$ [mmol/l] & 4,16 & 4,14 & 6,94 & 5,50 & 3,82 & 1,98 & 8,89 & 6,30 & 2,04 & 1,33 \\
\hline Methan[mmol/d] & 6,79 & 6,73 & 7,38 & 6,28 & 7,04 & 4,31 & 8,57 & 4,72 & 6,58 & 4,07 \\
\hline Protozoen [1.000/ml] & 16,90 & 0,00 & 64,73 & 0,11 & 57,57 & 0,00 & 35,18 & 0,00 & 26,36 & 0,00 \\
\hline $\mathrm{C} 2[\mathrm{mmol} / \mathrm{d}]$ & 45,06 & 34,66 & 50,48 & 56,76 & 51,86 & 54,09 & 68,12 & 74,20 & 54,09 & 58,92 \\
\hline C3 [mmol/d] & 16,94 & 21,70 & 23,26 & 45,57 & 26,25 & 40,16 & 31,88 & 68,47 & 29,75 & 48,99 \\
\hline iC4[mmol/d] & 1,11 & 1,16 & 1,36 & 0,48 & 0,56 & 0,53 & 0,63 & 0,36 & 0,50 & 0,34 \\
\hline $\mathrm{nC} 4[\mathrm{mmol} / \mathrm{d}]$ & 7,30 & 4,14 & 12,24 & 2,42 & 9,52 & 3,03 & 16,20 & 2,46 & 14,40 & 1,82 \\
\hline iC5 $[\mathrm{mmol} / \mathrm{d}]$ & 1,94 & 1,06 & 3,38 & 0,95 & 2,52 & 0,72 & 4,02 & 1,27 & 3,44 & 0,48 \\
\hline $\mathrm{nC} 5[\mathrm{mmol} / \mathrm{d}]$ & 1,35 & 0,43 & 1,90 & 0,77 & 1,39 & 0,30 & 2,84 & 1,32 & 1,40 & 0,39 \\
\hline$\Sigma$ SCFA [mmol/d] & 73,70 & 63,14 & 92,61 & 106,95 & 92,09 & 98,82 & 123,69 & 148,08 & 103,59 & 110,95 \\
\hline Mikroben-N [mg/d] & 117,02 & 107,82 & 143,00 & 139,49 & 107,08 & 96,92 & 152,51 & 202,29 & 87,11 & 120,60 \\
\hline Zell-Trockenmasse [mg/d] & 1462,7 & 1347,7 & 1787,5 & 1743,6 & 1338,5 & 1211,5 & 1906,4 & 2528,6 & 1088,9 & 1507,5 \\
\hline \multicolumn{11}{|c|}{ Durchgang 2} \\
\hline Ration & \multicolumn{2}{|c|}{1} & \multicolumn{2}{|c|}{2} & \multicolumn{2}{|c|}{3} & \multicolumn{2}{|c|}{4} & \multicolumn{2}{|c|}{5} \\
\hline Faunierungsstatus & $f$ & $d$ & $f$ & $d$ & $f$ & d & $f$ & $d$ & $f$ & $\mathrm{D}$ \\
\hline $\mathrm{pH}$-Wert & 6,69 & 6,64 & 6,60 & 6,56 & 6,59 & 6,57 & 6,36 & 6,13 & 6,38 & 6,36 \\
\hline $\mathrm{NH} 4-\mathrm{N}[\mathrm{mmol} / \mathrm{l}]$ & 4,04 & 3,56 & 5,83 & 4,51 & 4,00 & 2,31 & 6,87 & 4,56 & 1,44 & 0,65 \\
\hline Methan $[\mathrm{mmol} / \mathrm{d}]$ & 6,96 & 5,93 & 5,52 & 5,39 & 5,65 & 4,29 & 7,13 & 3,02 & 4,94 & 3,24 \\
\hline Protozoen [1.000/ml] & 17,54 & 0,00 & 82,20 & 0,00 & 50,06 & 0,00 & 26,29 & 0,00 & 22,64 & 0,00 \\
\hline $\mathrm{C} 2[\mathrm{mmol} / \mathrm{d}]$ & 39,54 & 41,83 & 42,61 & 50,61 & 43,56 & 46,78 & 57,36 & 83,34 & 52,68 & 51,10 \\
\hline C3 [mmol/d] & 15,51 & 21,62 & 22,13 & 27,58 & 23,72 & 26,81 & 30,56 & 37,54 & 27,93 & 32,89 \\
\hline iC4[mmol/d] & 0,50 & 0,53 & 0,84 & 0,59 & 0,60 & 0,55 & 0,75 & 0,37 & 0,48 & 0,51 \\
\hline $\mathrm{nC} 4[\mathrm{mmol} / \mathrm{d}]$ & 6,79 & 5,04 & 8,64 & 5,41 & 8,17 & 4,65 & 11,24 & 2,50 & 9,52 & 3,32 \\
\hline iC5 [mmol/d] & 1,90 & 0,75 & 2,50 & 1,05 & 2,47 & 2,29 & 2,98 & 3,23 & 3,34 & 3,34 \\
\hline $\mathrm{nC} 5[\mathrm{mmol} / \mathrm{d}]$ & 0,99 & 1,16 & 1,83 & 1,05 & 1,49 & 0,53 & 2,90 & 1,12 & 0,67 & 0,17 \\
\hline$\Sigma$ SCFA [mmol/d] & 65,22 & 70,93 & 78,54 & 86,28 & 80,02 & 81,62 & 105,78 & 128,10 & 94,62 & 91,33 \\
\hline Mikroben-N [mg/d] & 105,61 & 113,80 & 125,01 & 121,97 & 105,30 & 91,59 & 134,96 & 180,11 & 76,95 & 88,06 \\
\hline Zell-Trockenmasse [mg/d] & 1320,1 & 1422,5 & 1562,6 & 1524,6 & 1316,2 & 1144,9 & 1687,0 & 2251,4 & 956,3 & 1100,8 \\
\hline
\end{tabular}




\begin{tabular}{|c|c|c|c|c|c|c|c|c|c|c|}
\hline \multicolumn{11}{|c|}{ Durchgang 3} \\
\hline Ration & \multicolumn{2}{|c|}{1} & \multicolumn{2}{|c|}{2} & \multicolumn{2}{|c|}{3} & \multicolumn{2}{|c|}{4} & \multicolumn{2}{|c|}{5} \\
\hline Faunierungsstatus & $f$ & $d$ & $f$ & d & $f$ & d & $f$ & $d$ & $f$ & $\mathrm{D}$ \\
\hline $\mathrm{pH}$-Wert & 6,69 & 6,67 & 6,54 & 6,60 & 6,61 & 6,56 & 6,46 & 6,42 & 6,44 & 6,51 \\
\hline $\mathrm{NH} 4-\mathrm{N}[\mathrm{mmol} / \mathrm{l}]$ & 3,71 & 3,31 & 5,12 & 4,38 & 3,41 & 1,81 & 5,63 & 4,52 & 1,54 & 1,36 \\
\hline Methan $[\mathrm{mmol} / \mathrm{d}]$ & 6,42 & 5,87 & 6,15 & 5,50 & 6,91 & 4,22 & 6,90 & 3,89 & 5,30 & 4,69 \\
\hline Protozoen [1.000/ml] & 17,68 & 0,11 & 76,96 & 0,00 & 57,57 & 0,11 & 30,56 & 0,00 & 15,63 & 0,00 \\
\hline $\mathrm{C} 2[\mathrm{mmol} / \mathrm{d}]$ & 37,40 & 40,78 & 47,98 & 43,07 & 36,29 & 38,99 & 43,78 & 49,90 & 33,31 & 35,18 \\
\hline C3 [mmol/d] & 14,19 & 18,38 & 22,53 & 25,86 & 23,01 & 34,24 & 33,05 & 34,28 & 31,56 & 39,11 \\
\hline $\mathrm{iC} 4[\mathrm{mmol} / \mathrm{d}]$ & 0,83 & 0,78 & 0,76 & 0,72 & 0,36 & 0,25 & 0,32 & 1,92 & 0,30 & 0,29 \\
\hline $\mathrm{nC} 4[\mathrm{mmol} / \mathrm{d}]$ & 6,64 & 4,84 & 9,21 & 6,02 & 10,56 & 3,65 & 6,70 & 6,74 & 7,55 & 5,84 \\
\hline $\mathrm{iC5}[\mathrm{mmol} / \mathrm{d}]$ & 1,94 & 1,14 & 3,29 & 1,70 & 2,96 & 0,87 & 4,16 & 1,81 & 3,12 & 0,91 \\
\hline $\mathrm{nC5}[\mathrm{mmol} / \mathrm{d}]$ & 1,04 & 0,98 & 1,82 & 1,74 & 1,11 & 0,68 & 1,69 & 2,78 & 0,38 & 0,06 \\
\hline$\Sigma$ SCFA [mmol/d] & 62,04 & 66,89 & 85,60 & 79,10 & 74,29 & 78,68 & 89,69 & 97,43 & 76,21 & 81,39 \\
\hline Mikroben-N [mg/d] & 95,55 & 102,81 & 115,53 & 111,83 & 97,71 & 89,74 & 111,30 & 114,37 & 63,66 & 77,55 \\
\hline Zell-Trockenmasse [mg/d] & 1194,4 & 1285,1 & 1444,1 & 1397,9 & 1221,4 & 1121,7 & 1391,3 & 1429,6 & 795,8 & 969,4 \\
\hline \multicolumn{11}{|c|}{ Durchgang 4} \\
\hline Ration & \multicolumn{2}{|c|}{1} & \multicolumn{2}{|c|}{2} & \multicolumn{2}{|c|}{3} & \multicolumn{2}{|c|}{4} & \multicolumn{2}{|c|}{5} \\
\hline Faunierungsstatus & $f$ & $d$ & $f$ & $d$ & $f$ & d & $f$ & $d$ & $f$ & $\mathrm{D}$ \\
\hline $\mathrm{pH}-$ Wert & 6,67 & 6,68 & 6,58 & 6,55 & 6,61 & 6,61 & 6,59 & 6,33 & 6,51 & 6,58 \\
\hline $\mathrm{NH} 4-\mathrm{N}[\mathrm{mmol} / \mathrm{l}]$ & 3,75 & 3,33 & 4,33 & 3,78 & 2,88 & 2,36 & 5,06 & 4,71 & 1,46 & 1,21 \\
\hline Methan [mmol/d] & 7,28 & 5,77 & 6,29 & 5,69 & 6,20 & 4,30 & 6,51 & 5,61 & 5,90 & 5,93 \\
\hline Protozoen [1.000/ml] & 16,79 & 0,00 & 92,10 & 0,00 & 63,35 & 0,00 & 19,77 & 0,00 & 14,99 & 0,00 \\
\hline $\mathrm{C} 2[\mathrm{mmol} / \mathrm{d}]$ & 35,79 & 36,37 & 42,92 & 48,16 & 36,60 & 36,35 & 33,23 & 59,60 & 32,52 & 33,72 \\
\hline C3 [mmol/d] & 13,47 & 18,85 & 20,70 & 26,96 & 19,41 & 21,41 & 23,00 & 27,67 & 24,49 & 28,85 \\
\hline iC4[mmol/d] & 0,80 & 0,75 & 0,80 & 0,78 & 0,78 & 0,66 & 0,71 & 0,54 & 0,45 & 0,44 \\
\hline $\mathrm{nC} 4[\mathrm{mmol} / \mathrm{d}]$ & 6,56 & 4,13 & 10,12 & 6,32 & 7,82 & 4,97 & 6,25 & 5,64 & 8,78 & 8,05 \\
\hline iC5 $[\mathrm{mmol} / \mathrm{d}]$ & 1,64 & 0,82 & 2,40 & 1,17 & 2,51 & 0,82 & 3,55 & 1,63 & 2,81 & 0,69 \\
\hline $\mathrm{nC} 5[\mathrm{mmol} / \mathrm{d}]$ & 1,08 & 0,73 & 1,64 & 1,96 & 0,99 & 0,75 & 1,64 & 3,02 & 0,74 & 0,33 \\
\hline$\Sigma$ SCFA [mmol/d] & 59,34 & 61,65 & 78,58 & 85,35 & 68,11 & 64,97 & 68,38 & 98,10 & 69,79 & 72,08 \\
\hline Mikroben-N [mg/d] & 111,59 & 114,52 & 129,97 & 125,67 & 105,14 & 108,50 & 100,03 & 127,03 & 68,12 & 81,02 \\
\hline Zell-Trockenmasse [mg/d] & 1394,9 & 1431,5 & 1624,6 & 1570,9 & 1314,2 & 1356,3 & 1250,4 & 1587,9 & 851,5 & 1012,8 \\
\hline
\end{tabular}




\begin{tabular}{|c|c|c|c|c|c|c|c|c|c|c|}
\hline \multicolumn{11}{|c|}{ Durchgang 5} \\
\hline Ration & \multicolumn{2}{|c|}{1} & \multicolumn{2}{|c|}{2} & \multicolumn{2}{|c|}{3} & \multicolumn{2}{|c|}{4} & \multicolumn{2}{|c|}{5} \\
\hline Faunierungsstatus & $f$ & $d$ & $f$ & d & $f$ & d & $f$ & d & $f$ & D \\
\hline $\mathrm{pH}-$ Wert & 6,67 & 6,74 & 6,63 & 6,61 & 6,63 & 6,61 & 6,42 & 6,47 & 6,46 & 6,53 \\
\hline $\mathrm{NH} 4-\mathrm{N}$ [mmol/l] & 3,78 & 3,29 & 4,33 & 3,78 & 2,88 & 2,36 & 5,06 & 4,72 & 1,46 & 1,21 \\
\hline Methan $[\mathrm{mmol} / \mathrm{d}]$ & 8,48 & 5,77 & 6,04 & 5,05 & 6,08 & 4,37 & 7,16 & 5,54 & 5,87 & 4,78 \\
\hline Protozoen [1.000/ml] & 19,51 & 0,00 & 95,03 & 0,21 & 54,32 & 0,00 & 19,66 & 0,00 & 22,22 & 0,11 \\
\hline $\mathrm{C} 2[\mathrm{mmol} / \mathrm{d}]$ & 44,25 & 40,08 & 43,52 & 49,39 & 47,93 & 46,21 & 56,88 & 57,92 & 39,30 & 40,35 \\
\hline C3 $[\mathrm{mmol} / \mathrm{d}]$ & 16,41 & 18,99 & 21,72 & 27,37 & 20,12 & 23,24 & 27,32 & 29,12 & 28,72 & 33,87 \\
\hline iC4[mmol/d] & 0,71 & 0,54 & 0,75 & 0,50 & 0,40 & 0,41 & 0,61 & 0,49 & 0,32 & 0,26 \\
\hline $\mathrm{nC} 4[\mathrm{mmol} / \mathrm{d}]$ & 8,47 & 4,19 & 10,64 & 4,10 & 2,75 & 3,75 & 8,69 & 8,03 & 8,74 & 5,60 \\
\hline iC5 [mmol/d] & 2,33 & 0,91 & 2,89 & 1,60 & 2,69 & 1,08 & 3,08 & 1,82 & 2,05 & 0,64 \\
\hline $\mathrm{nC5}[\mathrm{mmol} / \mathrm{d}]$ & 1,35 & 1,19 & 1,72 & 2,27 & 1,07 & 0,97 & 2,39 & 1,49 & 0,86 & 0,14 \\
\hline$\Sigma$ SCFA $[\mathrm{mmol} / \mathrm{d}]$ & 73,51 & 65,90 & 81,23 & 85,23 & 74,97 & 75,66 & 98,95 & 98,87 & 79,99 & 80,86 \\
\hline Mikroben-N [mg/d] & 121,19 & 111,59 & 127,36 & 120,68 & 110,50 & 98,35 & 110,29 & 106,87 & 84,80 & 101,80 \\
\hline Zell-Trockenmasse [mg/d] & 1514,9 & 1394,9 & 1592,0 & 1508,5 & 1381,2 & 1229,4 & 1378,6 & 1335,9 & 1060,0 & 1272,5 \\
\hline
\end{tabular}


A7

Biotinkonzentrationen in den Inkubationsrückständen aus den in vitro- Untersuchungen (in $\mu \mathrm{g}$ Biotin / kg festem Rückstand bzw. in $\mu \mathrm{g}$ Biotin / Liter Überlaufflüssigkeit)]

\begin{tabular}{|c|c|c|c|c|c|c|c|c|c|c|}
\hline \multicolumn{11}{|c|}{ Durchgang 1} \\
\hline Ration & \multicolumn{2}{|c|}{1} & \multicolumn{2}{|c|}{2} & \multicolumn{2}{|c|}{3} & \multicolumn{2}{|c|}{4} & \multicolumn{2}{|c|}{5} \\
\hline Faunierungsstatus & $f$ & $d$ & $f$ & $d$ & $f$ & $d$ & $f$ & $d$ & $f$ & $d$ \\
\hline Fester Rückstand n.I. & 47,87 & 59,00 & 51,37 & 51,00 & 71,71 & 56,33 & 50,92 & 49,50 & 82,50 & 59,25 \\
\hline Überlauf & 3,86 & 3,15 & 2,72 & 4,87 & 3,26 & 4,86 & 3,62 & 2,34 & 3,47 & 3,15 \\
\hline \multicolumn{11}{|c|}{ Durchgang 2} \\
\hline Ration & \multicolumn{2}{|c|}{1} & \multicolumn{2}{|c|}{2} & \multicolumn{2}{|c|}{3} & \multicolumn{2}{|c|}{4} & \multicolumn{2}{|c|}{5} \\
\hline Faunierungsstatus & $f$ & $d$ & $f$ & $d$ & $f$ & $d$ & $f$ & $d$ & $f$ & $d$ \\
\hline Fester Rückstand n.I. & 153,75 & 230,50 & 106,12 & 111,00 & 100,87 & 107,5 & 415,00 & 201,50 & 230,50 & 252,50 \\
\hline Überlauf & 4,22 & 3,54 & 3,87 & 5,21 & 3,85 & 4,15 & 4,00 & 2,44 & 3,90 & 2,93 \\
\hline \multicolumn{11}{|c|}{ Durchgang 3} \\
\hline Ration & \multicolumn{2}{|c|}{1} & \multicolumn{2}{|c|}{2} & \multicolumn{2}{|c|}{3} & \multicolumn{2}{|c|}{4} & \multicolumn{2}{|c|}{5} \\
\hline Faunierungsstatus & $f$ & $d$ & $f$ & $d$ & $f$ & $d$ & $f$ & $d$ & $f$ & $d$ \\
\hline Fester Rückstand n. I. & 122,00 & 175,50 & 105,00 & 116,00 & 81,87 & 85,20 & 107,17 & 107,25 & 82,12 & 100,50 \\
\hline Überlauf & 2,07 & 4,19 & 2,80 & 3,92 & 2,90 & 3,23 & 3,49 & 2,93 & 3,34 & 3,21 \\
\hline \multicolumn{11}{|c|}{ Durchgang 4} \\
\hline Ration & \multicolumn{2}{|c|}{1} & \multicolumn{2}{|c|}{2} & \multicolumn{2}{|c|}{3} & \multicolumn{2}{|c|}{4} & \multicolumn{2}{|c|}{5} \\
\hline Faunierungsstatus & $f$ & $d$ & $f$ & $d$ & $f$ & $d$ & $f$ & $d$ & $f$ & $d$ \\
\hline Fester Rückstand n. I. & 82,25 & 124,50 & 87,67 & 89,50 & 85,83 & 55,50 & 103,75 & 62,00 & 51,25 & 52,50 \\
\hline Überlauf & 3,14 & 5,78 & 2,23 & 4,22 & 2,07 & 3,89 & 2,97 & 2,60 & 2,85 & 3,25 \\
\hline \multicolumn{11}{|c|}{ Durchgang 5} \\
\hline Ration & \multicolumn{2}{|c|}{1} & \multicolumn{2}{|c|}{2} & \multicolumn{2}{|c|}{3} & \multicolumn{2}{|c|}{4} & \multicolumn{2}{|c|}{5} \\
\hline Faunierungsstatus & $f$ & $d$ & $f$ & $d$ & $f$ & d & $f$ & $d$ & $f$ & $d$ \\
\hline Fester Rückstand n. I. & 60,75 & 119,87 & 52,00 & 55,50 & 47,00 & 61,37 & 49,95 & 59,20 & 68,00 & 59,75 \\
\hline Überlauf & 3,90 & 4,95 & 5,06 & 4,53 & 5,56 & 6,36 & 4,81 & 4,31 & 5,84 & 7,40 \\
\hline
\end{tabular}


Erfasste Einzelwerte der bei den in vivo-Untersuchungen untersuchten Parameter

\begin{tabular}{|c|c|c|c|c|c|c|c|c|}
\hline \multicolumn{9}{|c|}{ Ration 1} \\
\hline Tier & \multicolumn{2}{|c|}{ Anke } & \multicolumn{2}{|c|}{ Salta } & & & & \\
\hline Periode & 1 & 2 & 1 & 2 & & & & \\
\hline T-Aufnahme $[\mathrm{kg} / \mathrm{d}]$ & 8,92 & 8,92 & 8,92 & 8,92 & & & & \\
\hline OS-Aufnahme [kg/d] & 8,25 & 8,41 & 8,25 & 8,41 & & & & \\
\hline XP-Aufnahme $[\mathrm{g} / \mathrm{d}]$ & 1230 & 1143 & 1230 & 1143 & & & & \\
\hline Biotin-Aufnahme [mg/d] & 2,574 & 2,529 & 2,574 & 2,529 & & & & \\
\hline duodenaler T-Fluss [kg/d] & 4,856 & 4,603 & 5,293 & 4,987 & & & & \\
\hline XP am Duodenum (g/d) & 1126 & 1211 & 1214 & 1248 & & & & \\
\hline FOS $[\mathrm{kg} / \mathrm{d}]$ & 5,891 & 6,111 & 5,735 & 6,016 & & & & \\
\hline Mikroben-N [g/d] & 110,5 & 113,2 & 127,2 & 129,1 & & & & \\
\hline UDP $[\mathrm{g} / \mathrm{d}]$ & 267,6 & 337,7 & 236,5 & 264,0 & & & & \\
\hline Biotin im Chymus $[\mu \mathrm{g} / \mathrm{kg} \mathrm{T}]$ & 461,2 & 501,0 & 295,0 & 247,0 & & & & \\
\hline Biotin am Duodenum [mg/d] & 2,24 & 2,31 & 1,56 & 1,23 & & & & \\
\hline \multicolumn{9}{|c|}{ Ration 2} \\
\hline Tier & \multicolumn{2}{|c|}{ Leisa } & \multicolumn{2}{|c|}{ Romke } & \multicolumn{2}{|c|}{ Ulane } & \multicolumn{2}{|c|}{ Sanara } \\
\hline Periode & 1 & 2 & 1 & 2 & 1 & 2 & 1 & 2 \\
\hline T-Aufnahme $[\mathrm{kg} / \mathrm{d}]$ & 10,49 & 11,29 & 10,49 & 11,29 & 10,49 & 11,29 & 10,49 & 11,29 \\
\hline OS-Aufnahme [kg/d] & 9,91 & 10,63 & 9,91 & 10,63 & 9,91 & 10,63 & 9,91 & 10,63 \\
\hline XP-Aufnahme $[\mathrm{g} / \mathrm{d}]$ & 1329 & 1487 & 1329 & 1487 & 1329 & 1487 & 1329 & 1487 \\
\hline Biotin-Aufnahme [mg/d] & 2,114 & 2,587 & 2,114 & 2,587 & 2,114 & 2,587 & 2,114 & 2,587 \\
\hline duodenaler T-Fluss [kg/d] & 5,977 & 6,524 & 5,249 & 5,431 & 5,908 & 6,054 & 4,701 & 5,208 \\
\hline XP am Duodenum (g/d) & 1447 & 1533 & 1368 & 1926 & 1558 & 1419 & 1237 & 1217 \\
\hline FOS $[k g / d]$ & 7,556 & 7,564 & 7,803 & 8,998 & 7,616 & 7,698 & 7,576 & 7,799 \\
\hline Mikroben-N [g/d] & 197,6 & 188,3 & 168,8 & 221,9 & 196,2 & 160,3 & 134,9 & 129,1 \\
\hline UDP $[\mathrm{g} / \mathrm{d}]$ & 2,4 & 130,1 & 123,8 & 317,2 & 118,3 & 207,5 & 224,2 & 230,3 \\
\hline Biotin im Chymus $[\mu \mathrm{g} / \mathrm{kg} \mathrm{T}]$ & 723,8 & 604,4 & 1107,5 & 647,9 & 845,7 & 750,0 & 797,5 & 785,6 \\
\hline Biotin am Duodenum [mg/d] & 4,33 & 3,93 & 5,81 & 3,52 & 5,00 & 4,54 & 3,75 & 4,09 \\
\hline
\end{tabular}




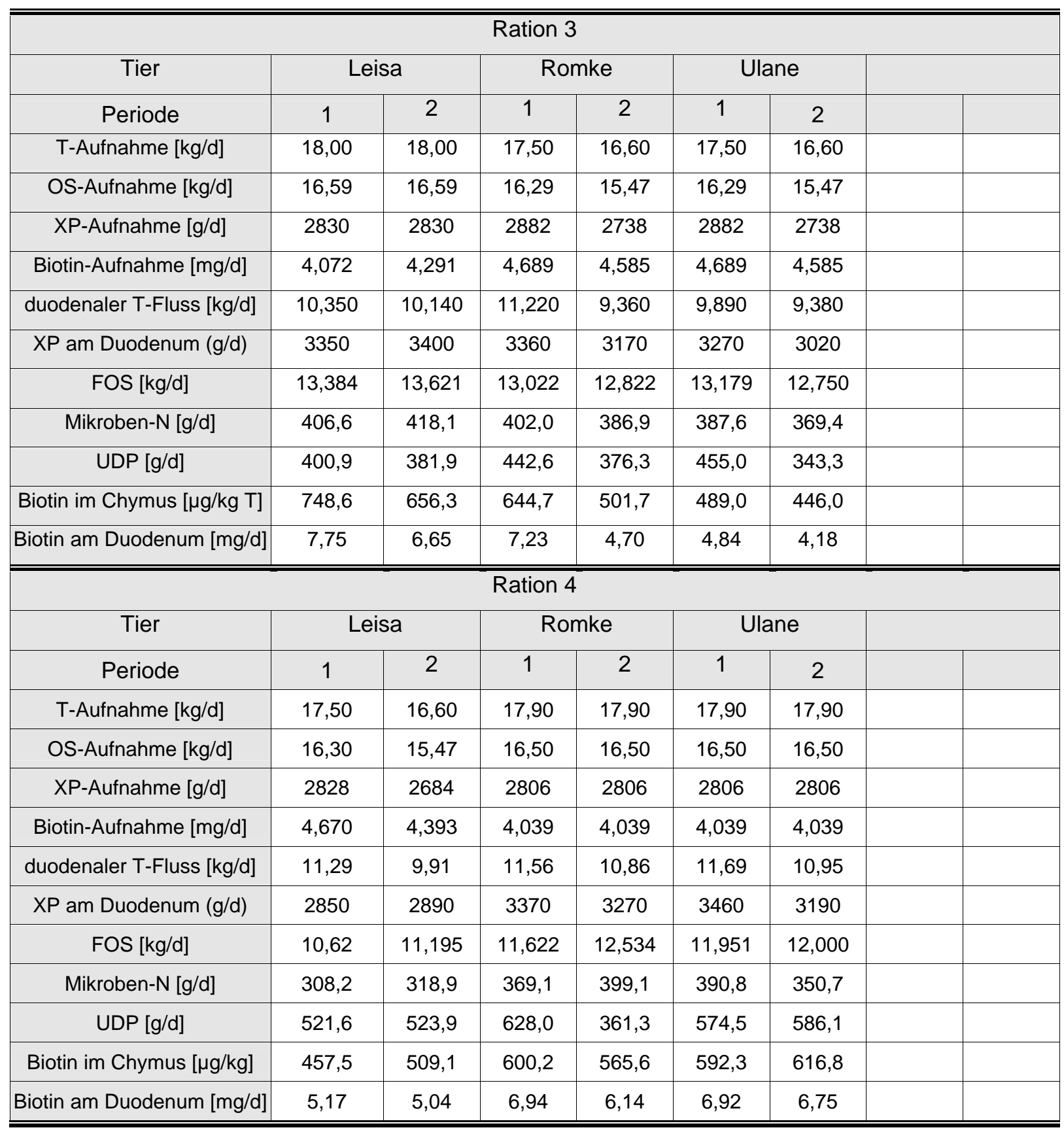




\section{Danksagung}

An dieser Stelle möchte ich mich bei allen bedanken, die zum Gelingen dieser Arbeit beigetragen haben.

Herrn Professor Dr. Hj. Abel danke ich herzlich für die Überlassung des Themas, das mir entgegengebrachte Vertrauen und seine stete Diskussionsbereitschaft auch unter widrigen Umständen, die mich fachlich und auch persönlich bereicherte.

Herrn Professor Dr. G. Flachowsky, Präsident der Bundesforschungsanstalt für Landwirtschaft und Direktor des Instituts für Tierernährung derselben danke ich für die Übernahme des Korreferates.

Herrn Dr. P. Lebzien vom Institut für Tierernährung der Bundesforschungsanstalt für Landwirtschaft sei herzlich gedankt für die zuverlässige und freundliche Unterstützung rund um die in vivo-Untersuchungen.

Den Herren R. Jeromin und B. Lenz danke ich für die geduldige Einführung in die praktische Laborarbeit, für die sehr gute Zusammenarbeit bei den RUSITEC- Versuchen und die dafür geopferten Wochenenden.

Die Biotinanalytik wurde in Anlehnung an die Methodik der Fa. F.Hoffmann-LaRoche AG, Basel durchgeführt. Allen Verantwortlichen sei für die Möglichkeit, sie dort zu erlernen, gedankt. Besonderer Dank gilt dabei Frau Chr. Wurz und Frau F. Wachter für ihre ausführliche und freundliche Einführung in die Analytik und die prompte Hilfe bei aufgetretenen Problemen, Dr. W. Steinberg und seiner Familie danke ich für die freundliche Aufnahme während meiner Aufenthalte in Basel.

Herrn Dr. A. Siemer danke ich für die erfolgreichen Wiederbelebungsversuche meiner statistischen Kenntnisse, meiner Mitdoktorandin Frau Despal für die Hilfe bei deren praktischer Umsetzung.

Ich habe mich am Institut immer wohlgefühlt. Daher sei allen Mitarbeiterinnen und Mitarbeitern des Institutes für Tierphysiologie und Tierernährung Dank für die freundliche Kooperation im Großen wie im Kleinen, die dazu beigetragen hat.

Allen Mitdoktoranden, Freunden und besonders meinen Schwestern und allen anderen Familienmitgliedern möchte ich herzlich danken für ihren Zuspruch und die Anteilnahme an den großen und kleinen Problemen des Doktorandenalltags.

Ohne das Verständnis, das Vertrauen und auch die Unterstützung meiner Eltern wäre meine Ausbildung und auch die Anfertigung dieser Arbeit nicht möglich gewesen. Dafür danke ich ihnen von Herzen.

Meinen Lieben danke ich für ihre liebevolle und geduldige Unterstützung und besonders für die -bewussten oder unbewussten- Aufmunterungen und Motivationshilfen in der letzten Phase dieser Arbeit.

Diese Arbeit wurde dankenswerterweise finanziell gefördert durch die Deutsche Forschungsgemeinschaft und die $\mathrm{H}$. Wilhelm Schaumann-Stiftung 


\section{Lebenslauf}

\section{Persönliche Daten}

Name

Vorname

Geburtsdatum, -ort

Familienstand

\section{Schulischer Werdegang}

$1980-1984$

$1984-1993$

\section{Studium}

08/1993 - 07/1994

10/1994 - 03/1999

$10 / 1999-07 / 2003$

$07 / 2000-07 / 2002$

07/2002-05/2004
Schröder

Benjamin

16.März 1974, Höxter

verheiratet, 3 Kinder
Kath. Grundschule am Nicolaitor, Höxter

Städt. König-Wilhelm-Gymnasium, Höxter

Abschluss: Allgemeine Hochschulreife

Landwirtschaftliches Praktikum, Landwirtschaftkammer Westfalen-Lippe, Landwirtschaftszentrum Haus Düsse, Bad Sassendorf-Ostinghausen

Abschluss: Praktikantenprüfung

Diplomstudium der Agrarwissenschaften, Fachrichtung Tierproduktion, Georg-August-Universität Göttingen Abschluss: Diplom (Dipl.-Ing. agr.)

Promotionsstudium, Georg-August-Universität Göttingen

Wissenschaftlicher Mitarbeiter am Institut für Tierphysiologie und Tierernährung, Georg-August-Universität Göttingen

mit der Abfassung der Dissertation beschäftigt 